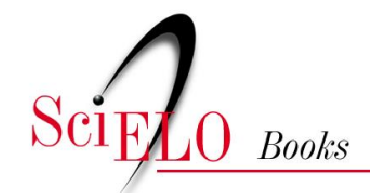

\title{
A pesquisa e a estatística na psicologia e na educação
}

\author{
Ana Maria Lopez Calvo de Feijoo
}

SciELO Books / SciELO Livros / SciELO Libros

FEIJOO, AMLC. A pesquisa e a estatística na psicologia e na educação [online]. Rio de Janeiro: Centro Edelstein de Pesquisas Sociais, 2010, 109p. ISBN: 978-85-7982-048-9. Available from SciELO Books $<$ http://books.scielo.org $>$.

\section{@)(1)(2)}

All the contents of this chapter, except where otherwise noted, is licensed under a Creative Commons Attribution-Non Commercial-ShareAlike 3.0 Unported.

Todo o conteúdo deste capítulo, exceto quando houver ressalva, é publicado sob a licença Creative Commons Atribuição Uso Não Comercial - Partilha nos Mesmos Termos 3.0 Não adaptada.

Todo el contenido de este capítulo, excepto donde se indique lo contrario, está bajo licencia de la licencia Creative Commons Reconocimento-NoComercial-CompartirIgual 3.0 Unported. 


\section{BIBLIOTECA VIRTUAL DE CIÊNCIAS HUMANAS}

\section{A PESquisa e a Estatística}

NA PSICOLOGIA E NA EDUCAÇÃo

Ana Maria Lopez Calvo de Feijoo 


\section{A pesquisa e a estatística na psicologia e na educação}

Esta publicação é parte da Biblioteca Virtual de Ciências Humanas do Centro Edelstein de Pesquisas Sociais - www.bvce.org

Copyright (c) 2010, Ana Maria Lopez Calvo de Feijoo

Copyright (c) 2010 desta edição on-line: Centro Edelstein de Pesquisas Sociais Ano da última edição: 1996, Bertrand Brasil

Nenhuma parte desta publicação pode ser reproduzida ou transmitida por qualquer meio de comunicação para uso comercial sem a permissão escrita dos proprietários dos direitos autorais. A publicação ou partes dela podem ser reproduzidas para propósito não comercial na medida em que a origem da publicação, assim como seus autores, seja reconhecida.

ISBN 978-85-7982-048-9

Centro Edelstein de Pesquisas Sociais

www.centroedelstein.org.br

Rua Visconde de Pirajá, 330/1205

Ipanema - Rio de Janeiro - RJ

CEP: 22410-000. Brasil

Contato: bvce@centroedelstein.org.br 


\section{SUMÁRIO}

Prefácio . V

\section{PARTE I ESTATÍSTICA DESCRITIVA}

\section{Introdução}

Definição ...2

Conceitos fundamentais........................................................... 2

2. Organização e interpretação da tabela .............................................4

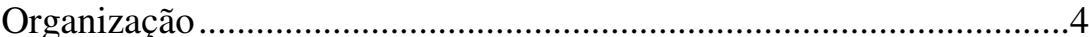

Interpretação .........................................................................

Leitura da Tabela ............................................................................4

3. Distribuição de frequência ........................................................6

Distribuição de frequência por classes ...............................................

Definição dos termos ..........................................................................

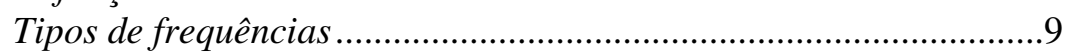

Representação gráfica...................................................................10

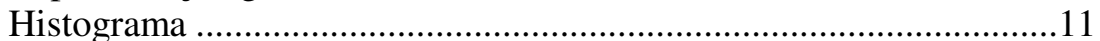

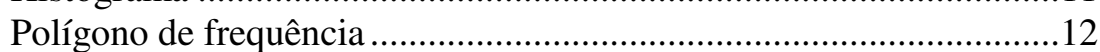

4. Medidas de tendência central ........................................................

Média aritmética ..........................14

Cálculo da média aritmética ........................................................15

Propriedades da média aritmética..................................................16

Vantagens e desvantagens na utilização da média aritmética ........17

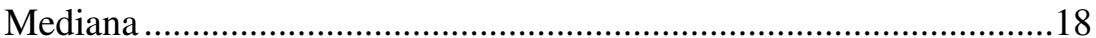

Cálculo da mediana ........................18

Propriedades da mediana ............................................................19

Vantagens na utilização da mediana .............................................20

Desvantagens na utilização da mediana ......................................20
Moda

Vantagens e desvantagens na utilização da moda ............................ 21

Utilização das medidas de tendência central ..................................... 21

Forma da distribuição

Objetivo da pesquisa ............................................................ 22

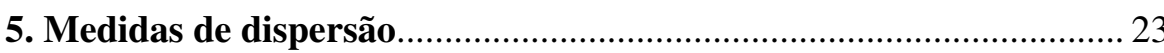

Intervalo total ou amplitude total .................................................... 23

Desvantagens da utilização da amplitude total ............................... 23

Desvio médio ............................................................................... 24

Cálculo do desvio médio: ................................................................. 24

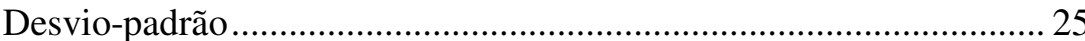

Cálculo do desvio-padrão.................... 25

Propriedades do desvio-padrão .................................................. 26

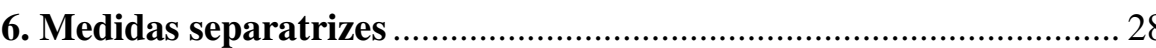

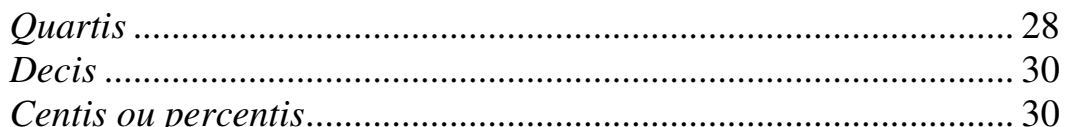

\section{PARTE II INFERÊNCIA ESTATÍSTICA}

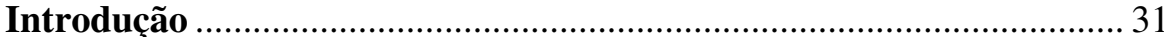

1. Objetivos da inferência estatística ........................................... 31

Estimativa dos parâmetros de uma população .................................. 31

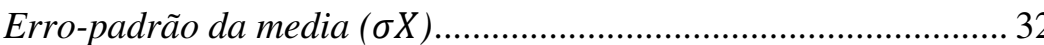

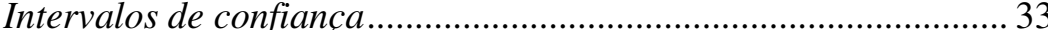

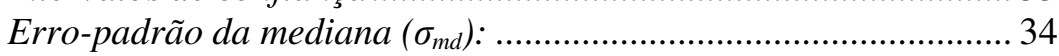

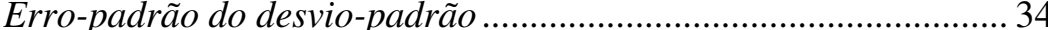

Erro-padrão do desvio semi-interquartil ........................................ 34

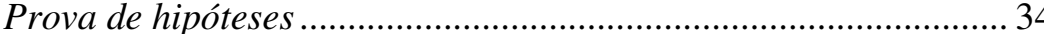


Critérios para a escolha da prova estatística .........................................35

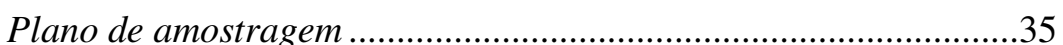

Natureza da população da qual se extraiu a amostra .......................36

Nivel de mensuração das variáveis ..................................................37

Variância da população ...................................................................37

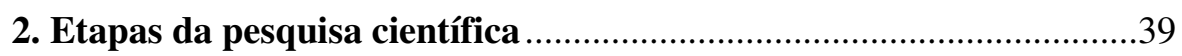

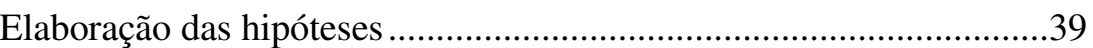

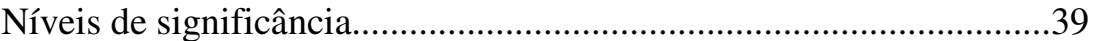

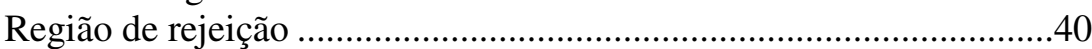

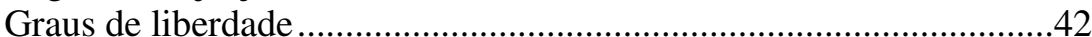

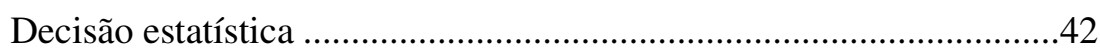

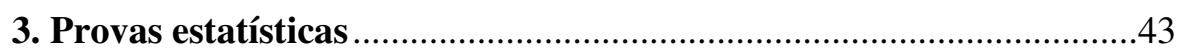

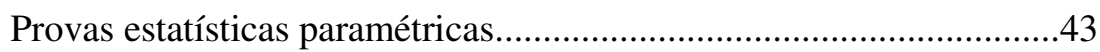

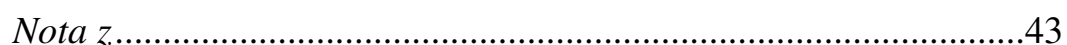

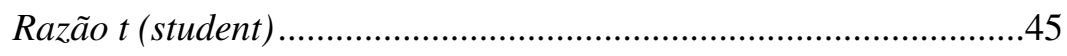

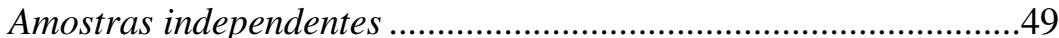

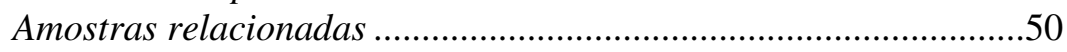

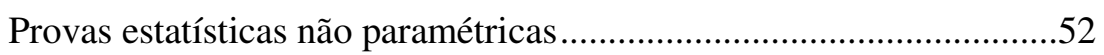

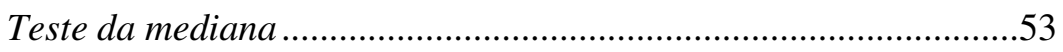

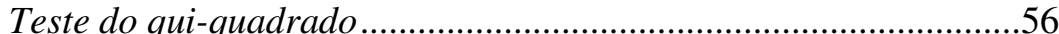

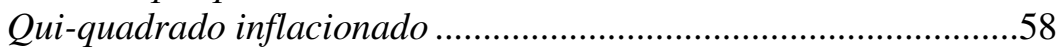

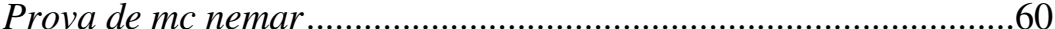

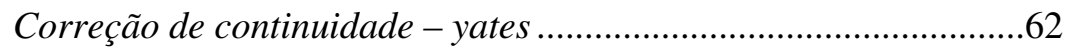

Prova de wilcoxon: teste da soma das ordenações ............................65

Observações importantes.................................................................67

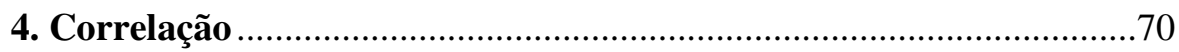

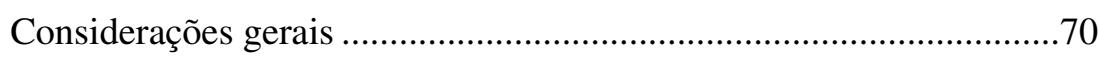

Aplicações do coeficiente de correlação ............................................70

Representação gráfica ...............................................................

Derivações do coeficiente de correlação ..............................................73

Coeficiente de determinação ..........................................................73

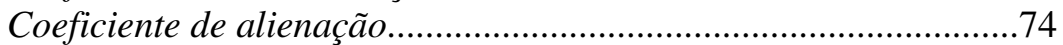

Coeficiente de correlação de pearson .................................................... 75

Coeficiente de correlação spearman-brown..................................... 76

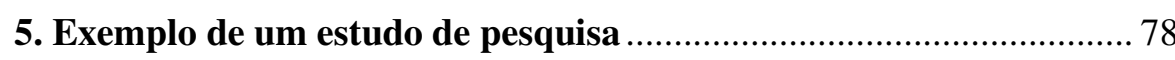

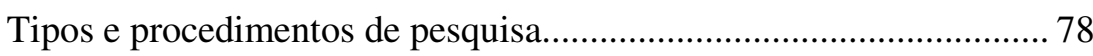

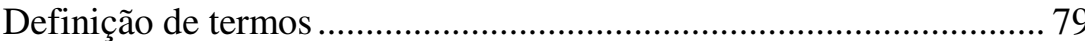

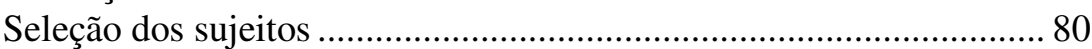

Coleta de dados............... 80

Estudos psicométricos dos instrumentos ............................................. 81

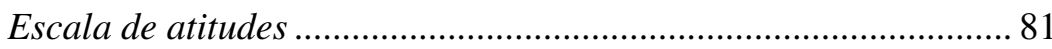

Instrumento de avaliação do aproveitamento ..................................... 82

Hipóteses e tratamento estatístico ....................................................... 82

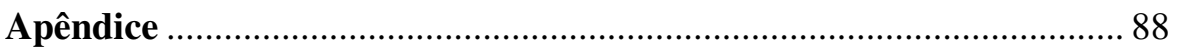

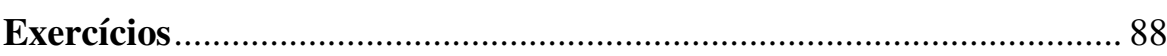

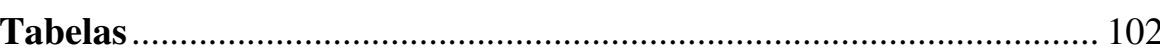

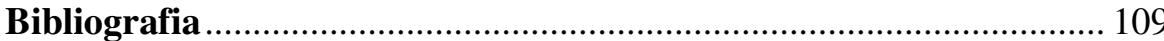




\section{Prefácio}

A disciplina Estatística, da maneira como vem sendo ministrada no Curso de Formação de Psicólogos, é alvo de desinteresse e insatisfação nas relações educativa e pedagógica.

Com acentuada frequência alunos e professores reincidem em protestos relativos ao processo ensino-aprendizagem desta disciplina, fornecendo indicadores de uma explícita realidade: os alunos não atingem um aprendizado eficaz; de onde se conclui que os professores não alcançam um ensino eficiente.

As queixas dos discentes giram em torno do conteúdo programático, dos critérios de avaliação e das características do professor. Os professores, por sua vez, tendem a alegar que os alunos se encontram despreparados para a assimilação da disciplina Estatística. A disciplina Estatística consta do currículo básico de todos os cursos de Formação de Psicólogos, sendo ministrada nos primeiros períodos do curso. Observa-se, a partir daí, o surgir das primeiras dificuldades, aparentemente superadas, tendo em vista o resultado final das avaliações: os alunos, em sua maioria, são aprovados.

A disciplina Estatística é pré-requisito para matrícula na disciplina Psicometria. Os professores de Psicometria esperam receber os alunos com suficientes conhecimentos das técnicas estatísticas e, a partir desse conhecimento, iniciar o ensino das técnicas psicométricas. Surpreendentemente, constatam estes professores que tais estudantes nada sabem do conteúdo estatístico. Esqueceram-se de tudo quanto haviam aprendido. Reagem como se o conteúdo a ser ensinado fosse algo para o qual não tivessem sido preparados. Este fato não é peculiar deste período, pois tais alunos, quando tentam ingressar no mestrado em Psicologia, expressam a mesma dificuldade, ou seja, um total esquecimento tanto da disciplina Estatística como da disciplina Psicometria. Reagem, aversivamente, a qualquer disciplina que tenha alguma relação, ou apenas mencione, os procedimentos estatísticos.

Esta situação desagrada não só aos alunos, mas também aos professores, que se mostram desejosos de mudança.

Para que sejam promovidas inovações, no entanto, é necessária muita reflexão para que não se realizem mudanças que venham reproduzir efeitos igualmente insatisfatórios.
Ao refletir a respeito deste problema, várias questões foram surgindo: em que consiste a dificuldade dos alunos? Que fatores estariam originando tamanha dificuldade no processo ensino-aprendizagem? Que alternativas poderão ser utilizadas pelo professor para sanar tais dificuldades?

$\mathrm{Na}$ tentativa de buscar tais respostas, averiguaram-se as dificuldades encontradas pelos alunos e pelos professores. Analisou-se, também, a forma como o conteúdo da disciplina Estatística é abordado nos livros didáticos de Estatística aplicada à Psicologia e à Educação.

A partir destas análises, formularam-se os seguintes pressupostos: os alunos, ao não conseguirem entender os objetivos das técnicas estatísticas, recorrem ao processo de memorização. Através deste recurso, alcançam seu objetivo imediato, ou seja, acertar as questões da prova. Por outro lado, os professores, ao se defrontarem com as dificuldades dos alunos, orientam o ensino desta disciplina, enfatizando o domínio das operações através de cálculos repetitivos. Isto se dá, em parte, pela suposição de que levar os alunos à compreensão é uma tarefa mais árdua.

Piaget (1976) resume tal situação na seguinte afirmativa: "De uma maneira geral, quanto mais se procura aperfeiçoar a escola, mais a tarefa do professor fica pesada; e quanto melhores os métodos, mais difíceis são de aplicar (p. 129)".

Nos livros didáticos que versam sobre "A Estatística aplicada à Psicologia e à Educação", observam-se explicações simplistas que, de forma alguma, levam o leitor à compreensão dos objetivos relativos ao conteúdo exposto. Os exemplos utilizados na elucidação de qualquer tópico raramente se referem aos fenômenos estudados pela ciência psicológica ou pedagógica, muito embora o título destes livros indique ser esse o seu propósito.

Realizou-se um levantamento dos tipos de exercícios relacionados em tais livros. Foram encontrados os seguintes resultados percentuais com relação ao enunciado: $72 \%$ diziam "calcule"; 6\%, "faça" e 9\%, "resolva". Neste tipo de exercício, portanto, nada mais é exigido do que a simples rotina de cálculos. Por outro lado, para questões compostas de situações que reivindiquem compreensão para sua resolução encontraram-se um total de $13 \%$.

Estes fatos podem, de certo modo, esclarecer tanto o desinteresse dos alunos quanto o sentimento de insatisfação dos professores. A rotina de 
cálculos toma a tarefa de aprender enfadonha, e o todo, incompreensível. E, no final, constatam eles a irrelevância desta disciplina, pois o que levou tanto tempo para fazer seria feito por uma calculadora em fração de segundos.

Numa tentativa de resolver tal problema, pensou-se em averiguar a origem da dificuldade. Constatou-se que este obstáculo, no processo de aprendizagem, não consiste numa exclusividade da disciplina Estatística. $\mathrm{O}$ ensino da matemática apresenta problemas similares desde o início da escolaridade.

Conferências, palestras e congressos reúnem profissionais de diversas áreas, na perspectiva de se encontrarem meios para solucionar os problemas do processo ensino-aprendizagem da disciplina Matemática.

Por se tratar a Estatística de matemática aplicada, os problemas encontrados no ensino da matemática podem, de alguma forma, ter relações com as dificuldades do ensino da disciplina Estatística. As soluções encontradas para resolver os problemas do ensino da matemática também podem ser aplicadas com relação à Estatística. Considera-se, portanto, de suma importância a análise das discussões desenvolvidas a respeito do processo ensino-aprendizagem da matemática.

Os matemáticos partiram do princípio de que a forma como a matemática vinha sendo ensinada até o final do século passado diluía o desenvolvimento integral do aluno, levava-o à memorização e estimulava a tarefa repetitiva de executar cálculos.

Esta ideia levou-os a revolucionar o ensino da matemática. Organizaram um movimento que teve como objetivo o ensino da matemática moderna. Acreditavam que dessa forma exterminariam a memorização e a rotina dos cálculos, e promoveriam a compreensão e a explicação prática. O que seria possível devido ao fato de que os propósitos da matemática moderna consistem no ensino de axiomas desde as classes mais elementares. Mas, em seguida, constatou-se que tal alternativa de ensino revelou-se insatisfatória, não levava a nenhum grande avanço em matéria de compreensão. Basicamente, os alunos continuavam orientados para reter de memória uma série de conceitos. Deixaram, pois, de decorar a tabuada e passaram a decorar noções de conjuntos.
A matemática moderna foi, então, alvo de críticas dos matemáticos e professores de todo o mundo.

Pisot e Marc (1972) repudiam-na, dizendo: "espírito maligno que sopra em França e que de uma simples brisa tornou-se furacão". Continuam, ainda estes autores, advertindo que:

(...) atualmente os jovens e adolescentes esqueceram o que era raciocínio e creem na 'virtude' e na 'magia' das palavras, e daí surgem as consequências. Introduziu-se a lógica e ela desapareceu. Pensou-se fundamentar as bases do cálculo e os alunos não sabem mais calcular (p. X).

No Comitê Internacional para o Ensino da Matemática (CIAEM), realizado em 1979, surgiram críticas contundentes ao ensino da matemática moderna, e foram apresentadas alternativas para o processo ensinoaprendizagem.

Diante dos fracassos atribuídos ao ensino da matemática moderna, ergueu-se um movimento denominado "Back to Basics", cujo objetivo seria o retorno ao ensino da matemática pela forma tradicional. Este movimento foi repudiado pela maioria dos integrantes do Comitê.

Alguns congressistas, entre eles, Ricardo e Mary Losada, afirmam que o fracasso da matemática moderna ocorreu porque os conteúdos modernos eram ensinados de forma tradicional - "memorização dos nomes das propriedades". Afirmam ainda que menos de $45 \%$ do material aprendido é lembrado depois de oito meses, após ter ocorrido a aprendizagem. Mas as pessoas que aprenderam "memoristicamente" lembram menos do que as que aprenderam através da compreensão. Propuseram uma alternativa de ensino, denominada "Matemática Ultramoderna", que trataria de um conteúdo de maior utilidade prática: computação, estatística e probabilidade.

No entanto, essas ideias não são originais. Em 1970, na primeira conferência do Comprehensive School Mathematics Program (CSMP), tal alternativa para o ensino da matemática já havia sido proposta. Uma reformulação no currículo da matemática incluía a estatística e a probabilidade desde o curso secundário. 
Várias razões foram apontadas a favor da inclusão da estatística e da probabilidade nos currículos da disciplina Matemática:

- A relevância da probabilidade e da estatística em quase todas as atividades da sociedade moderna.

- Muitos estudantes, nas suas vidas futuras, usarão noções de probabilidade e estatística como instrumentos em suas profissões e, quase todos, terão que argumentar baseados na probabilidade e no raciocínio estatístico.

- A introdução da probabilidade e da estatística no currículo de matemática produzirá um forte efeito estimulante por ser um ramo dinâmico da matemática e por já ficarem evidentes suas aplicações.

Viu-se, então, uma clara tendência à introdução do ensino da estatística a partir dos níveis secundários e até mesmo primários de ensino. Alguns estudiosos do assunto acreditam ser esta a solução para as atuais dificuldades encontradas.

No entanto, como já foi exposto, no primeiro ano do terceiro grau, quando esta disciplina é introduzida, os alunos continuam apresentando os mesmos problemas verificados nos alunos de níveis primário e secundário com relação à matemática. Parece, então, que esta alternativa pode resultar em novo fracasso. Muda-se o conteúdo, porém o processo de ensino continua o mesmo: memorização e exercício.

A fim de que novas propostas sejam introduzidas no ensino da estatística no terceiro grau, no curso de Formação de Psicólogos, faz-se mister explorar adequadamente tais dificuldades. Serão estas resultantes de falta de conhecimento anterior? Será que tais alunos trazem consigo atitudes preconceituosas com relação à disciplina, dificultando assim um aprendizado mais eficaz? Será o hábito da memorização, reforçado, principalmente, através de "cursinhos" preparatórios para o vestibular, além do que enfatizam, no estudante, o fato de serem bem-sucedidos nas provas ao invés de desenvolverem um real interesse pelo conteúdo?

Brito (1973) mostrou-se otimista quanto à resolução desta problemática. Diz ela:

Acreditamos que as reestruturações I70 ensino da matemática permitirão que, num futuro próximo, os alunos cheguem à universidade mais bem preparados, possibilitando mais produtividade no ensino da Estatística (p. 4).

No entanto, em 1994, vê-se que tal dificuldade não foi superada, embora o ensino da matemática em níveis mais elementares já tenha sofrido as reestruturações citadas por Brito (1973).

Rodriguez (1976) acredita que as dificuldades encontradas por parte dos alunos em matemática advenham de uma atitude negativa frente a tal disciplina. Esta atitude desenvolve-se devido a dois fatores: condições didáticas dos professores de matemática e influência da atitude dos pais diante da disciplina (p.102).

As ideias de Witter (1975) vão de encontro às expostas por Rodriguez. Diz Witter:

Este quadro se agrava pela facilidade com que este 'não gostar' e até mesmo a aversão pela matemática se generaliza para disciplinas próximas como a Física e a Estatística. Atitudes favoráveis a uma disciplina são consideradas desejáveis em termos de facilitar a aprendizagem (p .151).

Estes autores defendem a hipótese de que a mudança de atitude seria uma alternativa em direção a uma aprendizagem mais eficaz na disciplina Matemática e, em consequência, na Física e na Estatística.

A atitude favorável pode constituir, portanto, um fator determinante no processo ensino-aprendizagem da disciplina Estatística.

A atitude desfavorável é observada quando alunos do curso de Formação de Psicólogos se deparam com a disciplina e emitem suas queixas: "eu não vim para a faculdade de Psicologia com o propósito de estudar matemática", "isto é muito difícil", "o professor é muito rápido ao transmitir a matéria".

Muitos teóricos defendem a hipótese de que a dificuldade no aprendizado da matemática se desenvolve porque os alunos não compreendem seus procedimentos e, então, partem para a memorização. Resulta, daí, o desinteresse.

O desinteresse, a memorização, a execução exagerada de cálculos são, também, frequentes no processo ensino-aprendizagem da Estatística no terceiro grau. 
A memorização é um processo tão arraigado nos nossos jovens que as alternativas de ensino aplicadas, como, por exemplo, "a matemática moderna", resultaram em fracasso. Pois, embora o objetivo fosse a compreensão, os alunos continuaram a apelar para a aprendizagem por memorização.

Parece, então, ser de suma importância despertar o interesse dos alunos para a disciplina.

No caso do ensino da Estatística no curso de Psicologia, os exemplos e os exercícios utilizados para a explicação do conteúdo deveriam estar ligados aos fenômenos e pesquisas psicológicas, mostrando, assim, a aplicabilidade dos princípios estatísticos à psicologia. Dessa forma, os alunos conheceriam a dinâmica da estatística e não necessitariam mais memorizar; já a teriam compreendido. Seria atribuído um novo sentido à aprendizagem.

Este aspecto também foi abordado no CSMP por alguns estudiosos do assunto. Constava do primeiro objetivo a ser tratado pelos congressistas, ou seja, o desenvolvimento de um conteúdo mais agradável e apropriado às necessidades e habilidades do aluno.

Preconizam os conferencistas que a estatística e a probabilidade deveriam constituir o currículo escolar desde o segundo grau, e o seu ensino deveria consistir de fatos os mais realísticos possíveis; levando, então, o aluno a ter contatos com os procedimentos estatísticos antes mesmo de conhecê-los.

William Kruskal*, afirma que a estatística é constituída por aspectos matemáticos e não matemáticos. Os aspectos não matemáticos são relevantes para as ciências sociais e trabalhos em laboratório. Cabe que os aspectos não matemáticos sejam ensinados juntamente com os matemáticos. Enfatiza que a dificuldade no aprendizado da estatística matemática advém da forma como esse material se mostra desinteressante, levando o aluno a ver toda a estatística da mesma forma. Seu primeiro projeto é a preparação de um livro de exercícios que contenha dados reais e discussões com aspectos matemáticos e não matemáticos. Acredita que, dessa forma, o

* Da Universidade de Chicago. material estatístico se tome acessível a $80 \%$ dos estudantes secundários e também auxilie a crítica e a clareza do pensamento estatístico.

Para Jerzy Neyman*, o ensino da estatística deveria iniciar com um curso elementar em estatística matemática, constando os seguintes conteúdos: regras de manipulações numéricas, medidas de tendência central e medidas de dispersão; e dar continuidade a três principais objetivos:

- fazer com que os estudantes compreendam a natureza do objeto de

- documentar a importância de alguns problemas da vida contemporânea que dependem de um tratamento estatístico correto;

- ilustrar o fato de que a escolha dos métodos estatísticos pode fazer grande diferença.

Radhakrisma Rao, no Indian Statistical Institute, acompanhou um curso dirigido por B. Sat, para estudantes de nível secundário. O curso tinha como objetivo "oferecer uma instrução compreensiva na teoria e prática da Estatística, e prover, ao mesmo tempo, uma educação geral com o necessário background de conhecimentos nas ciências sociais previsto por um profissional de estatística". Acreditava ele, que, dessa forma, tanto o aprendizado quanto a atitude se tornariam mais favoráveis.

Pode-se supor que as dificuldades encontradas, por alunos e professores, no processo ensino-aprendizagem da Estatística aplicada à Psicologia, decorrem, também, da metodologia de ensino que vem sendo empregada.

No momento em que o autor se encontrava envolvido com tais reflexões, surgiu a oportunidade de que ele lecionasse a disciplina Estatística no primeiro ano do curso de Formação de Psicólogos.

Ocorreu-lhe, então, a ideia de realizar um trabalho de pesquisa a fim de averiguar o que realmente acontece no processo ensino-aprendizagem da disciplina Estatística. Toda a atividade didática foi planejada de modo que, ao término do semestre, fossem apresentados resultados de uma investigação sistemática e controlada, viabilizando conclusões que clarificassem, na medida do possível, as variáveis que atuam neste processo de ensino.

* Da Universidade da Califórnia. 
Pensou-se em ensinar através de uma metodologia alternativa a até então utilizada. Princípios psicológicos lhe serviriam de apoio. Denominouse, então, a referida metodologia de Metodologia Renovadora, enquanto que a metodologia que vinha sendo aplicada chamou-se de Metodologia Tradicional.

$\mathrm{Na}$ Metodologia Tradicional o processo ensino-aprendizagem enfatizará os processos de memorização e a rotina dos cálculos, enquanto que na Metodologia Renovadora a ênfase recairá sobre a compreensão e a aplicabilidade dos conceitos estatísticos.

A partir destas constatações surgiu, então, a ideia de escrever um livro que atendesse às necessidades e objetivos descritos.

Este livro de estatística destinado à facilitação da aprendizagem de alunos do curso de Psicologia e Pedagogia traz em seu bojo a intenção de atender às necessidades e interesses dos alunos, considerando suas áreas de estudo.

Ana Maria Lopez Calvo de Feijoo

\section{PARTE I \\ ESTATÍSTICA DESCRITIVA}

\section{INTRODUÇÃO}

Em Psicologia, como em qualquer outra ciência, o pesquisador levanta hipóteses a respeito de fenômenos observados. Ao desejar conhecer a viabilidade de suas hipóteses, utiliza a pesquisa sistemática. Primeiramente estabelece relações entre as variáveis. Relações essas que devem ser passíveis de mensuração através de instrumentos adequados, de modo que essas variáveis sejam expressas numericamente.

A esses dados numéricos são aplicados os métodos estatísticos na seguinte ordem:

$1^{\circ}$ ) Coleta dos dados: os dados são coletados através de questionários, testes, escalas ou qualquer outro instrumento de medida.

$2^{\circ}$ ) Classificação e condensação dos resultados: as informações colhidas são codificadas e apresentam-se como dados brutos (ou ro estatístico), que devem ser ordenados e organizados.

$3^{\circ}$ ) Apresentação dos dados por meio de tabelas e gráficos.

$4^{\circ}$ ) Descrição dos dados

$5^{\circ}$ ) Análise dos resultados e previsão.

Exemplo de uma pesquisa em psicologia: pesquisa realizada por Torres (1978) seguiu os passos a que nos referimos anteriormente. Seu estudo teve, por objetivo, verificar a relação entre diferentes períodos do desenvolvimento cognitivo e a evolução do conceito de morte em crianças.

A hipótese de sua pesquisa foi a seguinte: “Crianças de diferentes períodos de desenvolvimento cognitivo (subperíodo pré-operacional, subperíodo das operações concretas, período formal), tal como avaliadas por tarefas similares às propostas por Piaget, diferem significativamente quanto à compreensão do conceito de morte nas dimensões: extensão, significado e duração, tal como avaliadas pelo instrumento de sondagem do conceito de morte". 
Entende-se por extensão - o grau de compreensão acerca dos seres que morrem; por significado - o grau de compreensão acerca do que é morte; por duração - o grau de compreensão dos sujeitos acerca do tempo de permanência da morte.

Essas três dimensões foram medidas através de um instrumento de sondagem do conceito de morte.

\section{Definição}

Segundo Nick*, a Estatística é a ciência que nos permite tomar decisões em face da incerteza. Isto não quer dizer que ajuda a eliminar a incerteza e sim a diminuí-la.

Cerdá (1972) apresenta a seguinte definição:

"É um conjunto de técnicas que uma ciência utiliza, que se pode aplicar a um conjunto de dados para ordená-los, classificá-los e diferenciá-los. Dessa forma pode-se descrever os fenômenos como também deduzir leis que servem para generalizar tais modalidades de manifestações e que permitem realizar predições."

Como se pode observar, a estatística é mais um meio do que um fim. É um instrumento do qual qualquer pesquisador pode lançar mão.

\section{Conceitos fundamentais}

Variável - alguma característica de pessoas ou objetos que podem assumir diferentes valores.

Variável discreta - são características que assumem valores claramente separados; não há graduação. graduados.

Variável contínua - são características que podem assumir valores

Notação simbólica das variáveis - X, Y, Z.

População - conjunto de elementos definidos no espaço e no tempo, em termos de um "atributo" comum a todos os elementos.
População homogênea - população que apresenta pouca variação do atributo em questão.

População heterogênea - população que se caracteriza pela alta variação do atributo em questão.

População finita - o número de seus elementos é determinado.

População infinita - o número de seus elementos é indeterminado.

Amostra - é uma parte representativa da população em questão.

Na pesquisa que nos serve como exemplo, a amostra foi extraída da população de 641 alunos de um curso vespertino, de um colégio particular, situado no bairro de Ipanema, na cidade do Rio de Janeiro.

A amostra compõe-se de sujeitos de 4 a 13 anos e 11 meses de idade, de ambos os sexos, católicos, que não sofreram a perda de nenhum dos pais ou irmão, e cuja escolaridade estende-se do jardim de infância à $7^{\mathrm{a}}$ série do primeiro grau. 


\section{ORGANIZAÇÃO E INTERPRETAÇÃO DA TABELA}

\section{Organização}

A tabela tem como objetivo a transformação dos dados brutos num conjunto de mensurações dotadas de sentido. Exemplo:

Tabela 3

Distribuição de amostra por período de desenvolvimento cognitivo

\begin{tabular}{c|c|c|c}
\hline \multicolumn{3}{c|}{ Período de desenvolvimento cognitivo } & Total \\
\hline $\begin{array}{c}\text { Subperíodo pré- } \\
\text { operacional [PO] }\end{array}$ & $\begin{array}{c}\text { Subperíodo de } \\
\text { operações } \\
\text { concretas [OC] }\end{array}$ & $\begin{array}{c}\text { Período de } \\
\text { operações formais } \\
{[\mathrm{OF}]}\end{array}$ & \\
\hline 68 & 63 & 52 & 183 \\
\hline
\end{tabular}

Fontes: Torres (1978).

Toda tabela deve ter um título, que é a indicação do que a tabela pretende demonstrar; um cabeçalho com as indicações das linhas e colunas, e um número que as identifique dentro do estudo em questão.

Deve-se verificar as notas de rodapé, pois estas darão mais detalhes sobre os aspectos considerados na tabela, como também observar as unidades utilizadas.

\section{Interpretação}

Interpretar não é transcrever aquilo que está explícito na tabela e sim estabelecer relações entre os dados da tabela através de comparações, cálculos com os números apresentados através da combinação de duas ou mais colunas ou linhas.

Deve-se ter em mente que interpretar não consiste em fazer conjecturas que não decorrem da tabela apresentada.

\section{Leitura da Tabela}

A primeira coisa a fazer é inferir, pelo título, a natureza do que a tabela apresenta. $\mathrm{O}$ exemplo abaixo apresenta a distribuição da amostra por período de desenvolvimento cognitivo.
Tabela 1

Pré-teste: distribuição das respostas das 32 crianças de 4 a 13 anos quanto à compreensão do significado da morte (itens do tipo Sim e Não).

\begin{tabular}{l|c|c|c|c|c|c|c|c|c}
\hline \multirow{2}{*}{$\begin{array}{l}\text { Categoria de } \\
\text { respostas }\end{array}$} & \multicolumn{7}{|c}{ Porcentagem das respostas para cada idade } \\
\cline { 2 - 10 } & 4 & 5 & 6 & 7 & 8 & 9 & 11 & 12 & 13 \\
\hline Personificação & 75,00 & 41,67 & 58,33 & 66,67 & 50,00 & 0 & 25,00 & 18,75 & 0 \\
\hline Não personificação & 25,00 & 58,00 & 41,67 & 33,33 & 50,00 & 100,00 & 75,00 & 81,25 & 100,00 \\
\hline
\end{tabular}

Verificando as unidades utilizadas, vê-se que os números referem-se a dados expressos em percentagens.

Interpretar não é transcrever; por exemplo, dizer: "A tabela mostra que $75 \%$ não personificam”. Esta frase apenas repete o que a própria tabela já nos diz. No entanto, se dizemos que "na medida em que aumenta a idade cronológica diminui o número de crianças que personificam a morte", aí então se estabelece uma relação entre os dados; portanto, há interpretação.

Não se deve extrapolar os dados da tabela. Portanto, dizer: “À medida que aumenta a idade cronológica, diminui o significado personificado da morte porque as crianças mais velhas têm uma vivência maior da morte" implica uma conjectura, afirma-se algo que a tabela não mostra. 


\section{DISTRIBUIÇÃO DE FREQUÊNCIA}

A distribuição por frequência é um meio de sintetizar e organizar os dados coletados, e assim dispô-los de forma clara e significativa, facilitando sua compreensão e evidenciando as tendências significativas desses dados.

Primeiramente, ordenam-se os valores das variáveis em ordem crescente ou decrescente; depois determina-se a frequência de cada valor. Tem-se, então, a distribuição de frequência simples.

\section{Exemplo:}

$1^{\circ}$ ) Escores brutos. Escores obtidos pelas crianças nas três dimensões do instrumento de sondagem do conceito de morte.

\begin{tabular}{c|c|c|c}
\multirow{2}{*}{ Sujeitos } & \multicolumn{3}{|c}{ Período Pré-operacional } \\
\cline { 2 - 4 } & ext & sig & dur \\
\hline 1 & 14 & 12 & 4 \\
2 & 14 & 8 & 2 \\
3 & 22 & 13 & 2 \\
4 & 4 & 3 & 1 \\
5 & 8 & 17 & 3 \\
6 & 17 & 17 & 5 \\
7 & 10 & 6 & 6 \\
8 & 18 & 12 & 3 \\
9 & 13 & 5 & 1 \\
10 & 13 & 15 & 1 \\
\hline
\end{tabular}

$2^{\circ}$ ) Ordenam-se os dados brutos.

Extensão: 481013131414171822

$3^{\circ}$ ) Determina-se a frequência de cada valor.

\begin{tabular}{c|c} 
Extensão & Frequência \\
\hline 4 & 1 \\
8 & 1 \\
10 & 1 \\
13 & 2 \\
14 & 2 \\
17 & 1 \\
18 & 1 \\
22 & 1
\end{tabular}

A distribuição de frequência simples, na qual a cada valor é atribuída sua respectiva frequência, embora trabalhosa, não distorce os resultados. No entanto, às vezes têm-se tantos dados que se torna necessário agrupá-los. Neste caso, temos uma distribuição de frequência por classes.

\section{Distribuição de frequência por classes}

$1^{\circ}$ ) Verifica-se a amplitude total.

A amplitude total (AT) é igual à diferença entre o maior valor (VM) da distribuição e o menor valor $(\mathrm{Vm})$ da distribuição mais um.

$$
\mathrm{AT}=(\mathrm{VM}-\mathrm{Vm})+1
$$

$\left.2^{\circ}\right)$ Determinam-se quantos elementos terá cada grupo, ou seja, o intervalo de classe.

\section{Nesta etapa deve-se considerar:}

$\mathrm{O}$ número de classes, que deve permanecer entre 6 e 12. Se utilizarmos mais de 12 pode haver diluição das frequências pelas classes, perdendo-se a tendência da distribuição dos itens; se utilizarmos menos de 6 pode ocorrer uma demasiada condensação dos mesmos.

O intervalo de classes (I) é determinado dividindo-se amplitude total pelo número de classes.

$$
\mathrm{I}=\mathrm{AT}+\text { número de classes }
$$

Exemplo:

Escores obtidos pelas crianças nas três dimensões de instrumento de sondagem do conceito de morte.

Período pré-operacional - extensão

$14,14,22,4,8,17,10,18,13,13,18,16,15,2,16,12,9,14,14,21,7,16$ $14,12,15,21,21,21,10,18,17,14,16,16,16,12,19,22,17,3,20,21$, $19,19,26,13,21,27,22$ 
$1^{\circ}$ ) Ordenar

\begin{tabular}{lllllllll}
\hline 2 & 10 & 13 & 14 & 16 & 17 & 19 & 21 & 22 \\
3 & 10 & 13 & 14 & 16 & 17 & 19 & 21 & 22 \\
4 & 12 & 13 & 14 & 16 & 18 & 19 & 21 & 26 \\
7 & 12 & 13 & 14 & 16 & 18 & 20 & 21 & 27 \\
8 & 12 & 14 & 15 & 16 & 18 & 21 & 22 & \\
9 & 13 & 14 & 15 & 17 & 18 & 21 & 22 & \\
\hline
\end{tabular}

$2^{\circ}$ ) Amplitude total

$$
\begin{gathered}
\mathrm{AT}=(\mathrm{VM}-\mathrm{Vm})+1 \\
\mathrm{AT}=27-2=25+1=26
\end{gathered}
$$

$3^{\circ}$ ) Intervalo de classe

$$
\mathrm{I}=\mathrm{AT} \div \mathrm{n}^{\circ} \text { de classes }
$$$$
\mathrm{I}=26 \div 7=3,7 \text { - intervalo } 4
$$

$\mathrm{X}=$ (extensão do conceito de morte) variável

$\mathrm{F}=$ frequência (número de vezes que aparece cada valor da variável) $\sum=$ somatório

\begin{tabular}{|c|c|}
\hline $\mathbf{X}$ & $\mathbf{F}$ \\
\hline $2-5$ & 3 \\
$6-9$ & 3 \\
$10-13$ & 10 \\
$14-17$ & 16 \\
$18-21$ & 14 \\
$22-25$ & 4 \\
$26-29$ & 2 \\
\hline$\sum$ & 52 \\
\hline
\end{tabular}

\section{Definição dos termos}

Classe - grupo de valores da variável.

Ponto médio de uma classe - ponto intermediário e representativo de uma classe. É obtido somando-se o limite inferior ao limite superior da classe, e dividindo-se por dois.

$$
\mathrm{PM}=(\mathrm{Ls}+\mathrm{Li}) / 2
$$

Limite superior da classe - valor maior de uma classe.
Limite inferior da classe - menor valor de uma classe.

\section{Tipos de frequências}

Frequência simples - indica o número de vezes em que aparece um determinado resultado.

\section{Símbolo: fi}

Frequência acumulada - é a frequência que reúne certa frequência mais todas as frequências anteriores. É utilizada especialmente quando tentamos situar o indivíduo em função do desempenho total do grupo.

\section{Símbolo: fac}

Frequência percentual - significa a frequência com que determinada categoria ocorre em relação ao número 100. Indica o tamanho relativo de um conjunto de valores em termos de percentagem.

Símbolo: f\%

$$
\text { Onde } \quad \mathrm{f} \%=\frac{\mathrm{fi}}{\mathrm{N}} \cdot 100
$$

$\mathrm{fi}=$ frequência simples

$\mathrm{N}=$ número total de casos.

\section{Exemplo:}

Escores obtidos pelas crianças da dimensão: significado do instrumento de sondagem do conceito de morte.

\begin{tabular}{c|c|c|c|c}
\hline Significado(X) & F & F\% & Fac & Fac\% \\
\hline 3 & 1 & $10 \%$ & 1 & $10 \%$ \\
5 & 1 & $10 \%$ & 2 & $20 \%$ \\
6 & 1 & $10 \%$ & 3 & $30 \%$ \\
8 & 1 & $10 \%$ & 4 & $40 \%$ \\
12 & 2 & $20 \%$ & 6 & $60 \%$ \\
13 & 1 & $10 \%$ & 7 & $70 \%$ \\
15 & 1 & $10 \%$ & 8 & $80 \%$ \\
17 & 2 & $20 \%$ & 10 & $100 \%$ \\
\hline
\end{tabular}


Tabela 8

Primeira sondagem: distribuição de respostas das crianças de 7 a 13 anos quanto à compreensão da morte. Percentagem das respostas para cada idade

\begin{tabular}{l|c|c|c|c|c|c|c}
\hline $\begin{array}{l}\text { Categoria de } \\
\text { respostas }\end{array}$ & 7 & 8 & 9 & 10 & 11 & 12 & 13 \\
\hline Afetivas & 27,27 & 11,11 & 26,58 & 28,81 & 39,39 & 40,9 & 65,22 \\
\hline Funeral & 9,09 & 40,74 & 29,11 & 27,12 & 18,18 & 15,91 & 21,74 \\
\hline Personificação & 36,36 & 18,52 & 13,92 & 8,47 & 6,06 & 2,27 & 0 \\
\hline Vida na morte & 0 & 7,41 & 7,59 & 1,69 & 3,03 & 2,27 & 0 \\
\hline Causas específicas & 27,27 & 22,22 & 17,72 & 27,12 & 18,18 & 6,82 & 13,04 \\
\hline Inevitabilidade & 0 & 0 & 6,33 & 6,78 & 12,12 & 20,45 & 0 \\
\hline Irreversibilidade & 0 & 0 & 0 & 0 & 3,03 & 11,36 & 0 \\
\hline
\end{tabular}

Fonte: Torres, 1978

Na pesquisa realizada por Torres (1978), a percentagem das respostas de cada uma das categorias (dimensão, extensão e significado) foi calculada para cada nível de idade, a fim de possibilitar comparações:

O exame da distribuição das respostas revelou a existência de uma certa direção nos tipos de respostas dadas nos diferentes níveis de idade. Assim, respostas evidenciando preocupação com aspectos ligados à causalidade da morte em termos específicos (doença, velhice, atropelamento etc.), interpretação da morte em termos de personificação e aceitação da vida na morte mostram, com certa regularidade, um decréscimo em relação aos aspectos da irreversibilidade e com relação à inevitabilidade da morte ocorre o contrário, isto é, o índice percentual de respostas apresenta um incremento com a idade. De todas as categorias, a que atinge o mais alto nível percentual é a afetiva, na idade de 13 anos.

\section{Representação gráfica}

Por vezes torna-se conveniente representar uma distribuição de frequências por meio de diagrama (gráfico em duas dimensões), pois este nos oferece uma vista geral das observações, tornando, desta forma,- mais legíveis as informações.
Utilizam-se, então, as coordenadas cartesianas. Colocam-se, no eixo horizontal, os valores das variáveis, e, no eixo vertical, as respectivas frequências.

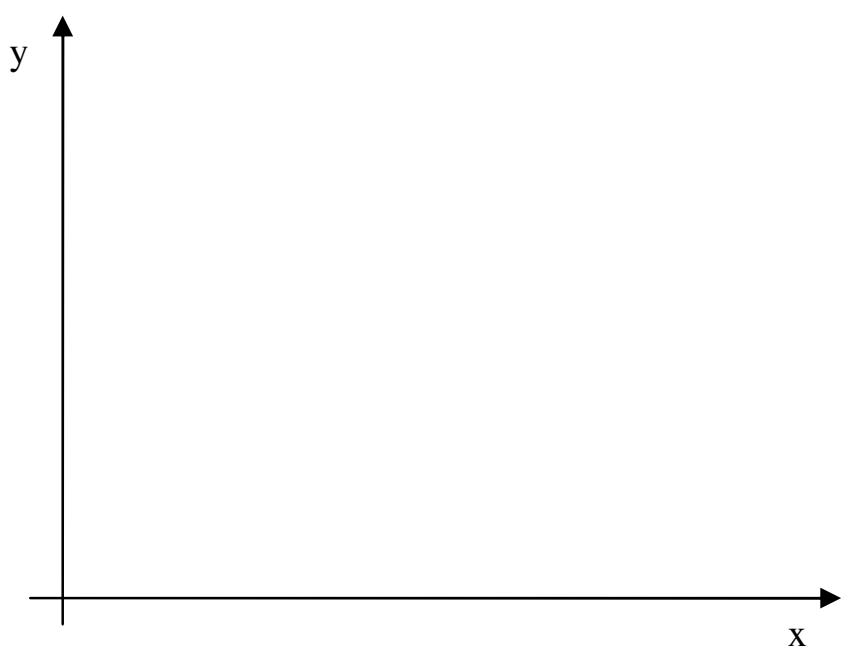

O traçado do gráfico ou locação faz-se com referência a dois eixos coordenados, um vertical (eixo dos Y) e outro horizontal (eixo dos X). Estas linhas são perpendiculares entre si. Chama-se de $\mathrm{O}$, ou origem, $\mathrm{O}$ ponto em que elas se interceptam.

\section{Histograma}

Muitas vezes é conveniente representar uma distribuição de frequências por meio de um histograma.

Para construído, faz-se necessário: na linha horizontal (eixo dos $\mathrm{X}$ ) marcam-se os valores da variável; na linha vertical (ou eixo dos Y), localizam-se as frequências relativas a cada valor da variável.

As frequências de cada valor da variável são indicadas por barras retangulares. 


\begin{tabular}{c|c}
\hline $\mathbf{X}$ & $\mathbf{f}$ \\
\hline $2-5$ & 5 \\
\hline $6-9$ & 3 \\
\hline $10-13$ & 10 \\
\hline $14-17$ & 16 \\
\hline $18-21$ & 14 \\
\hline $22-25$ & 4 \\
\hline $26-29$ & 2 \\
\hline$\sum$ & 52 \\
\hline
\end{tabular}

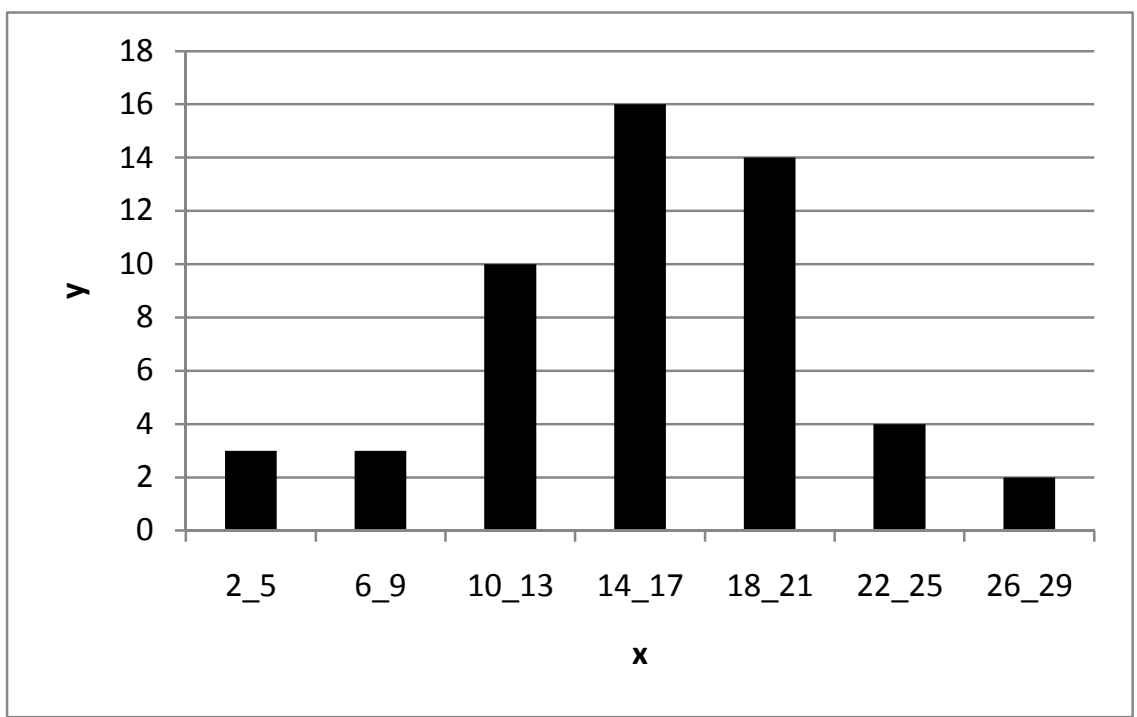

\section{Polígono de frequência}

Unindo-se os pontos médios das bases superiores do retângulo da mesma largura do histograma, ter-se-á outra representação gráfica denominada polígono de frequência. São representados por segmentos de reta chamados polígonos.
Colocam-se, no gráfico, os pontos médios dos intervalos de classe.

Exemplo: Período pré-operacional - extensão

\begin{tabular}{c|c|c}
\hline $\mathbf{X}$ & $\mathbf{f}$ & $\mathbf{P m}$ \\
\hline $2-5$ & 3 & 3,5 \\
$6-9$ & 3 & 7,5 \\
$10-13$ & 10 & 11,5 \\
$14-17$ & 16 & 15,5 \\
$18-21$ & 14 & 19,5 \\
$22-25$ & 4 & 23,5 \\
$26-29$ & 2 & 27,5 \\
\hline
\end{tabular}

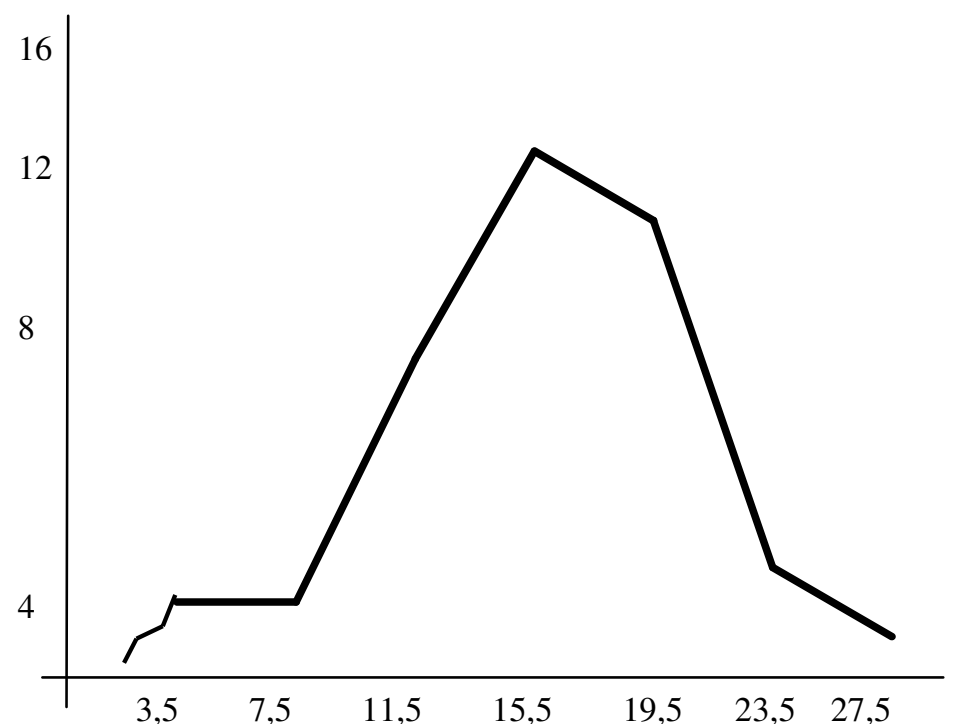




\section{MEDIDAS DE TENDÊNCIA CENTRAL}

a) Definição: são as medidas típicas ou representativas de um conjunto de dados.

b) Objetivo: indicar o valor típico ou prevalente de uma distribuição de frequência, quando esta apresenta os valores intermediários da variável com frequência maior que os valores extremos, ou seja, uma tendência central.

c) Tendência central: é a tendência das notas incidirem para o centro da distribuição.

d) Utilidade: diante de uma distribuição de frequência, faz-se necessário dispor de um número que nos indique onde está a tendência central, ou, então, o valor mais capaz de substituir todos os outros.

e) Medida mais usada: média aritmética.

f) Outras medidas: mediana, moda.

g) Restrições: por si só dão informações insuficientes; precisam ser acopladas a uma medida de variabilidade.

\section{Média aritmética}

A média aritmética representa o "centro de gravidade" da distribuição, isto é, o ponto de qualquer distribuição em torno do qual se equilibram as discrepâncias positivas e negativas.

Situa-se entre o valor máximo e o valor mínimo da distribuição. Não pode, portanto, ser inferior ou superior ao valor mínimo e ao máximo da distribuição.

A média aritmética é um valor que pretende ser o resumo de todos os valores da distribuição. Dessa forma, pode vir a ser um valor não presente na distribuição.

Permite fazer interpretações quando é utilizada na comparação de dois ou mais grupos, constatando qual é o grupo com resultados mais ou menos elevados.

\section{Cálculo da média aritmética}

No cálculo do valor da média aritmética faz-se a soma dos valores e divide-se esta pelo número de observações da série.

\section{DADOS NÃO AGRUPADOS}

Acha-se o quociente do somatório dos valores da série pelo número deles.

$$
\mathrm{X}_{\mathrm{i}}=\frac{\mathrm{X}_{1}+\mathrm{X}_{2}+\mathrm{X}_{3}+\cdots+\mathrm{X}_{\mathrm{n}}}{\mathrm{N}}
$$

$\mathrm{X}_{1}, \mathrm{X}_{2}, \ldots, \mathrm{X}_{\mathrm{n}}$ são valores particulares que as variáveis assumem naquela série de observações.

$$
\bar{X}=\frac{\sum_{\mathrm{i}}^{\mathrm{N}} \mathrm{X}_{\mathrm{i}}}{\mathrm{N}}
$$

$\overline{\mathrm{X}}=$ média aritmética

$\mathrm{X}_{\mathrm{i}}=$ nota do i-ésimo elemento

$\mathrm{N}=$ número total de notas

$\Sigma=$ somatório

Na distribuição de frequência, alguns valores podem ocorrer mais de uma vez. É possível, portanto, elaborar uma distribuição de frequência e verificar que o produto do valor da variável pela sua respectiva frequência $\left(\mathrm{F}_{\mathrm{i}} \cdot \mathrm{X}_{\mathrm{i}}\right)$ é idêntico à soma de todos os valores iguais de uma variável. Neste caso, para se obter a média aritmética, somam-se todos os produtos $F_{i} \cdot X_{i}$ e divide-se o resultado pelo número total de casos.

$$
\overline{\mathrm{X}}=\frac{\sum_{\mathrm{i}}^{\mathrm{N}} \mathrm{F}_{\mathrm{i}} \cdot \mathrm{X}_{\mathrm{i}}}{\mathrm{N}}
$$

$\overline{\mathrm{X}}=$ média aritmética

$F_{i} \cdot X_{i}=$ nota do i-ésimo elemento

$\mathrm{N}=$ total de casos

$\Sigma=$ somatório 
Exemplo: Escores obtidos pelas crianças na dimensão duração

\begin{tabular}{c|c|c}
\hline $\mathbf{X}_{\mathbf{i}}$ & $\mathbf{F}_{\mathbf{i}}$ & $\mathbf{F}_{\mathbf{i}} \mathbf{X}_{\mathbf{i}}$ \\
\hline 1 & 3 & 3 \\
2 & 2 & 4 \\
3 & 2 & 6 \\
4 & 1 & 4 \\
5 & 1 & 5 \\
6 & 1 & 6 \\
\hline$\sum$ & 10 & 28 \\
\hline
\end{tabular}

$$
\begin{gathered}
\bar{X}=\frac{\sum X_{i} \cdot F_{i}}{N} \\
\bar{X}=\frac{20}{10} \\
\bar{X}=2,8
\end{gathered}
$$

\section{Propriedades da média aritmética}

$\left.1^{\circ}\right)$ A soma algébrica dos afastamentos ou desvios dos valores da série em relação à média é nula.

Essa propriedade implica a seguinte afirmativa: se calcularmos os desvios em relação a um outro termo qualquer da série, diferente da sua média aritmética, a soma destes desvios será diferente de zero.

$\left.2^{\circ}\right)$ A média aritmética é influenciada pelas alterações sofridas pelos valores da série.

Ficará aumentada na mesma quantidade que for adicionada a todos os valores da série. da série.

Ficará diminuída da quantidade que for subtraída a todos os valores

Ficará multiplicada pela quantidade que for multiplicada a todos os valores da série.

Ficará dividida pela quantidade pela qual foram divididos todos os valores da série. $3^{\circ}$ ) A soma dos quadrados dos afastamentos dos valores da série em relação à média aritmética é um mínimo.

Isto significa que se tornarmos a soma dos quadrados dos desvios em relação a outro termo qualquer da série, esta soma será sempre maior do que a encontrada, utilizando-se os quadrados dos desvios em relação à média aritmética.

$4^{\circ}$ ) A média aritmética depende de todos os valores da série, porque todos entram no seu cálculo, sendo por isso um valor representativo da série.

$5^{\circ}$ ) A média aritmética é grandemente influenciada pelos valores extremos da série.

\section{Vantagens e desvantagens na utilização da média aritmética}

- É influenciada pelos valores extremos, ou seja, um valor excepcionalmente alto ou baixo a altera. Por isso não deve ser utilizada quando a distribuição é muito assimétrica.

- Permite apenas uma descrição incompleta na distribuição, por não fornecer informações a respeito do número de casos que estão acima ou abaixo do valor da média aritmética; e também a respeito do valor mais frequente.

Na pesquisa realizada por Torres (1978), verifica-se a utilização da média aritmética para fins de comparações entre distribuições.

Médias e desvios-padrão obtidos em

cada dimensão nos três grupos considerados

\begin{tabular}{c|c|c|c}
\hline & $\begin{array}{c}\text { Subperíodo pré- } \\
\text { operacional (PO) }\end{array}$ & $\begin{array}{c}\text { Subperíodo de } \\
\text { operação } \\
\text { concreta (O) }\end{array}$ & $\begin{array}{c}\text { Período de } \\
\text { operações } \\
\text { formais (OF) }\end{array}$ \\
\hline \multirow{2}{*}{ Extensão } & $\overline{\mathrm{X}}=15,67$ & $\overline{\mathrm{X}}=24,73$ & $\overline{\mathrm{X}}=28,87$ \\
\hline \multirow{2}{*}{ Significado } & $\mathrm{S}=5,36$ & $\mathrm{~S}=3,99$ & $\mathrm{~S}=3,54$ \\
\hline \multirow{2}{*}{ Duração } & $\overline{\mathrm{X}}=16,79$ & $\overline{\mathrm{X}}=29,23$ & $\overline{\mathrm{X}}=33,62$ \\
& $\mathrm{~S}=8,34$ & $\mathrm{~S}=5,46$ & $\mathrm{~S}=4,07$ \\
\hline & $\overline{\mathrm{X}}=3,37$ & $\overline{\mathrm{X}}=7,85$ & $\overline{\mathrm{X}}=9,40$ \\
$\mathrm{~S}=2,47$ & $\mathrm{~S}=5,46$ & $\mathrm{~S}=0,57$ \\
\hline
\end{tabular}


Analisando-se as médias aritméticas em relação às três dimensões, verifica-se que houve uma evolução do conceito de morte na medida em que há uma evolução cognitiva, pois houve um aumento das médias.

Observando-se as médias aritméticas das três dimensões, conclui-se que a compreensão do conceito de morte, quanto à sua duração, é mais difícil qualquer que seja a fase cognitiva em que se encontre a criança, visto que nesta dimensão os valores das médias aritméticas são mais baixos do que os demais.

A tabela apresenta também valores dos desvios-padrão que devem ser acoplados aos valores da média aritmética como veremos mais adiante.

\section{Mediana}

A mediana é o valor médio de uma distribuição ordenada, o qual apresenta o mesmo número de valores abaixo e acima desse valor.

A mediana é um ponto da distribuição, tal que a probabilidade de um valor qualquer da distribuição, aleatoriamente escolhido, se situar acima da mediana é igual à probabilidade dele se situar abaixo da mesma. Isto é válido para qualquer distribuição, não importando a sua forma.

Através da interpretação do valor mediano, pode-se afirmar, ao comparar dois ou mais grupos, qual é o que apresenta resultados mais elevados, e qual o que apresenta resultados menos elevados.

\section{Cálculo da mediana}

Para se calcular o valor da mediana, primeiramente organizam-se os dados em ordem crescente ou decrescente.

$\mathrm{O}$ valor da mediana é aquele abaixo e acima do qual encontra-se a mesma quantidade de valores da série.

Primeiramente, localiza-se a mediana, e depois, observa-se o seu valor.

${ }^{*}$ Nick, notas de aula.

$$
\text { Posição } \frac{N+1}{2}
$$

$\mathrm{N}=$ número de casos

Exemplo: valores obtidos pelas crianças na dimensão duração no período pré-operacional

\begin{tabular}{|c|c|c|c|}
\hline $\mathrm{X}_{\mathrm{i}}$ & $\mathrm{F}_{\mathrm{i}}$ & $\mathrm{F}_{\mathrm{ac}}$ & \\
\hline 1 & 3 & 3 & \\
\hline 2 & 2 & 5 & $N+1-11$ \\
\hline 3 & 2 & $7 \Leftarrow$ & $\overline{2}=\overline{2}=5,5$ \\
\hline 4 & 1 & 8 & \\
\hline 5 & 1 & 9 & Md (posição) \\
\hline 6 & 1 & 10 & $5,5^{\circ}$ \\
\hline
\end{tabular}

$$
\mathrm{Md}=\mathrm{L}_{\mathrm{ir}}+\frac{N / 2-F a c}{F_{i}} . \mathrm{h}
$$

$\mathrm{Md}=$ mediana

$\mathrm{L}_{\mathrm{ir}}=$ limite inferior real

$\mathrm{N} / 2=50 \%$

$\mathrm{Fac}=$ frequência acumulada da classe anterior

$\mathrm{F}_{\mathrm{i}}=$ frequência simples da classe

$$
\mathrm{Md}=2,5+\frac{5,0-5}{2}=2,5
$$

Ordenar : 4, 2, 2, 1, 3, 5, 6, 3, 1, 1

$$
\begin{gathered}
1,1,1,2,2,3,3,4,5,6 \\
M d=\frac{N+1}{2}=\frac{11}{2}=5,5^{\circ} \quad M d=2,5
\end{gathered}
$$

\section{Propriedades da mediana}

$1^{\circ}$ ) A mediana não é influenciada pelos valores extremos.

$2^{\circ}$ ) A soma dos valores absolutos dos desvios a partir da mediana é um mínimo. 
$3^{\circ}$ ) A mediana de uma série de classes indefinidas pode ser calculada, desde que conheça o número total de observações.

\section{Vantagens na utilização da mediana}

Sua determinação é fácil e rápida, não requer cálculos complexos.

Juntando-se o mesmo número de termos nas duas extremidades, a mediana continua sendo a mesma.

\section{Desvantagens na utilização da mediana}

- A mediana flutua mais de amostra para amostra do que a média aritmética; portanto, é menos confiável. Não utiliza a totalidade dos dados.

- É um valor posicional, não vem definido por uma expressão matemática; portanto, não é susceptível de tratamento algébrico. Não é possível calcular a mediana de um grupo total a partir das medianas de dois subgrupos.

\section{Moda}

É o valor da distribuição que ocorre com a maior frequência, ou seja, o valor que mais se repete dentro de uma série de observações.

A moda só pode ser utilizada como medida de tendência central quando apenas um valor da série ocorre com maior frequência.
Exemplo: Escore obtido por 10 crianças na dimensão duração

\begin{tabular}{c|c}
\hline $\mathbf{X}_{\mathbf{i}}$ & $\mathbf{F}_{\mathbf{i}}$ \\
\hline 1 & 3 \\
2 & 2 \\
3 & 2 \\
4 & 1 \\
5 & 1 \\
6 & 1 \\
\hline$\sum$ & 10 \\
\hline
\end{tabular}

$\mathrm{O}$ escore que apareceu maior número de vezes foi o 1 ; portanto, o valor da moda é igual a 1 . Consequentemente, este valor seria o valor representativo da distribuição.

\section{Vantagens e desvantagens na utilização da moda}

Embora de cálculo fácil, não pode ser utilizada em distribuições bimodais ou multimodais.

\section{Utilização das medidas de tendência central}

Em um dado momento, podem surgir dúvidas sobre que medida de tendência central utilizar; no entanto, dois fatores devem ser averiguados:

$1^{\circ}$ ) o aspecto ou forma da distribuição

$2^{\circ}$ ) o objetivo da pesquisa

\section{Forma da distribuição}

A forma da distribuição pode influenciar o pesquisador na escolha de uma medida de tendência central. Em uma distribuição unimodal e perfeitamente simétrica, a moda, a mediana e a média serão idênticas, uma vez que o ponto de frequência máxima (Mo) é também o valor que divide a distribuição em duas partes, contendo o mesmo número de termos em cada uma das partes; é também o "centro de gravidade" distribuição. 
$\mathrm{Na}$ distribuição assimétrica à esquerda, a média aritmética é deslocada para a esquerda da moda; na distribuição inclinada para a direita, a média incide à direita da moda.

Em cada caso, a média aritmética é deslocada na mesma direção da inclinação da distribuição.

A direção do deslocamento da mediana é o mesmo da direção do deslocamento da média, mas a extensão deste deslocamento é menos do que o da média aritmética, visto que esta é influenciada pelos valores extremos.

Em uma distribuição assimétrica, a mediana sempre se situa em algum lugar entre a média e a moda. É essa característica que a torna a medida de tendência central preferida, por alguns pesquisadores, para representar uma distribuição assimétrica.

\section{Objetivo da pesquisa}

A escolha da medida de tendência central depende das hipóteses ou objetivos do pesquisador.

Utilizará a moda se pretender uma medida descritiva, rápida e simples ainda que grosseira, e se a distribuição for unimodal. Se a pretensão for uma medida exata, ele poderá optar entre a média e a mediana. Se a distribuição for aproximadamente simétrica, a média aritmética é a mais indicada, mesmo porque esta poderá ser utilizada em estatística mais avançada e é uma medida mais estável.

\section{MEDIDAS DE DISPERSÃO}

a) Definição: é um índice que indica o grau de dispersão dos escores em tomo da posição central.

b) Objetivo: descreve a heterogeneidade do grupo.

c) Utilidade: é o complemento da medida de tendência central. Mediante seu uso sabe-se que se os valores estão "muito concentrados" ao redor da média aritmética, esta será muito representativa; mas se os valores estão muito dispersos ao redor da média aritmética, esta será pouco representativa.

d) Medida mais usada: desvio-padrão.

e) Outras medidas: amplitude total, desvio semi-interquartil, desvio médio.

\section{Intervalo total ou amplitude total}

A amplitude (ou intervalo total) de uma série é definida como a diferença entre o valor mais alto e o valor mais baixo da série.

A amplitude de uma série de valores é determinada rápida e facilmente, oferecendo uma ideia grosseira do grau de dispersão.

Conhecendo-se o valor da média e da amplitude, têm-se dados sobre o centro da distribuição e da dispersão em torno desse ponto.

It $=$ Intervalo total

$$
\mathrm{It}=\mathrm{X}_{\operatorname{máx}}-\mathrm{X}_{\min }
$$

$\mathrm{X}_{\text {máx }}=$ valor máximo

$\mathrm{X}_{\min }=$ valor mínimo

\section{Desvantagens da utilização da amplitude total}

- Por depender somente dos valores extremos da série, torna-se insensível à dispersão dos demais valores, compreendido entre o ponto máximo e o mínimo; principalmente quando a série é grande e existem lacunas extensas. 
- Não é uma medida exata. A alteração de apenas um valor extremo da série ocasiona uma mudança brusca de amplitude. Esta também é afetada pelo tamanho da amostra.

\section{Desvio médio}

Baseia-se na primeira propriedade da média: "A soma algébrica dos afastamentos dos valores em relação à média aritmética é nula." No entanto, para seu cálculo apenas são considerados os valores absolutos dos desvios, logo, representa o quociente do somatório dos desvios a partir da média pelo número total de casos. Trata-se, então, da média aritmética dos desvios em torno do valor central.

$$
\mathrm{DM}=\frac{\sum_{\mathrm{i} 1}^{\mathrm{N}}|\mathrm{X}|}{\mathrm{N}}
$$

$\mathrm{DM}=$ Desvio médio

$|\mathrm{X}|=\mathrm{X}_{\mathrm{i}}-\overline{\mathrm{X}}$

$\mathrm{N}$ = número total de casos

Este valor é uma estimativa da amplitude dentro da qual variam as observações médias do conjunto de itens ou mensurações.

A soma dos valores absolutos das discrepâncias tende a tornar-se maior à medida que a variabilidade da distribuição aumenta.

\section{Cálculo do desvio médio:}

$1^{\circ}$ ) Calcular a média aritmética da distribuição.

$2^{\circ}$ ) Subtrair de cada escore bruto a média aritmética.

$3^{\circ}$ ) Somar todos os valores absolutos dos desvios.

$4^{\circ}$ ) Dividir o somatório dos desvios pelo número total de casos.

O desvio médio não é muito utilizado atualmente pelos pesquisadores. Na maioria dos casos ele é substituído pelo desvio-padrão.

\section{Desvio-padrão}

O desvio médio é uma medida de pouco valor, pois não considera os sinais dos desvios. Uma tentativa de superar esta dificuldade reside na possibilidade de se elevar ao quadrado os desvios, tornando-os, dessa forma, positivos.

Denomina-se variância a média dos quadrados dos desvios tomados a partir do conjunto.

$$
\mathrm{V}=\frac{\sum_{\mathrm{i}=1}^{\mathrm{N}} \cdot \mathrm{X}_{\mathrm{i}} 2}{\mathrm{~N}}
$$

V= variância

$\mathrm{x}_{\mathrm{i}}^{2}=$ desvios ao quadrado

$\mathrm{N}=$ número total de casos

A raiz quadrada positiva da variância é o que se chama desvio ou afastamento quadrático ou simplesmente desvio-padrão.

$$
\mathrm{S}=+\sqrt{\frac{\sum_{i=l}^{N} \cdot X_{i^{2}}}{N}}
$$

$\mathrm{S}=$ desvio-padrão

$\mathrm{x}_{\mathrm{i}}^{2}=$ desvios ao quadrado

$\mathrm{N}=$ número total de casos

\section{Cálculo do desvio-padrão}

$1^{\circ}$ ) Calcular a média aritmética da distribuição.

$2^{\circ}$ ) Subtrair de cada escore bruto o valor da média aritmética.

$3^{\circ}$ ) Elevar os desvios ao quadrado.

$4^{\circ}$ ) Somatório de todos os desvios ao quadrado.

$5^{\circ}$ ) Dividir o somatório pelo número total de casos.

$\left.6^{\circ}\right)$ Extrair a raiz quadrada do resultado e dar-lhe sinal positivo. 
Exemplo: Escores obtidos por 10 crianças na dimensão duração

\begin{tabular}{c|c|c|c|c|c|c}
\hline $\mathbf{X}_{\mathbf{i}}$ & $\mathbf{F}_{\mathbf{i}}$ & $\mathbf{F}_{\mathbf{i}} \mathbf{X}_{\mathbf{i}}$ & $\mathbf{x}_{\mathbf{i}}\left(\mathbf{X}_{\mathbf{i}}-\overline{\mathbf{X}}\right)$ & $\mathbf{x}_{\mathbf{i}}$ & $\mathbf{x}_{\mathbf{1}}{ }^{2}$ & $\mathbf{x}_{\mathbf{i}} \mathbf{F}$ \\
\hline 1 & 2 & 3 & $1-2,8$ & $-1,8$ & 3,24 & 9,72 \\
2 & 2 & 4 & $2-2,8$ & $-0,8$ & 0,64 & 1,28 \\
3 & 2 & 6 & $3-2,8$ & $+0,2$ & 0,04 & 0,08 \\
4 & 1 & 4 & $4-2,8$ & $-1,2$ & 1,44 & 1,44 \\
5 & 1 & 5 & $5-2,8$ & $+2,2$ & 4,84 & 4,84 \\
6 & 1 & 6 & $6-2,8$ & $+3,2$ & 10,24 & 10,24 \\
\hline \multicolumn{7}{l}{}
\end{tabular}

$$
S=\sqrt{\frac{27,6}{10}}=\sqrt{2,76}=+1,66 \quad \bar{X}=\frac{28}{10}=2,8
$$

\section{Propriedades do desvio-padrão}

$1^{\circ}$ ) A média aritmética, aumentada e subtraída de um desvio-padrão, indica uma faixa de normalidade na qual há uma incidência maior das observações. Estas observações representam, via de regra, 68,26\% do total. $\mathrm{O}$ restante das observações, fora desse limite, é superior ou inferior às consideradas normais e aparece numa percentagem equivalente a 15,9\% em cada extremidade da distribuição. Tais percentagens são as que aparecem nas distribuições normais.

$\left.2^{\circ}\right) \mathrm{O}$ desvio-padrão aumenta à medida que aumenta a dispersão em torno da média aritmética.

$3^{\circ}$ ) Somando-se ou subtraindo-se todos os valores da série por uma constante, o desvio-padrão não será alterado.

$\left.4^{\circ}\right)$ Se todos os valores da série forem multiplicados por uma constante, o desvio-padrão será aumentado na mesma proporção.

A interpretação do desvio-padrão pode ser feita observando-se os valores numéricos. À medida que estes decrescem, menor será a variabilidade, e quanto mais aumentam, maior.

Referindo-se à tabela das médias aritméticas e desvios-padrão (pág. 17), verificamos que, em relação às dimensões extensão e significado, os desvios-padrão decrescem à medida que o desenvolvimento cognitivo evolui. Conclui-se que os grupos se tornam mais homogêneos à medida que há evolução cognitiva.

No período das operações formais, a concentração dos valores em torno da média aritmética é maior. No entanto, com relação à dimensão duração, as crianças do subperíodo das operações concretas apresentam-se mais heterogêneas. 


\section{MEDIDAS SEPARATRIZES}

Separatrizes são valores da distribuição que a dividem em partes quaisquer.

A mediana, apesar de ser uma medida de tendência central, é também uma separatriz de ordem $1 / 2$, ou seja, divide a distribuição em duas partes iguais.

Existem outras separatrizes. As mais comumente usadas são:

Quartis - dividem a distribuição em quatro partes iguais, de ordem 1/4.

Decis - dividem a distribuição em 10 partes iguais, de ordem 1/10.

Centis - dividem a distribuição em 100 partes iguais, de ordem 1/100.

\section{Quartis}

Os quartis são os 3 pontos que dividem a série em quatro partes iguais.

$\mathrm{Q}_{1}$ - primeiro quartil - separa os $25 \%$ dos valores mais baixos da distribuição dos resultantes $75 \%$.

$\mathrm{Q}_{2}$ - segundo quartil - coincide com a mediana, separa os $50 \%$ dos valores mais baixos dos $50 \%$ dos valores mais altos da distribuição.

$\mathrm{Q}_{3}$ - terceiro quartil - separa os $75 \%$ dos valores mais baixos da distribuição dos $25 \%$ dos valores mais altos.

Fórmula das separatrizes:

$$
\mathrm{Sp}=\mathrm{L}_{\mathrm{ir}}+\frac{\% \mathrm{n}-\mathrm{Fac}}{\mathrm{F}_{\mathrm{i}}} . \mathrm{h}
$$

Portanto:

$$
\mathrm{Q}=\mathrm{L}_{\mathrm{ir}}+\frac{\% \mathrm{n}-\mathrm{Fac}}{\mathrm{F}_{\mathrm{i}}} \cdot \mathrm{h}
$$

Passos para o cálculo:

$1^{\circ}$ ) Encontra-se a frequência acumulada da distribuição.

$2^{\circ}$ ) Posicionar os quartis através da fórmula.

$$
\begin{gathered}
\mathrm{Q}_{1}=\frac{\mathrm{N}}{4} \\
\mathrm{Q}_{2}=\frac{2 \mathrm{~N}}{4} \\
\mathrm{Q}_{3}=\frac{3 \mathrm{~N}}{4}
\end{gathered}
$$

$3^{\circ}$ ) Localizam-se as posições dos quartis na frequência acumulada. $4^{\circ}$ ) Aplica-se a fórmula.

Exemplo: Escores encontrados em 10 crianças na dimensão extensão no período pré-operacional.

\begin{tabular}{|c|c|c|}
\hline $\mathbf{X}$ & $\mathbf{F}$ & Fac \\
\hline 4 & 1 & 1 \\
8 & 1 & 2 \\
10 & 1 & $3 \leftarrow \mathrm{Q}_{1}$ \\
13 & 2 & 5 \\
14 & 2 & 7 \\
17 & 1 & 8 \\
18 & 1 & 9 \\
22 & 1 & 10 \\
\hline
\end{tabular}

$$
\mathrm{Q}_{1}=\frac{\mathrm{N}}{4}=\frac{10}{4}=2,5
$$

$14,22,13,14,18,10,8,13,4,17$

$1^{\circ}$ Colocar em ordem:

$4,8,10,13,13,14,14,17,18,22$

$$
\begin{gathered}
\mathrm{Q}_{1}=\frac{\mathrm{N}}{4}=\frac{10}{4}=2,5 \\
\frac{8+10}{2}=\frac{18}{2}=9
\end{gathered}
$$


Decis

Os decis são os nove pontos que dividem a distribuição em 10 partes iguais.

\section{Centis ou percentis}

Os percentis são os 99 valores que dividem a distribuição em 100 partes iguais, abrangendo, cada um, $1 \%$ do número total da distribuição.

As separatrizes são amplamente utilizadas em psicologia, com o objetivo de padronizar resultados. Testes psicológicos como o Bender, Bateria CEPA e outros utilizam as separatrizes em suas tabelas padronizadas.

A média aritmética, juntamente com o desvio-padrão, embora menos frequentemente, também são utilizadas como critérios de padronização. Elizabeth Koppitz, no Bender infantil, padronizou seus resultados a partir destas medidas.

\section{PARTE II INFERÊNCIA ESTATÍSTICA}

\section{INTRODUÇÃO}

O que se fez até agora, na Estatística descritiva, foi sumarizar resultados acerca de um grupo denominado amostra, que é representativo de um grupo maior, que se denomina população.

Às vezes se faz necessário extrair conclusões de uma determinada investigação científica sem se dispor de evidências suficientes. Neste caso, o pesquisador precisa saber quando dispõe de evidências suficientes para chegar a uma conclusão com determinado grau de confiança.

Ao se desejar concluir com evidências incompletas pode-se lançar mão de estatística. Chamam-se deduções probabilísticas. Ao se deduzir a partir da probabilidade, faz-se inferência estatística.

Para se recorrer à inferência estatística, faz-se uso do raciocínio indutivo e da teoria das probabilidades.

\section{OBJETIVOS DA INFERÊNCIA ESTATÍSTICA}

A inferência estatística aborda dois tipos fundamentais de problemas:

\section{Estimativa dos parâmetros de uma população}

A partir dos resultados obtidos na amostra, estimam-se os parâmetros da população.

$\mathrm{Na}$ maioria das vezes, torna-se impossível medir-se todos os membros de uma população; para tanto, extraem-se amostras dessa população. A composição das amostras acaba por comprometer os resultados, uma vez que as medidas estatísticas calculadas sofrem variações de amostra para amostra de uma dada população - erro amostral - ou seja, por pura obra do acaso, haverá sempre uma diferença entre os resultados da amostra e os da população da qual ela foi extraída. Isto significa que a média da amostra quase nunca será exatamente igual à média da população, 
e o desvio será idêntico ao desvio da população em raríssimas ocasiões, mesmo que o plano amostral tenha sido bem elaborado e executado.

Como, na maioria das vezes, utiliza-se apenas uma amostra, como se pode saber se esses resultados podem ou não ser inferidos à população, ou seja, como garantir os parâmetros de uma população?

As estatísticas, portanto, estão sujeitas ao que se designa flutuações de amostragem. Tais estatísticas, apenas sob determinadas condições, poderão vir a ser os parâmetros da população.

Para se saber até que ponto se pode acreditar na estimativa dos parâmetros com base nos dados obtidos da amostra, recorre-se ao erropadrão da estatística utilizada.

Segundo Nick e Kellner (1971): "O erro-padrão é teoricamente o desvio-padrão da distribuição amostral das médias, mas praticamente é uma estimativa de erro que cometemos ao substituir o parâmetro desconhecido pela estimativa obtida através de uma amostra".

\section{Erro-padrão da media $\left(\sigma_{\bar{X}}\right)$}

Mede o grau de eficiência da estimativa, mede o grau em que a média é afetada por erros de medida.

$$
\sigma_{\overline{\mathrm{X}}}=\frac{\mathrm{S}}{\sqrt{\mathrm{N}-1}}
$$

Onde

$$
\mathrm{S}=\frac{\sqrt{\sum \mathrm{X}^{2}}}{\sqrt{\mathrm{N}-1}}
$$

Usa-se $\mathrm{N}-1$ porque o desvio-padrão da amostra é menor que o desvio-padrão da população, e apenas é utilizado quando $\mathrm{N}<30$.

$\sigma_{\overline{\mathrm{X}}}=$ erro-padrão da média

$\mathrm{S}=$ desvio-padrão da amostra

$\mathrm{Na}$ verdade, seria o desvio-padrão da população, mas como seria muito trabalhoso calculá-lo, utiliza-se $\mathrm{N}-1$ no denominador.

$\mathrm{N}=$ número total da amostra.
Ao empregarmos o erro-padrão, devemos estar atentos ao tamanho da amostra e à variabilidade da distribuição.

- quanto maior N, menor é o erro-padrão da média.

- quanto maior o erro-padrão da média, maior o desvio-padrão.

- a distribuição amostral é sempre menor que a variabilidade da distribuição total

Através desse cálculo pode-se estabelecer o intervalo de confiança, isto é, o intervalo de valores dentro do qual a verdadeira média populacional pode cair.

\section{Intervalos de confiança}

Na estimativa da média da população.

a) $68 \%: \bar{X} \pm(1)$

$\overline{\mathrm{X}}=$ média amostral

$\sigma_{\overline{\mathrm{X}}}=$ erro-padrão da média

(1) = valor do desvio-padrão

Ao escolher-se um intervalo de confiança de $68 \%$ significa que há 68 possibilidades em 100 da média estar correta.

b) $95 \%: \bar{X} \pm(1,96)$

$\overline{\mathrm{X}}=$ média amostral

$\sigma_{\overline{\mathrm{X}}}=$ erro-padrão da média

$(1,96)=$ valor de 2 desvios-padrão

Pode-se acertar $95 \%$ das vezes e errar $5 \%$ das vezes.

c) $99 \%: \bar{X} \pm(2,58)$

$\overline{\mathrm{X}}=$ média amostral

$\sigma_{\overline{\mathrm{X}}}=$ erro-padrão da média

$(2,58)=$ valor de 3 desvios-padrão 
Pode-se acertar $99 \%$ das vezes e errar $1 \%$ das vezes.

Este procedimento deve ser realizado quando se desejar fazer generalizações de uma amostra para uma população, ou seja, utilizar a média da amostra como parâmetro da população.

\section{Erro-padrão da mediana $\left(\sigma_{m d}\right)$ :}

O erro-padrão da mediana é maior que o erro-padrão da média, o que mostra que a média é, em geral, mais fidedigna, menos sujeita às variações do que a mediana. paramétricas.

O erro-padrão da mediana é utilizado em estatísticas não

$$
\sigma_{\mathrm{md}}=\frac{1,253 \sigma}{\sqrt{\mathrm{N}}} \text { ou } \quad \sigma_{\mathrm{md}}=\frac{1,868 \mathrm{Q}}{\sqrt{\mathrm{N}}}
$$

Erro-padrão do desvio-padrão

$$
\sigma_{\sigma}=\frac{0,71 \sigma}{\sqrt{\mathrm{N}}}
$$

Erro-padrão do desvio semi-interquartil

Utilizado em estatísticas não paramétricas.

$$
\sigma_{\mathrm{Q}}=\frac{0,786 \mathrm{Q}}{\sqrt{\mathrm{N}}}
$$

\section{Prova de hipóteses}

A prova de hipóteses tem como objetivo testar a significância das diferenças. Para tanto, tenta-se provar uma hipótese, usando-se como intermediária a hipótese estatística. A análise estatística é, em parte, função da prova estatística empregada na análise. Por tal motivo, ao escolher-se a prova estatística, deve-se ficar atento ao fato de que as exigências para o uso de uma prova devem ser cumpridas.
A escolha da prova estatística deve estar condicionada aos seguintes fatores:

- Plano de amostragem

- Natureza da população da qual se extraiu a amostra

- Nível de mensuração das variáveis

- Variância das populações

\section{Critérios para a escolha da prova estatística}

\section{Plano de amostragem}

Consiste num processo de seleção que segue regras e operações para que elementos da população sejam incluídos na amostra.

Fatores tais como o número de elementos que contém a amostra, a extração de um elemento de uma amostra afetando ou não a composição de outra amostra e o método de amostragem interferem na escolha da prova estatística. Este processo necessita de um critério objetivo.

Sabe-se que quanto maior a amostra, maior é a probabilidade de se encontrar a normalidade. Ao aumentar o tamanho da amostra, aumenta a probabilidade desta assemelhar-se à população.

O recurso de se aumentar o tamanho da amostra para aumentar a precisão da estimativa da média da população tem seu grau de eficiência relacionado com a raiz quadrada do tamanho da amostra.

Só podemos considerar uma amostra como sendo representativa quando é constituída por elementos selecionados de acordo com uma técnica conhecida - processo de seleção - ou seja, regras e operações mediante as quais alguns membros da população são incluídos na amostra.

$$
\begin{aligned}
& \text { Processo de seleção: } \\
& \text { - seleção probabilística } \\
& \text { - seleção não probabilística }
\end{aligned}
$$


O método de amostragem que possibilita com maior grau de certeza a representativa da amostragem é o aleatório. Neste método, cada indivíduo da população possui a mesma chance de ser escolhido. Considera-se, também, que a seleção de um indivíduo não influenciará de forma alguma a escolha de outro.

A extração da amostra aleatória em psicologia apresenta três peculiaridades:

- A seleção sistemática dos componentes da amostra aproxima-se da aleatoriedade, uma vez que os membros estão arrolados. Assim, pode-se selecionar um nome de cada grupo. Os grupos vão depender do tamanho da amostra.

- Conhece-se a distribuição daquela característica que se deseja estudar. Por exemplo, sabe-se que inteligência distribui-se normalmente dentro da população; logo, uma amostra extraída aleatoriamente desta população também apresentará uma distribuição normal.

- A população, não sendo nitidamente definida, torna a amostragem inacessível. Quando isso ocorre, cabe uma verificação da adequação da amostra. Extraem-se diversas amostras aleatórias de aproximadamente o mesmo tamanho; caso tais amostras apresentem resultados muito diferentes, nenhuma delas é representativa.

\section{Natureza da população da qual se extraiu a amostra}

A população pode ser, em sua natureza, normal ou não normal. Muitos fenômenos na natureza distribuem-se de acordo com a normalidade, como, por exemplo, a altura, o peso e a inteligência. Outros fenômenos, no entanto, por natureza não se encaixam na distribuição normal, como, por exemplo, mortalidade, amamentação por classe socioeconômica.

Quando o fenômeno a ser estudado se caracteriza por uma distribuição normal, utiliza-se a estatística paramétrica, caso contrário recorre-se à estatística não paramétrica.

\section{Nível de mensuração das variáveis}

A classificação de medidas em determinados níveis foi feita por Stevens. Do mais baixo para o mais alto nível, temos as escalas: nominal, ordinal, intervalar e razão. São distinguidas em termos de critérios diferentes.

De acordo com a definição de mensuração, é possível atribuir-se números a objetos de acordo com certas regras.

Existem também diferenças no modo como podem ser feitas as operações estatísticas com números aplicados de níveis de medida.

Os níveis são atingidos quando aplicados a eles os postulados básicos para a média.

$1^{\circ}$ nível: NOMINAL - É aplicado o postulado:

1 - Identidade: o número é ele mesmo e nem mais um outro.

$2^{\circ}$ nível: ORDINAL - São aplicados os postulados:

1 - Identidade

2 - Ordem: os números permitem relação de grandeza, podendo-se colocar em ordem crescente ou decrescente.

$3^{\circ}$ nível: INTERVALAR - São aplicados os postulados:

1 - Identidade

2 - Ordem

3 - Aditividade: os intervalos entre os números se dão de forma constante: dessa forma, fica garantida a adição de dois valores, por exemplo, $a+b=b+a$.

\section{Variância da população}

Sempre que o teste exigir homogeneidade da variância, pode-se calcular as variâncias de suas amostras. Para tanto, dever-se-á utilizar o teste F.

$\mathrm{S}^{2} \mathrm{M}=$ variância maior

$$
\mathrm{F}=\frac{\mathrm{S}^{2} \mathrm{M}}{\mathrm{S}^{2} \mathrm{~m}}
$$

$\mathrm{S}^{2} \mathrm{~m}=$ variância menor 
Consultar a tabela da distribuição $\mathrm{F}$, com graus de liberdade para o numerador e o denominador ( $\mathrm{N}$ de cada grupo menos 1 ). Verificar se a diferença entre as variâncias é ou não significativa.

Quanto maior o numerador e menor o denominador com maior probabilidade, vamos obter um resultado significativo em termos estatísticos.

Averiguados todos esses critérios, procede-se à escolha da prova estatística, cujo objetivo está em verificar se a diferença entre as amostras ocorre por puro erro amostrai ou realmente por tratar-se de amostras que diferem quanto às características estudadas.

\section{ETAPAS DA PESQUISA CIENTÍFICA}

Escolhida a prova estatística, após considerar todas as exigências para a prova, seguem-se os seguintes passos da pesquisa científica propriamente dita.

\section{Elaboração das hipóteses}

Hipótese é a afirmação conjecturai acerca da relação existente entre duas variáveis.

Hipótese nula: postula não existir diferença entre as médias, pois as amostras foram extraídas da mesma população; portanto, qualquer diferença é casual, ainda mais que um erro amostral. Quando a hipótese nula for aceita, não é possível generalizar os resultados para a população. $M_{1}=M_{2}$

Hipótese experimental: afirma existir uma verdadeira diferença entre as populações comparadas. Constitui a hipótese de pesquisa, que geralmente é uma predição deduzida de uma teoria.

$\mathrm{M}_{1} \neq \mathrm{M}_{2}$

$\mathrm{M}_{1}<\mathrm{M}_{2}$

$\mathrm{M}_{1}>\mathrm{M}_{2}$

A hipótese nula, sobre a qual versa toda a pesquisa, será rejeitada ou aceita. Se for rejeitada, a hipótese experimental torna-se viável. A aceitação da hipótese nula implica que esta não pode ser rejeitada, o que não quer dizer que haja relação de igualdade entre as variáveis em estudo.

\section{Níveis de significância}

É a probabilidade oferecida para que a diferença entre as médias seja considerada estatisticamente significativa.

Tem-se como objetivo diminuir ao máximo o risco de comprovar erroneamente $\mathrm{H}_{1}$. Por isso estipula-se um nível de significância de 0,05 , ou seja, consideram-se 5 chances em 100 de comprovar $\mathrm{H}_{1}$, erroneamente, e 95 chances em 100 de comprovar $\mathrm{H}_{0}$ erroneamente.

Alguns pesquisadores desejam limitar ao máximo a chance de provar $\mathrm{H}_{1}$ erroneamente, por isso estabelecem um nível de significância de 0,01 , ou 
seja, 1 chance em 100 de comprovar $\mathrm{H}_{1}$ erroneamente, e 99 chances em 100 de comprovar $\mathrm{H}_{0}$ erroneamente.

$\mathrm{H}_{0}$, portanto, pode recair numa zona em que é aceita - zona de aceitação. Pode também cair numa área em que é rejeitada - zona de rejeição.

O poder de um teste estatístico consiste na dinâmica aqui exposta, ou seja, na capacidade dele rejeitar $\mathrm{H}_{0}$, quando $\mathrm{H}_{0}$ é falsa. Quanto mais poder tem um teste estatístico, mais capaz será de detectar que $\mathrm{H}_{0}$ é falsa, quando realmente o é.

$\mathrm{O}$ nível de significância é a possibilidade de rejeitar a $\mathrm{H}_{0}$ quando ela é verdadeira. É convencional em Psicologia estabelecer-se o nível de significância igual a 0,05 (diz-se que em 100 vezes feita a experiência, 95 em 100, vai mostrar que 95 está acertando, e 0,05 o investigador está disposto a correr o risco de 5\% - 5 erros) de rejeitar a hipótese nula erroneamente.

"Uma prova estatística pode ser considerada boa se tem pequena probabilidade de rejeitar $\mathrm{H}_{0}$ quando $\mathrm{H}_{0}$ é verdadeira, porém grande probabilidade de rejeitar $\mathrm{H}_{0}$ quando $\mathrm{H}_{0}$ é falsa."

\section{Região de rejeição}

O teste estatístico pode ser unicaudal ou bicaudal. No unicaudal é postulada a direção da diferença e a zona de rejeição fica à direita ou à esquerda da distribuição. No bicaudal $\mathrm{H}_{1}$ postula a diferença entre as médias, mas não a direção das diferenças. Neste caso, a área de rejeição estará dividida por duas áreas da curva.

\section{REPRESENTAÇÃo}

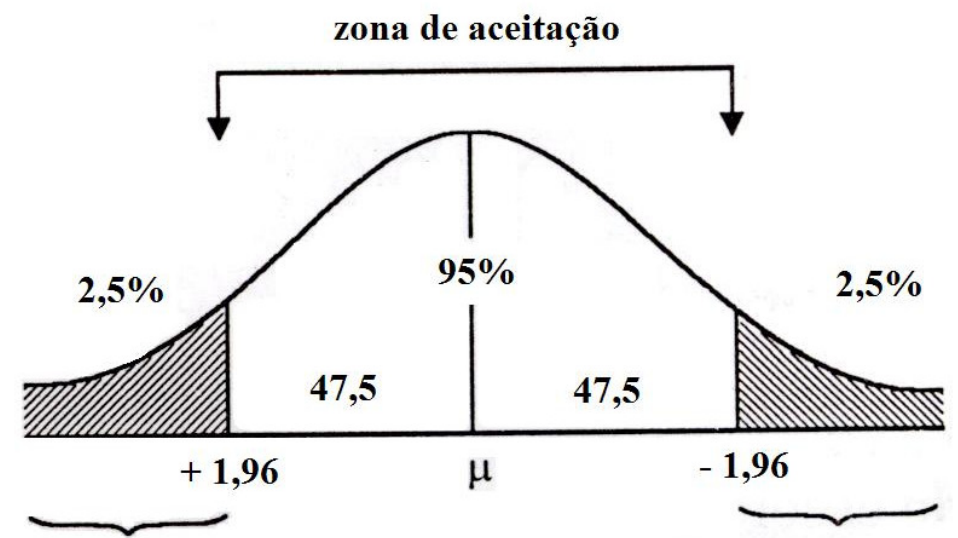

zona de rejeição

zona de rejeição

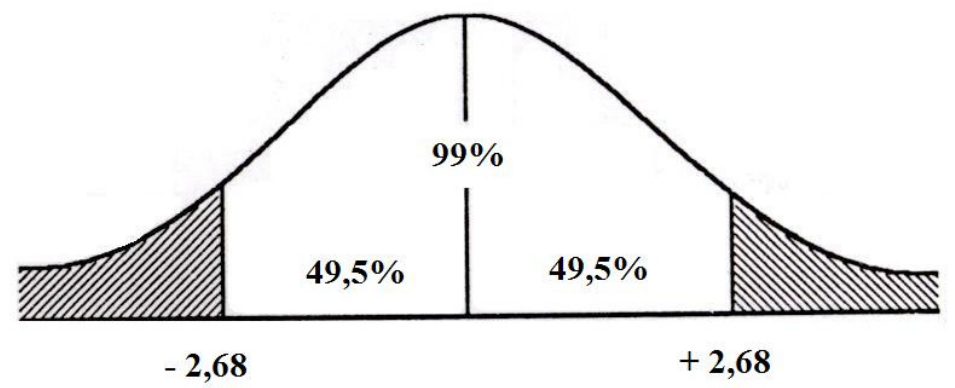

A nível de 1 desvio - ponto de corte $\mathrm{z}=1$

A nível de 2 desvios - ponto de corte $\mathrm{z}=1,96$

A nível de 3 desvios - ponto de corte $\mathrm{z}=2,58$

Erro a considerar:

- Falsa a hipótese verdadeira - tipo I

- Verdadeira a hipótese falsa - tipo II

Erro de tipo I- Quando se rejeita a hipótese nula (falsa) e, no entanto, ela é verdadeira. A probabilidade de se cometer esse tipo de erro é igual ao nível de significância. Quanto maior é o nível de significância, maior é a probabilidade de se cometer esse erro. 
Erro de tipo II - Quando se aceita como verdadeira a hipótese nula e, no entanto, ela é falsa. Isso quer dizer: aumenta a área de aceitação e diminui a de rejeição.

Pode-se diminuir a probabilidade de se cometer os dois tipos de erro aumentando-se o tamanho da amostra.

\section{Graus de liberdade}

Graus de liberdade significa a possibilidade de variação de escores dentro de uma série, quando se faz alguma restrição.

Assim nos escores: 3, 4, 5, 6, 7, cuja soma é 25, apenas 4 escores podem variar livremente, estando o último condicionado aos demais, para que a soma seja sempre igual a 25 .

\section{Decisão estatística}

Dizer que a diferença entre duas amostras é estatisticamente significativa é dizer que é reflexo de uma verdadeira diferença populacional e não apenas o resultado de erro de amostragem (ação do acaso). Tal afirmativa só pode ser feita com base num ponto de referência, comumente designado valor crítico, que possibilita decidir quando um resultado (diferença) é estatisticamente significativo.

Um resultado é estatisticamente significativo quando é igual ou maior que o valor crítico.

Decidir aceitar $\mathrm{H}_{0}$ significa que a explicação aleatória é provável; portanto, o resultado do teste tem probabilidade maior que o a adotado ( $\mathrm{p}>0,05)$; ao contrário, decidir aceitar $\mathrm{H}_{1}$ é rejeitar tal explicação, pois $\mathrm{o}$ resultado do teste tem probabilidade de ocorrência igual ou menor que o $\alpha$ adotado $(\mathrm{p}<0,05)$.

\begin{tabular}{l|l|l}
\hline $\mathbf{H}_{\mathbf{0}}$ & Aceitar & Rejeitar \\
\hline Falso & Erro tipo II $(\beta)$ & Decisão correta \\
\hline Verdadeiro & Decisão correta & Erro tipo I $(\alpha)$ \\
\hline
\end{tabular}

\section{Provas estatísticas}

As provas estatísticas é que permitirão concluir os dados da pesquisa. A partir dos resultados das provas poder-se-á verificar a validade das hipóteses.

\section{Provas estatísticas paramétricas}

Para aplicação das provas paramétricas são necessários os seguintes pressupostos: normalidade da distribuição; nível de medida intervalar; população de natureza normal e variável contínua. Estas provas indicarão o grau de diferença entre as médias.

Nota $z$

A nota z permite a comparação entre duas médias, a fim de se saber se a diferença existente entre elas é significativa a nível estatístico.

\section{Exigências:}

- amostras independentes

- amostras aleatórias

- amostra maior que 30

- população normal

- variáveis contínuas

- nível de medida: intervalar

$$
\mathrm{z}=\frac{\overline{\mathrm{X}}_{1}-\overline{\mathrm{X}}_{2}}{\sigma_{\mathrm{dif}}}
$$

$\sigma_{\text {dif }}=$ erro padrão da diferença

Passos:

$1^{\circ}$ ) Calcular a média de cada amostra:

$$
\overline{\mathrm{X}}=\frac{\sum \cdot \mathrm{X}_{\mathrm{i}}}{\mathrm{N}}
$$


$2^{\circ}$ ) Calcular o desvio-padrão de cada amostra:

$$
s=\sqrt{\frac{\sum \cdot x^{2}}{N}}
$$

$3^{\circ}$ ) Achar o erro-padrão de cada média:

$$
\sigma_{\overline{\mathrm{X}}}=\frac{\mathrm{s}}{\sqrt{\mathrm{N}-1}}
$$

$4^{\circ}$ ) Achar o erro-padrão da diferença:

$$
\sigma_{\text {dif }}=\sqrt{\sigma_{\overline{\mathrm{X}}_{1}^{2}}+\sigma_{\overline{\mathrm{X}}_{2}^{2}}}
$$

$\left.5^{\circ}\right)$ Calcular $\mathrm{z}:$

$$
\mathrm{z}=\frac{\overline{\mathrm{X}}_{1}-\overline{\mathrm{X}}_{2}}{\sigma_{\mathrm{dif}}}
$$

$6^{\circ}$ ) Se z obtido for inferior ao $\mathrm{z}$ estipulado, aceita-se $\mathrm{H}_{0}$.

\section{Exemplo:}

Desejando-se comparar a inteligência dos meninos e meninas, escolheram-se aleatoriamente 318 meninos e 197 meninas de 13 anos de idade. A hipótese é a de que a inteligência dos meninos difere significativamente da inteligência das meninas.

$\overline{\mathrm{X}}_{1}=38$

$\overline{\mathrm{X}}_{2}=36$

$\mathrm{S}_{1}=12$

$\mathrm{S}_{2}=13$

$$
\begin{gathered}
\overline{\mathrm{X}}_{1}-\overline{\mathrm{X}}_{2}=2 \\
\sigma_{\overline{\mathrm{X}}_{1}}=\frac{12}{\sqrt{318}}=0,67
\end{gathered}
$$

${ }^{*}$ Notas de aula da professora Eva Nick.

$$
\begin{gathered}
\sigma_{\overline{\mathrm{x}}_{2}}=\frac{13}{\sqrt{197}}=0,93 \\
\mathrm{Z}=\frac{36-38}{1,14} \cong 1,76 \\
\sigma_{\text {dif }}=\sqrt{(0,67)^{2}+(0,93)^{2}=1,14}
\end{gathered}
$$

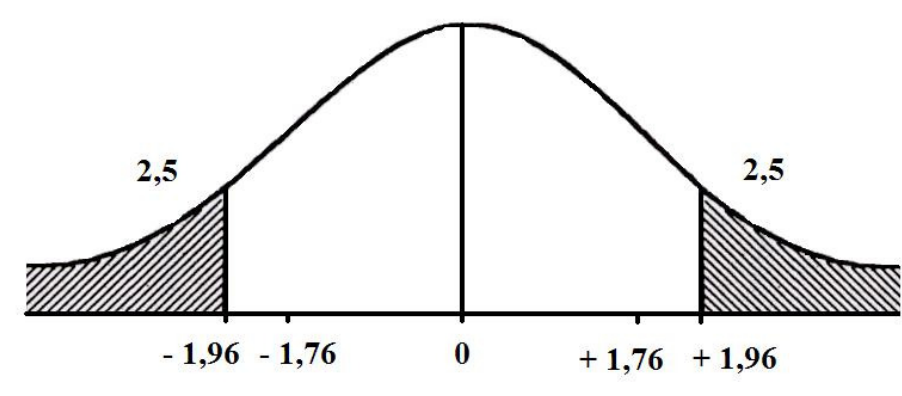

$$
5 \%=1,96 \times 1,14=2,2344
$$

Logo, o valor verdadeiro de $\overline{\mathrm{X}}_{1}-\overline{\mathrm{X}}_{2}$, ou seja, $\mu_{2}-\mu_{1}$ - estará situado entre $2+2,2344$ e $2-2,2344=4,2344$ e $2-2,2344=-0,2344$.

Como z calculado é menor que o z estipulado, aceita-se $\mathrm{H}_{0}$.

\section{Razão t (student)}

$\mathrm{O}$ teste $\mathrm{t}$ de Student permite-nos determinar se a diferença encontrada entre duas médias é ou não significativamente diferente de zero.

\section{Exigências:}

- Amostra aleatória

- Amostra menor que 30

- População normal

- Variáveis continuas

- Nível de medida: intervalar 
Fórmula geral:

$$
\mathrm{t}=\frac{\left(\overline{\mathrm{X}}_{1}-\overline{\mathrm{X}}_{2}\right)-\left(\mu_{1}-\mu_{2}\right)}{\mathrm{S}_{\overline{\mathrm{X}}_{1}-\overline{\mathrm{X}}_{2}}}
$$

Onde:

$\overline{\mathrm{X}}_{1}=$ média do grupo 1

$\overline{\mathrm{X}}_{2}=$ média do grupo 2

$\mu_{1}=$ média da população do grupo 1

$\mu_{2}=$ média da população do grupo 2

$\mathrm{S}_{\overline{\mathrm{X}}_{1}-\overline{\mathrm{X}}_{2}}=$ erro-padrão da diferença entre duas médias.

Passos:

a) duas amostras independentes com $N$ iguais

1. Calcula-se a $\bar{X}$ de cada amostra:

$$
\overline{\mathrm{X}}=\frac{\sum \mathrm{Xi}}{\mathrm{N}}
$$

2. Calcula-se o s de cada amostra:

$$
s=\sqrt{\frac{\sum \cdot \mathrm{x}^{2}}{\mathrm{~N}}}
$$

3. Calcula-se o $\sigma_{\text {dif }}$ :

$$
\sigma_{\mathrm{dif}}=\sqrt{\sigma_{\overline{\mathrm{X}}_{1}^{2}}}+\sigma_{\overline{\mathrm{X}}_{2}^{2}}
$$

4. Calcula-se t:

$$
t=\frac{\bar{X}_{1}-\bar{X}_{2}}{\sigma_{d i f}}
$$

5. Encontram-se os graus de liberdade:

$$
\mathrm{Fl}=\mathrm{N}_{1}+\mathrm{N}_{2}-2
$$

6. Procura-se na tabela o t (crítico) de acordo com o nível de significância e os graus de liberdade. (Tabela C)

7. Se o $t$ da tabela for maior ou igual ao $t$ calculado, aceita $\mathrm{H}_{0}$.

Exemplo 1:

Um pesquisador pretende verificar a eficácia de um determinado método de aprendizagem por compreensão. Compôs, aleatoriamente, dois grupos, a partir de uma lista de 20 indivíduos. Dez destes foram aleatoriamente incluídos no grupo experimental (que sofreram a influência da aprendizagem por compreensão e os outros 10 constituíram o grupo de controle, onde o método de aprendizagem foi mantido). Feito isto, mediu a atitude dos dois grupos através de uma escala de atitudes (nível intervalar).

Grupo experimental: 12, 8, 11, 10, 7, 12, 9, 11, 8, 9

Grupo de controle: 7, 8, 5, 7, 9, 4, 4, 6, 7, 10

$$
\begin{array}{cc}
\overline{\mathrm{X}}_{1}=9,7 & \overline{\mathrm{X}}_{2}=6,7 \\
\Sigma \mathrm{x}_{1}{ }^{2}=27,90 & \sum \mathrm{x}_{2}{ }^{2}=36,04 \\
\mathrm{~S}_{1}=1,67 & \mathrm{~S}_{2}=1,89 \\
\sigma_{\overline{\mathrm{X}}_{1}}=0,56 & \sigma_{\overline{\mathrm{X}}_{2}}=0,63 \\
\sigma_{\text {dif }}=\sqrt{0,56^{2}+0,63^{2}}=0,84
\end{array}
$$

Decisão estatística: A interferência da aprendizagem por compreensão é estatisticamente significativa no que diz respeito à atitude do indivíduo. Logo, rejeita-se $\mathrm{H}_{0}$.

b) duas amostras independentes com $\mathrm{N}$ diferentes•

1. Calcula-se a $\bar{X}$ de cada amostra.

2. Calcula-se o desvio-padrão de cada amostra.

3. Calcula-se o erro-padrão de diferença.

4. Calculam-se os graus de liberdade:

$$
\mathrm{Gl}=\mathrm{N}_{1}+\mathrm{N}_{2}-1
$$

5. Procura-se na tabela $\mathrm{C}$ o valor do tc.

6. Decisão estatística 


\section{Exemplo 2:}

Um pesquisador comparou dois grupos com relação à ansiedade. Teve como objetivo verificar se um grupo que passava por uma situação de prova apresentava maior ansiedade manifesta que o outro grupo em situação normal. Para tanto aplicou aos dois grupos a escala de ansiedade manifesta. Sabendo-se que a amostra foi aleatória e que a medida se deu a nível intervalar, verifique se há diferença significativa entre as médias.

Grupo 1 - Notas: $15,18,12,10$

Grupo 2 - Notas: 8, 10, 13, 17, 22

\begin{tabular}{|c|c|c|c|c|c|}
\hline $\mathbf{X}$ & $\mathbf{x}$ & $x^{2}$ & $\mathbf{X}$ & $\mathbf{x}$ & $x^{2}$ \\
\hline 15 & 1,25 & 1,56 & 8 & -6 & 36 \\
\hline 18 & 4,25 & 18,06 & 10 & -4 & 16 \\
\hline 12 & $-1,17$ & 3,06 & 13 & -1 & 1 \\
\hline 10 & $-3,75$ & 14,06 & 17 & +3 & 9 \\
\hline & & & 22 & +8 & 64 \\
\hline 55 & & 36,74 & 70 & & 126 \\
\hline
\end{tabular}

$$
\overline{\mathrm{X}}_{1}=13,75 \quad \overline{\mathrm{X}}_{2}=14
$$

$$
\begin{gathered}
\mathrm{S}_{1}=3,03 \quad \mathrm{~S}_{2}=5,02 \quad \mathrm{t}=\frac{-0,25}{1,61}=-0,15 \\
\sigma_{\overline{\mathrm{X}}_{1}}=1,75 \quad \sigma_{\overline{\mathrm{X}}_{2}}=2,51 \\
\sigma_{\text {dif }}=\sqrt{\frac{3,06}{3}+\frac{6,30}{4}}=1,61 \\
\mathrm{t}=\frac{-0,25}{1,61}=-0,15
\end{gathered}
$$

Passos:

$\left.1^{\circ}\right)$ Elaborar as hipóteses:

$\mathrm{H}_{0}=$ ansiedade é igual nos dois grupos

$$
\overline{\mathrm{X}}_{1}=\overline{\mathrm{X}}_{2}
$$

$\mathrm{H}_{1}=\mathrm{A}$ ansiedade é significativamente diferente nos dois grupos.

$$
\overline{\mathrm{X}}_{1} \neq \overline{\mathrm{X}}_{2}
$$

$2^{\circ}$ ) Nível de significância:

$0,05-5 \%$ de probabilidade de aceitar $\mathrm{H}_{0}$, quando $\mathrm{H}_{0}$ é falsa.

$3^{\circ}$ ) Região de rejeição:

\section{Bicaudal}

$4^{\circ}$ ) Graus de liberdade

$$
\begin{gathered}
\mathrm{gl}=\mathrm{N}_{1}+\mathrm{N}_{2}-2 \\
\mathrm{gl}=9-2=7
\end{gathered}
$$

$\left.5^{\circ}\right)$ Decisão estatística

Como t é crítico maior que $\mathrm{t}$ calculado, aceita-se $\mathrm{H}_{0}$.

Não existe diferença estatisticamente significativa entre os dois grupos.

\section{Amostras independentes}

A estatística $\mathrm{t}$ para amostras independentes com $\mathrm{N}$ iguais ou diferentes pode ser obtida através da fórmula alternativa:

$$
\mathrm{t}=\sqrt{\frac{\overline{\mathrm{X}}_{1}=\overline{\mathrm{X}}_{2}}{\frac{\sum \mathrm{x}_{1}{ }^{2}+\sum \mathrm{x}_{2}{ }^{2}}{\mathrm{~N}_{1}+\mathrm{N}_{2}-2} \cdot\left(\frac{1}{\mathrm{~N}_{1}}+\frac{1}{\mathrm{~N}_{2}}\right)}}
$$

\section{Procedimentos:}

$\left.1^{\circ}\right)$ Calculam-se as duas médias.

$2^{\circ}$ ) Elevam-se os escores ao quadrado.

$3^{\circ}$ ) Calcula-se o $\sum \mathrm{x}^{2}$ somatório dos quadrados dos desvios) de cada amostra pela fórmula:

$$
\Sigma \mathrm{x}^{2}=\Sigma \mathrm{x}^{2}-\frac{\Sigma \mathrm{x}^{2}}{\mathrm{~N}}
$$

$4^{\circ}$ ) Calcula-se $t$ de Student (para amostras relacionadas) 


\section{Amostras relacionadas}

Comparação de dados resultantes de duas mensurações temperalmente distintas da mesma amostra.

Em dados extraídos de duas amostras relacionadas aplica-se a prova $\mathrm{t}$ aos escores de diferenças. A prova $t$ admite que esses escores de diferenças sejam independentes e tenham distribuição normal na população da qual se extraiu a amostra.

\section{Passos:}

$\left.1^{\circ}\right)$ Calcular a média de cada momento.

$2^{\circ}$ ) Calcular o desvio-padrão da diferença entre os escores obtidos nos momentos 1 e 2 :

$$
\mathrm{s}=\sqrt{\frac{\Sigma \mathrm{D}^{2}}{\mathrm{~N}}-\left(\overline{\mathrm{X}}_{1}-\overline{\mathrm{X}}_{2}\right)^{2}}
$$

$\mathrm{s}=$ desvio-padrão da distribuição de escores diferenças antes/depois $\mathrm{D}=$ diferença resultante da subtração do "escore depois" do "escore antes" $\mathrm{N}=$ tamanho da amostra

$3^{\circ}$ ) Calcular o erro-padrão da diferença:

$$
\sigma_{\text {dif }}=\frac{\mathrm{s}}{\sqrt{\mathrm{N}-1}}
$$

$\left.4^{\circ}\right)$ Calcular t:

$$
\mathrm{t}=\frac{\overline{\mathrm{X}}_{1}-\overline{\mathrm{X}}_{2}}{\sigma_{\text {dif }}}
$$

$5^{\circ}$ ) Achar o número de graus de liberdade

$$
\mathrm{gl}=\mathrm{N}-1
$$

$6^{\circ}$ ) Comparar a razão $\mathrm{t}$ calculada com a razão $\mathrm{t}$ tabelada (ou $\mathrm{t}$ crítico). Tabela C.

\section{Exemplo:}

Doze pessoas são submetidas em dois momentos a uma escala de atitudes com relação à situação política do país. Tais pessoas não possuíam nenhuma informação sistemática sobre política $-1^{\circ}$ momento.

No $2^{\circ}$ momento, já havia passado pelo processo sistemático de tal informação.

\begin{tabular}{c|c|c|c|c}
\hline & $\mathbf{1}^{\mathbf{0}}$ momento & $\mathbf{2}^{\mathbf{0}}$ momento & $\mathbf{D}$ & $\mathbf{D}^{\mathbf{2}}$ \\
\hline $\mathrm{A}$ & 50 & 62 & -12 & 144 \\
$\mathrm{~B}$ & 42 & 40 & 2 & 4 \\
$\mathrm{C}$ & 26 & 61 & 35 & 1.225 \\
$\mathrm{D}$ & 35 & 35 & 12 & 144 \\
$\mathrm{E}$ & 42 & 30 & 8 & 64 \\
$\mathrm{~F}$ & 60 & 52 & & \\
$\mathrm{G}$ & 41 & 68 & -27 & 729 \\
$\mathrm{H}$ & 70 & 51 & & \\
$\mathrm{I}$ & 55 & 84 & -29 & 841 \\
$\mathrm{~J}$ & 62 & 63 & -1 & 1 \\
$\mathrm{~K}$ & 38 & 72 & -34 & 1.156 \\
$\mathrm{~L}$ & 51 & 50 & 1 & 1 \\
\hline
\end{tabular}

$$
\begin{array}{cc}
\overline{\mathrm{X}}_{1}=47,6 & \overline{\mathrm{X}}_{2}=55,6 \\
\left.\overline{\mathrm{X}}_{\mathrm{D}}=55,6-47,6=8,0\right\} & \mathrm{S}=18,03 \\
\sigma_{\text {dif }}=5,43 & \mathrm{t}=-1,47 \\
\mathrm{gl}=12-1=11 & \mathrm{t}_{\mathrm{c}}=2,20
\end{array}
$$

Como o objetivo é saber se a informação sistemática interfere na atitude dos indivíduos sobre política, rejeitamos $\mathrm{H}_{1}$. Logo, aceitamos $\mathrm{H}_{0}$, porque $\mathrm{t}$ calculado é menor que $\mathrm{t}$ tabelado.

* Notas de aula professora Eva Nick. 


\section{Provas estatísticas não paramétricas}

“As técnicas não paramétricas de provas de hipóteses são adaptáveis, particularmente, aos dados das ciências do comportamento.'

Razões para tal adaptabilidade:

1) Não é necessário, para sua utilização, fazer suposições sobre a distribuição da população:

- normalidade

- os pares não têm necessariamente que ser extraídos da mesma população.

2) Podem ser aplicadas a dados que não sejam exatos do ponto de vista numérico - nível ordinal e nominal de medida.

3) Realizam-se com cálculos simples.

4) Aplicam-se a pequenas amostras.

Provas estatísticas não paramétricas

\begin{tabular}{c|c|c}
\hline Nível de mensuração & Relacionadas & Independentes \\
\hline Nominal & $\begin{array}{c}\text { Prova de Mc } \\
\text { Nemar para significância } \\
\text { das mudanças }\end{array}$ & $\begin{array}{c}\text { (Prova de Fischer) } \\
\text { Prova X }\end{array}$ \\
\hline Ordinal & $\begin{array}{c}\text { (Prova dos sinais) } \\
\text { Prova de Wilcoxon }\end{array}$ & $\begin{array}{c}\text { Prova de mediana } \\
\text { Prova U de Mann Whitney }\end{array}$ \\
\hline Intervalar & $\begin{array}{c}\text { (Prova de Walsh) } \\
\text { Prova de aleatoriedade }\end{array}$ & Prova de aleatoriedade \\
\hline
\end{tabular}

Provas estatísticas não paramétricas para duas amostras relacionadas. Aplicam-se quando se deseja verificar se há diferença entre dois tratamentos ou se um tratamento é "melhor" que o outro.

Duas amostras relacionadas são utilizadas quando na escolha das mesmas deseja-se controlar as diferenças "extrínsecas" dos indivíduos da amostra. O indivíduo "serve como seu próprio controle".

No emparelhamento seleciona-se, para cada par, indivíduos que sejam tão semelhantes quanto possível, em relação a quaisquer variáveis extrínsecas que possam influenciar o resultado da pesquisa.
Exemplo:

\begin{tabular}{c|c}
\hline Nível 1 & Nível 2 \\
\hline $\mathrm{S} 1_{\mathrm{a}}$ & $\mathrm{S} 1_{\mathrm{b}}$ \\
\hline $\mathrm{S} 2_{\mathrm{a}}$ & $\mathrm{S} 2_{\mathrm{b}}$ \\
\hline $\mathrm{S} 3_{\mathrm{a}}$ & $\mathrm{S} 3_{\mathrm{b}}$ \\
\hline
\end{tabular}

Teste da mediana

\section{Requisitos:}

- Comparação entre duas ou mais amostras independentes, extraídas da mesma população ou de população com mesma mediana.

- Nível ordinal de medida.

- Amostragem aleatória.

Passos:

$\left.1^{\circ}\right)$ Juntam-se os dois grupos e calcula-se a mediana

- Md (combinada)

$2^{\circ}$ ) Conhecendo-se a $\mathrm{Md}_{\mathrm{c}}$, vai-se a cada amostra e conta-se em cada um o número de sujeitos acima e abaixo da $\mathrm{Md}_{\mathrm{c}}$

$3^{\circ}$ ) Aplica-se a fórmula $\chi^{2}$ (qui-quadrado).

$$
\chi 2=\frac{N(|A D-B C|-N / 2)^{2}}{(A+B)(C+D)(A+C)(B+D)}
$$

$\left.4^{\circ}\right)$ Estabelece-se o nível de significância.

$\left.5^{\circ}\right)$ Graus de liberdade:

$$
\mathrm{gl}=(\mathrm{L}-1)(\mathrm{c}-1)
$$

$6^{\circ}$ ) Consulta-se a tabela $\mathrm{D}$; se $\chi^{2} \geq$ que o tabelado, rejeita-se $\mathrm{H}_{0}$.

$$
\text { Exemplo:* }
$$

* Notas de aula professora Eva Nick. 
Um psicólogo deseja investigar os efeitos de uma droga tranquilizante sobre o tremor da mão. Quatorze pacientes do psiquiatra tomam a tal droga; a 18 pacientes combinados pela idade e sexo ela é dada como calmante (isto é, em dose inofensiva). Visto que a medicação é dada em forma de pílulas, os pacientes não sabem se lhes está sendo administrada a droga ou não. O primeiro grupo é experimental, o segundo é de controle. Mede-se o tremor pelo verificador de firmeza.

Obs.: Como se está interessado apenas em saber se a droga reduz o tremor, este será u teste unicaudal.

\begin{tabular}{c|c}
\hline Experimental & Controle \\
\hline $\mathrm{N}=14$ & $\mathrm{~N}=18$ \\
53 & 48 \\
39 & 65 \\
63 & 66 \\
36 & 38 \\
47 & 36 \\
58 & 45 \\
44 & 59 \\
38 & 53 \\
59 & 58 \\
36 & 42 \\
42 & 70 \\
43 & 71 \\
46 & 65 \\
46 & 46 \\
& 55 \\
& 61 \\
& 62 \\
\hline
\end{tabular}

$1^{\text {) }) ~ J u n t a m-s e ~ o s ~ d o i s ~ g r u p o s ~ e ~ c a l c u l a-s e ~ a ~} \mathrm{Md}_{\mathrm{c}}$

\begin{tabular}{lll}
\hline $\mathbf{X}$ & $\mathbf{F}$ & Fac \\
\hline 36 & 3 & 3 \\
38 & 3 & 5 \\
39 & 1 & 6 \\
42 & 2 & 8 \\
43 & 1 & 9 \\
44 & 1 & 10 \\
45 & 1 & 11 \\
46 & 3 & 14 \\
47 & 1 & 15 \\
48 & 1 & 16 \\
53 & 3 & $19 \leftarrow$ \\
55 & 1 & 20 \\
58 & 2 & 22 \\
59 & 2 & 24 \\
61 & 1 & 25 \\
62 & 1 & 26 \\
63 & 1 & 27 \\
65 & 2 & 29 \\
66 & 1 & 30 \\
70 & 1 & 31 \\
71 & 1 & 32 \\
$\sum$ & 32 &
\end{tabular}

$2^{\circ}$ ) Número de sujeitos acima e abaixo de Mdc em ambos os grupos

\begin{tabular}{c|c|c|c}
\hline & G. Experimental & \multicolumn{2}{|c}{ G. de controle } \\
\hline & $\mathrm{E}$ & $\mathrm{C}$ & $\mathrm{N}$ \\
\hline $\mathrm{Ac}$ & 4 & 12 & 16 \\
$\mathrm{Ab}$ & 10 & 6 & 16 \\
\hline $\mathrm{N}$ & 14 & 18 & 32 \\
\hline
\end{tabular}

$\left.3^{\circ}\right)$

$$
\chi 2=\frac{32(|24-120|-16)^{2}}{14 \times 18 \times 16 \times 16}=3,17
$$

$4^{\circ}$ ) Graus de liberdade:

$$
\mathrm{gl}=(1)(1)=1
$$


Quer saber se a Md do grupo experimental é significativamente inferior à do grupo de controle.

$\mathrm{A}=0,05$

$\chi^{2}$ calculado $=3,17$

$\chi^{2}$ tabelado $=3,84$

$\mathrm{H}_{0}$ é aceita.

\section{Teste do qui-quadrado}

Pode ser utilizado com dois objetivos:

$1^{\circ}$ ) Para comparar os dados obtidos experimentalmente com os dados esperados. Neste aspecto é um teste de significância, com o objetivo de distinguir as frequências obtidas das frequências esperadas.

Uma vez comparando-se, surgem as diferenças, que podem ser grandes ou pequenas. Se tais diferenças forem grandes (significativas), rejeita-se $\mathrm{H}_{0}$; se pequenas, aceita-se $\mathrm{H}_{0}$; e a diferença é atribuída ao acaso.

$\left.2^{\circ}\right)$ Para decidir se duas variáveis mantêm relação de dependência. Neste caso, o qui-quadrado é utilizado como teste de independência. Quanto menor a dependência entre as duas variáveis, menor o valor de $\mathrm{x}^{2}$ (calculado).

Passos para o cálculo:

$\left.1^{\circ}\right)$ Construir com os dados uma tabela de dupla entrada.

$2^{\circ}$ ) Obter a frequência esperada para cada casela:

$$
\mathrm{Fe}=\frac{(\text { total da linha })(\text { total da coluna })}{(\text { total geral })}
$$

$3^{\circ}$ ) Subtrai-se a frequência esperada da respectiva frequência obtida $(\mathrm{O}-\mathrm{E})$ em cada casela:

$\left.4^{\circ}\right)$ Elevar as diferenças ao quadrado.

$$
(0-E)^{2}
$$

$5^{\circ}$ ) Dividir o quadrado de cada diferença pela respectiva frequência esperada:

$$
\frac{(\mathrm{Fo}-\mathrm{Fe})^{2}}{\mathrm{Fe}}
$$

$\left.6^{\circ}\right)$ Somar esse quociente para obter o qui-quadrado:

$$
\frac{\Sigma(\mathrm{Fo}-\mathrm{Fe})^{2}}{\mathrm{Fe}}
$$

$\left.7^{\circ}\right)$ Achar os graus de liberdade:

$$
\begin{aligned}
& \mathrm{gl}=(\mathrm{L}-1)(\mathrm{c}-1) \\
& \mathrm{L}=\mathrm{n}^{\mathrm{o}} \text { de linhas } \\
& \mathrm{c}=\mathrm{n}^{\circ} \text { de colunas }
\end{aligned}
$$

$8^{\circ}$ ) Comparar o qui-quadrado obtido com o qui-quadrado tabelado.

Requisitos:

- Comparação entre duas ou mais amostras.

- Os valores das caselas devem ser resultado de contagens nível nominal de mensuração.

- Amostragem aleatória.

- O valor esperado em cada casela não poderá ser menor que 5 .

- Amostras independentes.

- A amostra não poderá ser menor que 30.

Fórmula - Torna o cálculo do qui-quadrado menos trabalhoso.

\begin{tabular}{c|c|c}
\multicolumn{3}{c}{$N(\mathrm{AD}-\mathrm{BC})^{2}$} \\
\cline { 2 - 3 }$(\mathrm{A}+\mathrm{B})(\mathrm{C}+\mathrm{D})(\mathrm{A}+\mathrm{C})(\mathrm{B}+\mathrm{D})$ \\
\hline $\mathrm{A}$ & $\mathrm{B}$ & $\mathrm{A}+\mathrm{B}$ \\
\hline $\mathrm{C}$ & $\mathrm{D}$ & $\mathrm{C}+\mathrm{D}$ \\
\hline $\mathrm{A}+\mathrm{C}$ & $\mathrm{B}+\mathrm{D}$ & $\mathrm{A}+\mathrm{B}+\mathrm{C}+\mathrm{D}=\mathrm{N}$ \\
\hline
\end{tabular}




\section{Exemplo:}

Numa pesquisa de opinião pública quanto à pergunta: "O que você pensa a respeito de as mulheres deverem ocupar cargos públicos?’, foi obtido o seguinte quadro:

\begin{tabular}{c|c|c|c}
\hline Respondente & Sim & Não & Total \\
\hline Mulheres & $40 / 30$ & $10 / 20$ & 50 \\
\hline Homens & $20 / 30$ & $30 / 20$ & 50 \\
\hline Total & 60 & 40 & 100 \\
\hline
\end{tabular}

$$
\begin{gathered}
\alpha=0,01 \\
\mathrm{Fe}_{1}=\frac{(50)(60)}{100}=30 \\
\mathrm{Fe}_{2}=\frac{(50)(40)}{100}=20 \\
\mathrm{Fe}_{3}=\frac{(60)(50)}{100}=30 \\
\mathrm{Fe}_{4}=\frac{(40)(50)}{100}=20 \\
\chi^{2}=\frac{100[(40)(30)-(10)(30)]^{2}}{(50)(50)(60)(40)}=6,66 \\
\chi_{\text {tab }}^{2}=6,63
\end{gathered}
$$

Como o que se quer é verificar se existe associação entre o tipo de resposta e o sexo do respondente, rejeita-se $\mathrm{H}_{0}$.

\section{Qui-quadrado inflacionado}

É utilizado quando as frequências esperadas ficam entre 5 e 10 e a tabela for do tipo 2 X 2. Pode ocorrer, nestes casos, um qui-quadrado inflacionado, isto é, um pouco maior do que ocorreria se as frequências esperadas fossem maiores - o valor do qui-quadrado maior do que o real.

Para evitar que $\mathrm{H}_{0}$ seja rejeitada sem necessidade, faz-se uma correção de continuidade, que consiste em subtrair 0,5 das diferenças, antes

\footnotetext{
${ }^{*}$ Notas de aula da professora Eva Nick
}

de elevá-las ao quadrado. Tal recurso diminui cada diferença entre as frequências de 0,5 unidade, diminuindo, portanto, o valor do qui-quadrado.

$$
\begin{gathered}
\chi^{2}=\frac{\Sigma(|\mathrm{Fo}-\mathrm{Fe}|-0,50)^{2}}{\mathrm{Fe}} \\
\chi 2=\frac{\mathrm{N}[|(\mathrm{AD}-\mathrm{BC})|-\mathrm{N} / 2]^{2}}{(\mathrm{~A}+\mathrm{B})(\mathrm{C}+\mathrm{D})(\mathrm{A}+\mathrm{C})(\mathrm{B}+\mathrm{D})}
\end{gathered}
$$

Exemplo*

Adams estudou a relação entre os interesses vocacionais e a escolha do currículo, e a taxa de desistência do curso universitário por parte de estudantes bem dotados. Os indivíduos observados eram estudantes classificados, no mínimo, no percentual 90 nos testes de admissão e que haviam resolvido mudar de carreira após a matrícula. $\mathrm{O}$ pesquisador comparou os estudantes destacados cuja escolha curricular se manteve na linha considerada desejável à vista do resultado obtido no Teste Vocacional de Strong (tais casos sendo considerados como "positivos") com os estudantes destacados cuja escolha curricular se processou em sentido diverso do indicado pelo teste de interesses. A hipótese do pesquisador é que os estudantes cuja escolha foi considerada "positiva" acusam maior frequência de permanência na faculdade ou curso universitário inicialmente escolhido.

\section{Passo:}

$1^{\text {o) }}$ Elaborar as hipóteses:

$\mathrm{H}_{0}=$ não há diferença entre os dois grupos no que diz respeito à proporção de estudantes que permanecem na faculdade.

$\mathrm{H}_{1}=$ a porcentagem de permanência na faculdade é maior entre os estudantes cuja escolha de currículo foi considerada positiva.

$2^{\circ}$ ) Escolha da prova estatística.

- variáveis em categorias discretas

- níveis de medida: nominal

- grupos independentes

* Notas de aula da professora Eva Nick 
$3^{\circ}$ ) Nível de significância:

$\mathrm{p}=(0,10)$

$\alpha=0,05$ (de cada lado)

$4^{\circ}$ ) Região de rejeição:

$$
\text { - unilateral }
$$

$5^{\circ}$ ) Decisão estatística:

$$
\begin{array}{cc}
\mathrm{gl}=(\mathrm{L}-1)(\mathrm{c}-1) & \mathrm{gl}=1 \\
\chi_{\text {tab }}^{2}=2,71 \text { (Tabela D) } &
\end{array}
$$

Tabela 1. Escolha de currículo e afastamento da universidade entre estudantes bem dotados

\begin{tabular}{lccc}
\hline & Positivo & Negativo & Total \\
\hline Afastamento & 10 & 11 & 21 \\
Permanência & 46 & 13 & 59 \\
Total & 56 & 24 & 80 \\
\hline
\end{tabular}

$$
\chi 2=\frac{[80(|(10)(13)-(11)(46)|)-80 / 2]^{2}}{(21)(59)(56)(24)}=5,42
$$

Conclui-se que os estudantes com alto QI, cuja escolha curricular foi "positiva", acusam maior frequência de permanência na universidade que os estudantes bem dotados, cuja escolha foi considerada "negativa".

\section{Prova de mc nemar}

Esta prova visa obter o grau em que mudanças ocorridas com relação às posições ocupadas foram significativas.

Equivale a uma prova binomial - por isso não exige continuidade da variável -, em que $\mathrm{P}=\mathrm{Q}=1 / 2$, onde $\mathrm{N}=$ ni de mudanças.

- Planejamento do tipo "antes e depois"

- Mensuração a nível nominal (ou ordinal)

- Não exige distribuição básica contínua
Passos:

$1^{\circ}$ ) Construir tabela de frequências (observadas) de quatro casas:

\begin{tabular}{|c|c|c|c|}
\hline \multicolumn{2}{|c|}{} & \multicolumn{2}{c|}{-Antes + } \\
\hline \multirow{2}{*}{ Depois } & + & A & B \\
\cline { 2 - 4 } & - & C & D \\
\hline
\end{tabular}

Cédula A - Locam-se os indivíduos que passaram de + para -

Cédula D - Locam-se os indivíduos que passaram de - para +

Cédula B - Locam-se os indivíduos de reação + (antes e depois)

Cédula C - Locam-se os indivíduos de reação - (antes e depois)

A + D - Representa o número total de indivíduos que apresenta modificação.

$2^{\circ}$ ) Determinar as frequências esperadas nas células A e B:

Hipótese nula: $1 / 2(\mathrm{~A}+\mathrm{D})$ acusam modificação em um sentido (-) e $1 / 2(\mathrm{~A}+\mathrm{D})$ acusam modificação em outro sentido $(+)$.

$$
\mathrm{E}=1 / 2(\mathrm{~A}+\mathrm{D})
$$

Portanto, a frequência esperada, sob $\mathrm{H}_{0}$, tanto na cédula A quanto na $D$ é de $1 / 2(A+D)$.

- Se as frequências esperadas são inferiores a 5 , emprega-se a prova binominal em substituição à prova de Mc Nemar.

- Se as frequências esperadas não são inferiores a 5, calcular o valor de $\chi^{2}$ com a fórmula:

$$
\chi 2=\frac{(|\mathrm{A}-\mathrm{D}|)^{2}}{\mathrm{~A}+\mathrm{D}}
$$

Antes, portanto, vamos entender:

$$
\chi 2=\sum_{i=1}^{K} \frac{\left(O_{i}-E_{i}^{2}\right)}{E_{i}}
$$

Onde:

$\mathrm{O}_{\mathrm{i}}=$ número de casos observados classificados na categoria 1 .

$\mathrm{E}_{\mathrm{i}}=$ número de casos esperados na categoria 1 sob $\mathrm{H}_{0}$. 


\section{$\sum$ = indica somatório sobre todas as $\mathrm{K}$ (categorias).}

Portanto, devem-se somar os quadrados das diferenças entre cada valor observado e a respectiva frequência esperada.

$$
\text { Graus de liberdade: } \mathrm{gl}=\mathrm{K}-1(\mathrm{~g} 1=(-1)(\mathrm{c}-1))
$$

$\mathrm{K}=$ categorias

\section{Explicação:}

"Há uma quantidade de distribuições amostrais diferentes para quiquadrado, uma para cada gl. O tamanho de gl reflete o número de observações livres (que podem variar) após feitas certas restrições sobre os dados. Tais restrições não são arbitrárias, ao contrário, são inerentes à organização dos dados. Por exemplo, se os dados se classificam em duas categorias - dados relativos a 50 casos - tão logo saibamos que 35 casos se enquadram numa categoria, sabemos que 15 se enquadrarão na outra.

Neste exemplo, $\mathrm{gl}=1$, porque há duas categorias e conhecendo-se $\mathrm{N}$, tão $\operatorname{logo}$ se conheça o número de casos em uma categoria, o número de outra está automaticamente determinado".

\section{Correção de continuidade - yates}

Viu-se que, na realidade, a fórmula da prova Mc Nemar é uma aproximação da distribuição qui-quadrado. No entanto, deve-se efetuar uma correção de continuidade à distribuição de Mc Nemar. A distribuição do qui-quadrado é uma distribuição contínua, enquanto que Mc Nemar é uma distribuição discreta. Quando todas as frequências esperadas são pequenas, tal aproximação pode ser fraca. Na tentativa de remover o erro usa-se a correção de continuidade. Tem-se:

$$
\begin{gathered}
\chi 2=\frac{(|A-D|-1)^{2}}{A+D} \\
\text { Com } g l=1
\end{gathered}
$$

Deve-se subtrair 1 do valor absoluto da diferença entre A e D antes de elevar ao quadrado.

$3^{\circ}$ ) Consulta-se a tabela D. Determina-se a probabilidade, sob $\mathrm{H}_{0}$, associada a um valor tão grande quanto o valor observado de $\chi^{2}$. Se se trata de uma prova unilateral, dividir por dois o valor da probabilidade exibido na tabela. Se o valor de $\mathrm{p}$, tabelado para o valor observado de $\chi^{2} \operatorname{com} \mathrm{gl}=1$, não

\begin{tabular}{|c|c|c|}
\hline Crianças & $\mathbf{1}^{\circ}$ dia & $30^{\circ}$ \\
\hline 1 & $\mathrm{~A}$ & $\mathrm{C}$ \\
\hline 2 & $\mathrm{~A}$ & $\mathrm{C}$ \\
\hline 3 & $\mathrm{~A}$ & $\mathrm{C}$ \\
\hline 4 & $\mathrm{~A}$ & $\mathrm{C}$ \\
\hline 5 & $\mathrm{~A}$ & $\mathrm{~A}$ \\
\hline 6 & $\mathrm{~A}$ & $\mathrm{C}$ \\
\hline 7 & $\mathrm{~A}$ & $\mathrm{~A}$ \\
\hline 8 & $\mathrm{C}$ & $\mathrm{C}$ \\
\hline 9 & $\mathrm{C}$ & $\mathrm{A}$ \\
\hline 10 & $\mathrm{~A}$ & $\mathrm{C}$ \\
\hline 11 & $\mathrm{C}$ & $\mathrm{A}$ \\
\hline 12 & $\mathrm{~A}$ & $\mathrm{~A}$ \\
\hline 13 & $\mathrm{C}$ & A \\
\hline 14 & $\mathrm{~A}$ & $\mathrm{~A}$ \\
\hline 15 & $\mathrm{~A}$ & $\mathrm{~A}$ \\
\hline 16 & A & $\mathrm{C}$ \\
\hline 17 & A & $\mathrm{C}$ \\
\hline 18 & A & $\mathrm{C}$ \\
\hline 19 & $\mathrm{~A}$ & $\mathrm{C}$ \\
\hline 20 & $\mathrm{C}$ & $\mathrm{A}$ \\
\hline 21 & $\mathrm{~A}$ & $\mathrm{C}$ \\
\hline 22 & $\mathrm{C}$ & $\mathrm{C}$ \\
\hline 23 & $\mathrm{C}$ & $\mathrm{C}$ \\
\hline 24 & A & $\mathrm{C}$ \\
\hline 25 & A & $\mathrm{C}$ \\
\hline \multicolumn{2}{|c|}{$A \rightarrow C=14$} & \\
\hline
\end{tabular}
supera $\alpha$, rejeitar $\mathrm{H}_{0}$ em favor de $\mathrm{H}_{1}$.

\section{Exemplo:}

1 - Suponha-se que um psicólogo esteja interessado em estudar a iniciação de crianças nos contatos sociais. Ele observou que as crianças recém-admitidas em uma escola maternal em geral estabelecem contatos pessoais com adultos de preferência a contatos com outras crianças. Supõe, porém, que na medida em que aumenta a familiaridade e a experiência, tais 
contatos passarão a voltar-se de preferência para outras crianças, ao invés de para adultos. A fim de testar a hipótese, o psicólogo observa 25 crianças recém-admitidas em uma escola maternal, no primeiro dia de frequência à escola de cada uma, e classifica a atitude de cada uma delas conforme seus primeiros contatos sociais se dirijam a outras crianças ou a adultos.

Decorrido um mês de frequência à escola maternal, ele observa as mesmas 25 crianças e faz a mesma classificação de comportamento.*

Passos para os procedimentos estatísticos:

$\left.1^{\circ}\right)$ Hipótese nula: para as crianças que modificaram a atitude, a probabilidade de mudar o objeto de seus contatos sociais de adulto para criança $\left(\mathrm{P}_{\mathrm{A}}\right.$ é igual à probabilidade de mudar de criança para adulto $\left(\mathrm{P}_{\mathrm{D}}\right)$, e ambas são iguais a 1/2.

$$
\begin{aligned}
& \mathrm{H}_{0}: \mathrm{P}_{\mathrm{A}}=\mathrm{P}_{\mathrm{D}} \\
& \mathrm{H}_{1}: \mathrm{P}_{\mathrm{A}}>\mathrm{P}_{\mathrm{D}}
\end{aligned}
$$

$2^{\circ}$ ) Prova estatística:

Mc Nemar - utilizam-se duas amostras relacionadas - antes e depois - mensuração nominal.

$3^{\circ}$ ) Região de rejeição:

$$
\begin{gathered}
\text { Unilateral } \\
\alpha=0,05
\end{gathered}
$$

$\left.4^{\circ}\right)$ Decisão:

Para $\mathrm{gl}=1$ a nível de 0,05 -consultando a tabela $\mathrm{D}$, o valor $\chi^{2}$ crítico é de 3,84 . O valor obtido é 4,5.

$$
\text { Com } \chi_{0}^{7}>\chi_{c}^{7} \text { rejeita-se } \mathrm{H}_{0} \text {. }
$$

\footnotetext{
* Exemplo extraído do livro Estatística Não paramétrica, de Sidney Siegel, Editora
} McGraw-Hill do Brasil Ltd., 1979, p. 71.
Objeto de interesse nos contatos sociais das crianças no $1^{\circ}$ e $30^{\circ}$ dias de frequência à escola maternal.

$$
\begin{gathered}
\text { Ad (+) } \\
\text { Cr (-) }
\end{gathered}
$$$$
\operatorname{Cr}(-)
$$$$
3
$$

Ad (+)

Para esses dados:

$$
\begin{gathered}
\chi 2=\frac{(|A-D|-1)^{2}}{A+D} \\
\chi 2=\frac{(|14-4|-1)^{2}}{14+4} \\
\chi 2=\frac{(9)^{2}}{18}=\frac{81}{18}=4,5 \\
\mathrm{gl}=\mathrm{k}-1=2-1=1
\end{gathered}
$$

Uma consulta à tabela revela que, quando $\chi^{2} \geq 4,5$, e $\mathrm{gl}=1$, a probabilidade de ocorrência sob $\mathrm{H}_{0}$ é $\mathrm{p}<1 / 2(0,05)$, ou seja, $\mathrm{p}<0,025$.

Como a probabilidade, sob $\mathrm{H}_{0}$, associada à ocorrência observada é $\mathrm{p}$ $<0,025$ e é menor que $\alpha=0,05$, o valor observado de $\chi^{2}$ está na região de rejeição e, assim, nossa decisão deve ser rejeitar $\mathrm{H}_{0}$ em favor de $\mathrm{H}_{1}$. Com tais dados artificiais, pois, concluímos que as crianças apresentam tendência significativa para mudar o objeto de seu interesse de adulto para outra criança, após 30 dias de frequência à escola maternal.

\section{Prova de wilcoxon: teste da soma das ordenações}

- Sensível a diferentes localizações

- Planejamento do tipo duas amostras relacionadas (RBD)

- Mensuração a nível ordinal

- Distribuição (básica) contínua (isto é, a variação, não a mensuração)

- Forma de distribuição: desconhecida 


\section{Passos:}

$1^{\circ}$ ) Para cada par, determinar a diferença $\left(d_{1}\right)$, com sinal, entre os dois escores.

$2^{\circ}$ ) Atribuir postos a esses di's independentes do sinal

$3^{\circ}$ ) Atribuir a cada ponto o sinal + ou - do d que ele representa.

$\left.4^{\circ}\right)$ Determinar $\mathrm{T}=$ a menor das somas de postos de mesmo sinal, ou seja, a nota $\mathrm{T}$ será a de menor somatório.

$5^{\circ}$ ) Mediante contagem, determinar $\mathrm{N}=$ total de d's com sinal (os de valor zero, ignora-se).

$\left.6^{\circ}\right)$ O processo para determinação da significância do valor de $T$ vai depender de $\mathrm{N}$.

Se $\mathrm{N} \leq 25$, a tabela $\mathrm{G}$ dá os valores críticos de $\mathrm{T}$ para diversos tamanhos de $\mathrm{N}$. Se o valor observado $\mathrm{T}$ não supera o valor indicado na tabela para um dado nível de significância e em particular $\mathrm{N}, \mathrm{H}_{0}$ pode ser rejeitada àquele nível.

Se $\mathrm{N}>25$, calcular o valor de $\mathrm{Z}$ pela fórmula. Determinar sua probabilidade associada, sob $\mathrm{H}_{0}$, mediante referência à tabela $\mathrm{F}$. Para uma prova bilateral, duplicar o valor de $\mathrm{p}$ dado. Se o $\mathrm{p}$ assim obtido não for superior a $\alpha$, rejeitar $\mathrm{H}_{0}$.

\section{Observações:}

1 - Quando há empate nas observações de um mesmo bloco, o valor de D para aquele bloco será zero. Neste caso $\mathrm{N}$ fica diminuído de tantos zeros quantos forem os encontrados.

2 - Se todos os D forem de mesmo sinal, o valor de T será zero.

3 - Número de blocos igual ou superior a 25 , a distribuição $\mathrm{T}$ se aproximará da normal com média igual a $\mathrm{N}(\mathrm{N}+1) 14$ e desvio-padrão igual a $\mathrm{N}(\mathrm{N}+1)$ $(2 \mathrm{~N}+1) / 24$, onde $\mathrm{N}$ é o número de blocos.
Utiliza-se, então, a estatística Z:

$$
Z=\frac{T-\frac{N(N+1)}{4}}{\sqrt{\frac{N(N+1)(2 N+1)}{25}}}
$$

Consulta-se a tabela da curva normal (Tabela $A$ ) para verificar a significância ou não da diferença encontrada entre as duas médias. Se $\mathrm{Z}$ calculado $\geq \mathrm{Z}$ tabelado, rejeita-se $\mathrm{H}_{0}$.

4- Quando há empate nas posições, calcula-se a média das posições.

\section{Observações importantes}

Aceita-se $\mathrm{H}_{0}$ quando a diferença entre a soma dos di's negativos e a soma dos di's positivos é muito pequena. Se, entretanto, a diferença entre a soma dos di's e a soma dos di's negativos é muito grande, o tratamento A difere do tratamento $\mathrm{B}$, rejeita-se $\mathrm{H}_{0}$.

$\mathrm{H}_{0}$ : a soma dos postos positivos será igual à soma dos postos negativos.

$\mathrm{H}_{1}$ : a soma dos postos negativos será diferente da dos positivos.

\section{Exemplo:}

Suponha-se um psicólogo interessado em testar se a frequência à escola maternal tem algum efeito sobre a percepção social das crianças. Ele classifica a percepção através da atitude da criança em relação a um conjunto de figuras que ilustram uma diversidade de situações sociais, formulando um grupopadrão de perguntas sobre cada figura. Assim, ele pode obter um escore entre 0 e 100 para cada criança.

$\mathrm{O}$ pesquisador admite que um escore mais elevado indica maior percepção social do que um escore mais baixo; não tem certeza de que o intervalo entre os escores seja constante.

Para testar sua hipótese, o pesquisador seleciona oito pares de gêmeos idênticos para servirem como indivíduos de suas observações. Escolhe ao acaso um gêmeo de cada par para frequentar a escola maternal. 
O outro não frequentara a escola. Ao fim de um período escolar, as 16 crianças são submetidas ao teste de perceptividade social. ${ }^{*}$

\section{Procedimentos estatísticos}

$\left.1^{\circ}\right)$ Hipóteses

$\mathrm{H}_{0}$ : não há diferença entre os graus de percepção das crianças que ficaram em casa e das que frequentaram a escola.

$\mathrm{H}_{1}$ : os graus de percepção social dos dois grupos de crianças são diferentes.

$2^{\circ}$ ) Prova estatística - Wilcoxon

- duas amostras relacionadas

- nível ordinal

- variável - percepção social - continua

$3^{\circ}$ ) Nível de significância

$\alpha=0,05$
$\mathrm{~N}=8$

$4^{\circ}$ ) Amostra:

$5^{\circ}$ ) Região de rejeição:

$$
\mathrm{N}<25
$$

\section{Bilateral}

\section{$6^{\circ}$ ) Decisão}

Rejeita-se $\mathrm{H}_{0}$, concluindo-se que a permanência na escola maternal afeta significativamente a perceptividade social da criança.
Tabela 1. Escores de percepção social de crianças que

frequentam a escola maternal e que ficaram em casa

\begin{tabular}{cccccc} 
Par. & F. escola & F. casa & d & Posto de D & Posto com sinal menos frequente \\
\hline a & 82 & 63 & 9 & 7 & \\
b & 69 & 42 & 27 & 8 & 1 \\
c & 73 & 74 & -1 & -1 & \\
d & 43 & 37 & 6 & 4 & \\
e & 58 & 51 & 7 & 5 & 3 \\
f & 56 & 43 & 13 & 6 & $\mathrm{~T}=4$ \\
g & 76 & 80 & -4 & -3 & \\
h & 65 & 62 & 3 & 2 &
\end{tabular}

Para $\mathrm{N}$ (número de blocos) $=8$, um valor de $\mathrm{T}=4$ permite-nos rejeitar a hipótese de nulidade ao nível 0,05 para uma prova bilateral.

* Exemplo extraído do livro Estatística Não-paramétrica, Sidney Siegel, Editora McGrawHill do Brasil Ltd., 1979, p. 86. 


\section{Correlaçã̃o}

Em estatística descritiva, foram estudados, especialmente, os métodos de cálculo das medidas estatísticas destinadas a representar de maneira fidedigna a execução de um indivíduo ou de um grupo no tocante a determinada característica.

Frequentemente, porém, é de importância maior examinar a relação entre duas variáveis do que mediar a execução de cada uma por si. Nesse aspecto pode-se falar em correlação, que estuda a relação concomitante entre duas ou mais variáveis. Quanto mais aumenta a concomitância, maior correlação existe entre as variáveis.

O coeficiente de correlação é um índice que expressa o grau de associação entre duas ou mais variáveis. Para se atingir este coeficiente, é preciso medir as duas variáveis. O primeiro passo é conseguir, na mesma amostra, duas medidas dos respectivos indivíduos: uma medida de $\mathrm{X}$ e outra de $\mathrm{Y}$, as quais serão emparelhadas.

\section{Considerações gerais}

O coeficiente de correlação é expresso por um índice numérico que varia de $1 \mathrm{a}+1$. Onde:

- 1: Correlação negativa, inversa e perfeita.

+1 : Correlação positiva, direta e perfeita.

\section{Aplicações do coeficiente de correlação}

Utiliza-se o cálculo da correlação quando se deseja recorrer à prova de hipóteses e na construção de testes psicológicos na análise de itens, validade e fidedignidade, e fazer previsões em termos de seleção de pessoal.

\section{Representação gráfica}

O coeficiente de correlação é expresso graficamente da seguinte forma:

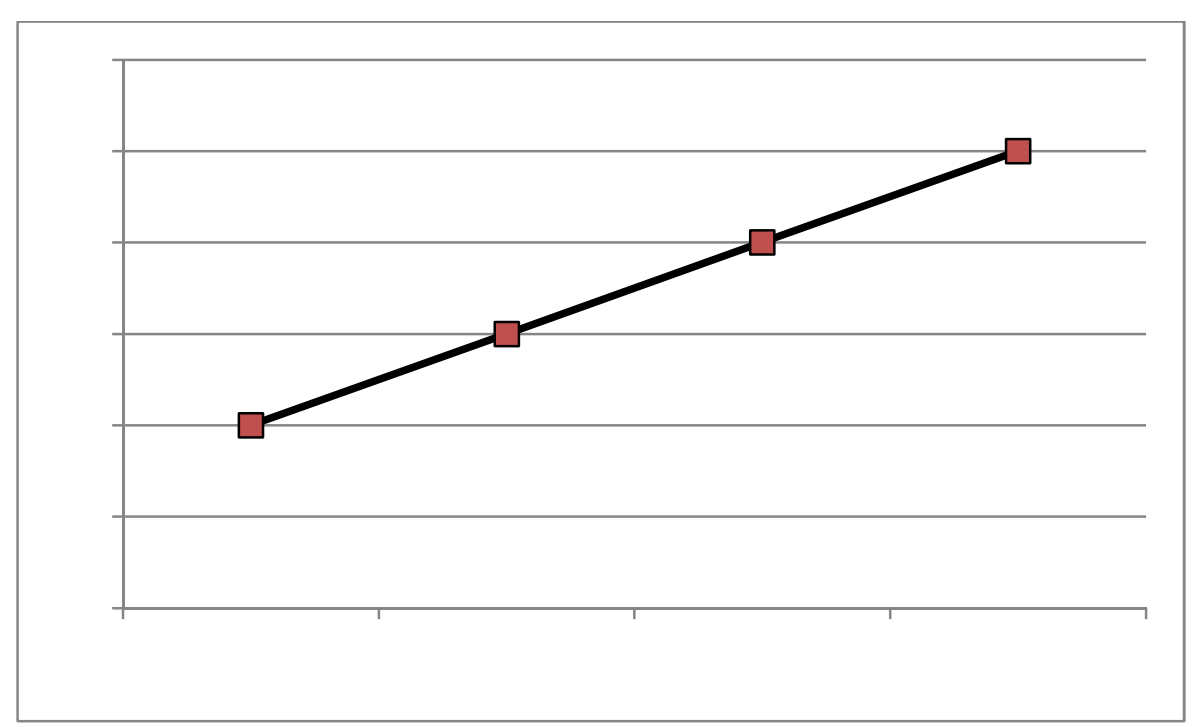

Positiva, direta e perfeita $\mathrm{r}=+1$

$\begin{array}{ccc}\text { Ind. } & \mathbf{x} & \mathbf{y} \\ \text { A } & 2 & 4 \\ \text { B } & 4 & 6 \\ \text { C } & 6 & 8 \\ \text { D } & 10 & 10\end{array}$




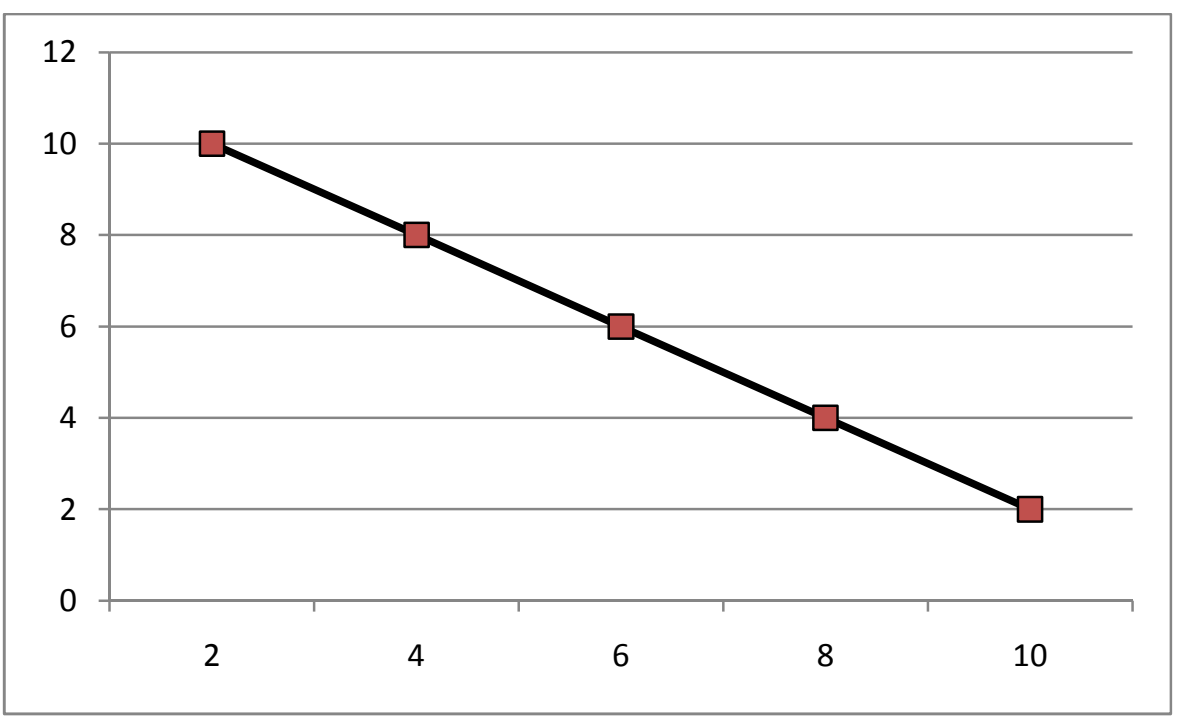

Negativa, inversa e perfeita $r=-1$

$\begin{array}{ccc}\text { Ind. } & \mathbf{x} & \mathbf{y} \\ \text { A } & 2 & 10 \\ \text { B } & 4 & 8 \\ \text { C } & 6 & 6 \\ \text { D } & 8 & 4 \\ \text { E } & 10 & 2\end{array}$

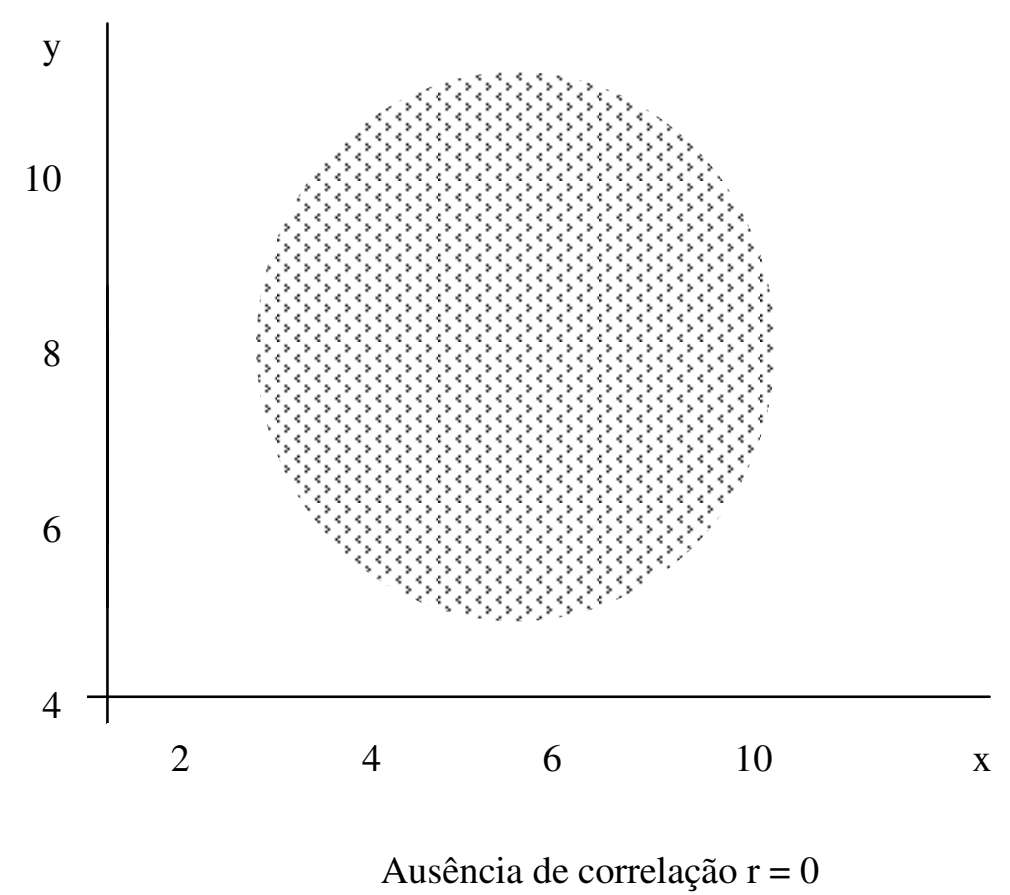

\section{Derivações do coeficiente de correlação}

1 - Predição: sabendo-se a relação entre duas variáveis, pode-se predizer uma a partir da outra.

Na predição faz-se necessária a equação de regressão.

Ou então:

\section{Coeficiente de determinação}

É a variância independente:

$$
\mathrm{K}^{2}=1,00-\mathrm{r}^{2}
$$

73 


\section{Coeficiente de alienação}

Importante para verificar o erro de prognóstico:

$$
\mathrm{K}=\sqrt{1-\mathrm{r}^{2}}
$$

$\mathrm{O}$ erro de prognóstico é maior quanto maior é o valor de $\mathrm{K}$.

$\mathrm{K}=$ medida de ausência de relação entre dias variáveis $\mathrm{X}$ e $\mathrm{Y}$.

Quando $\mathrm{K}=1,00, \mathrm{r}=$ zero.

Quanto mais exatos forem os prognósticos que possamos fazer, tanto melhor será o valor preditivo.

Se a correlação entre um teste e um critério é zero, o valor de nossos prognósticos será nulo. Quando a correlação entre o teste e o critério é perfeita não se comete nenhum erro de predição.

Quando a correlação entre o teste e o critério diminui de 1 a 0 , o coeficiente de alienação aumenta rapidamente.

2 - Pesquisa: controle no processo de investigação - averiguar leis.

É necessário, para tanto, partindo do objetivo, formular: $\mathrm{H}_{0}$ e $\mathrm{H}_{1}$, estabelecer os graus de liberdade (N-2) e o teste de significância do R de Pearson - Razão t.

Calcula-se, então:

$$
\text { razão } t=\frac{r \sqrt{\mathrm{N}-2}}{\sqrt{1-\mathrm{r}^{2}}}
$$

Compara-se o t calculado e o t tabelado:

$\mathrm{t}$ cal $>\mathrm{t}$ tab - aceita-se $\mathrm{H}_{1}$

$\mathrm{t}$ cal $<\mathrm{t}$ tab - aceita-se $\mathrm{H}_{0}$

3 - Construção de instrumentos de medida psicológicos

- Fidedignidade - correlacionam-se:

teste - reteste

consistência interna

$\mathrm{r}=$ teste/acerto/erro

0,60 - dados razoáveis
0,80 - fidedignidade boa

- Validade - correlacionam-se os escores do teste com os escores do critério:

Acima de 0,40

Na interpretação do coeficiente de correlação, deve ser considerada a finalidade com a qual or foi calculado.

$\mathrm{Na}$ escolha do coeficiente de correlação deve-se considerar alguns critérios a fim de que se encontre um resultado confiável, a saber:

- nível de mensuração

- tipos de variáveis

- normalidade da distribuição

- homocedasticidade (linha de regressão)

- linearidade

\section{Coeficiente de correlação de pearson}

Exigências:

- distribuição normal (ver assimetria e curtose em amostra < 30)

- medida intervalar (nas duas variáveis)

- variáveis continuas

- variância aproximada - homocedasticidade

- linearidade

$$
\mathrm{v}=\frac{\sum \chi 2}{\mathrm{~N}}
$$

Fórmulas:

$$
\text { 1) } r=\frac{\sum z x \cdot z y}{N}
$$

(quando $\mathrm{N}$ é pequeno)

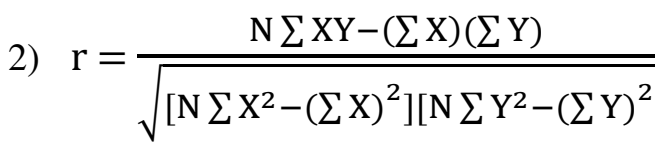


Exemplo:

\begin{tabular}{c|c|c|c|c|c}
\hline Ind. & $\mathbf{X}$ & $\mathbf{Y}$ & $\mathbf{X Y}$ & $\mathbf{X}^{\mathbf{2}}$ & $\mathbf{Y}^{\mathbf{2}}$ \\
\hline $\mathrm{A}$ & 2 & 4 & 8 & 4 & 16 \\
\hline $\mathrm{B}$ & 4 & 6 & 24 & 16 & 36 \\
\hline $\mathrm{C}$ & 6 & 8 & 48 & 36 & 64 \\
\hline $\mathrm{D}$ & 8 & 10 & 80 & 64 & 100 \\
\hline $\mathrm{E}$ & 10 & 12 & 120 & 100 & 144 \\
\hline$\sum$ & 30 & 40 & 280 & 220 & 360 \\
\hline
\end{tabular}

\section{Coeficiente de correlação spearman-brown}

Exigências:
- poucos dados
- linearidade
- nível de medida original
- amostra aleatória

$$
\text { Onde: } \quad r_{s}=1-\frac{6 \sum D^{2}}{N\left(N^{2}-1\right.}
$$

$\mathrm{r}_{\mathrm{s}}=$ coeficiente de correlação de postos

$\mathrm{D}=$ diferença entre postos (relativa ao mesmo sujeito em ambas as variáveis)

$\mathrm{N}=$ número de respondentes

$$
\text { Exemplo: }
$$

\begin{tabular}{c|c|c|c|c}
\hline Ind. & $\mathbf{X}$ & $\mathbf{Y}$ & $\mathbf{D}$ & $\mathbf{D}^{\mathbf{2}}$ \\
\hline 1 & $6^{\mathbf{o}}$ & $4^{\mathbf{o}}$ & 2 & 4 \\
\hline 2 & $4^{\mathbf{o}}$ & $1^{\mathbf{o}}$ & 3 & 9 \\
\hline 3 & $7^{\mathbf{0}}$ & $9^{\mathbf{o}}$ & -2 & 4 \\
\hline 4 & $2^{\mathbf{o}}$ & $3^{\mathbf{o}}$ & -1 & 1 \\
\hline 5 & $3^{\mathbf{o}}$ & $5^{\mathbf{o}}$ & -2 & 4 \\
\hline 6 & $1^{\mathbf{o}}$ & $6^{\mathbf{o}}$ & -5 & 25 \\
\hline 7 & $8^{\mathbf{o}}$ & $2^{\mathbf{o}}$ & 6 & 36 \\
\hline 8 & $5^{\mathbf{o}}$ & $8^{\mathbf{o}}$ & -3 & 9 \\
\hline 9 & $10^{\mathbf{o}}$ & $10^{\mathbf{o}}$ & 0 & 0 \\
\hline 10 & $9^{\mathbf{o}}$ & $7^{\mathbf{0}}$ & 2 & 2 \\
\hline$\Sigma$ & - & - & - & 96 \\
\hline
\end{tabular}

$$
\mathrm{r}_{\mathrm{s}}=1-\frac{6(96)}{10\left(10^{2}-1\right)}=0,42
$$

Obs.: No caso de postos empatados, devemos somar esses postos (o "valor" numérico deles) e dividir pelo número de empates. 


\section{EXEMPLO DE UM ESTUDO DE PESQUISA}

O presente estudo visa comprovar a eficácia de diferentes metodologias no processo ensino-aprendizagem da disciplina Estatística. $\mathrm{O}$ universo de discentes foi caracterizado como constituído por aluno de cursos de Formação de Psicólogos.

Neste estudo foram utilizadas duas metodologias distintas, que denominamos: Tradicional e Renovadora.

A partir da utilização destes dois enfoques metodológicos, foram realizadas comparações entre duas amostras, ambas constituídas por alunos regularmente matriculados na primeira série do curso de Formação de Psicólogos da Faculdade de Humanidades Pedro II.

Tais comparações pretendem comprovar se existem, entre os dois grupos, diferenças com relação ao aproveitamento e às atitudes relacionadas à disciplina Estatística.

\section{Tipos e procedimentos de pesquisa}

Devido à impossibilidade de controlar adequadamente a variável independente a ser utilizada em cada grupo, isto é, a metodologia de ensino, empregou-se, neste estudo, um plano de pesquisa quase experimental, definido por Didio (Stanley e Campbell, 1979) como sendo um tipo de pesquisa caracterizada pela "impossibilidade de atribuição aleatória dos grupos e pela falta de completo controle na programação dos estímulos” (p. XII).

A pesquisa, portanto, objetivou comparar as variáveis dependentes em dois grupos intactos, isto é, grupos aos quais não foi possível alocar aleatoriamente os elementos, pois a composição dos grupos ocorreu através da opção dos próprios integrantes pelo primeiro ou terceiro turno, segundo os critérios estabelecidos pela instituição de ensino, na qual foi realizada a pesquisa.

Não se pode afirmar que exista equivalência, entre os grupos, com relação às variáveis que poderiam exercer influência sobre as variáveis dependentes. No entanto, pressupõe-se que os dois grupos sejam razoavelmente equivalentes no que tange ao nível intelectual, motivação, interesse, nível socioeconômico, sexo e idade, pois os participantes de ambos os grupos foram aprovados no mesmo exame vestibular, cursam a mesma série e escolheram a mesma formação acadêmica.

Foram controladas as seguintes variáveis: professor, tempo de duração do ensino da disciplina, conteúdo programático, procedimentos e recursos de ensino.

A determinação da metodologia de ensino para cada grupo foi feita por sorteio, cabendo ao primeiro turno (diurno) o Método Tradicional, e ao terceiro turno (noturno) o Método Renovador.

Ambos os grupos foram submetidos a dois instrumentos de medida. Primeiramente aplicou-se uma escala de atitudes cujo objetivo foi verificar a atitude inicial dos alunos frente à disciplina Estatística no curso de Psicologia (pré-teste).

Em seguida, introduziu-se a variável independente, metodologias Tradicional e Renovadora, simultânea e respectivamente nos dois grupos: diurno e noturno.

No final de 4 meses, aplicou-se a mesma escala de atitude inicial a fim de se verificar possíveis mudanças e diferenças de atitudes entre os dois grupos e os dois períodos, isto é, no início e no final do curso (pós-teste).

O plano de pesquisa pré-teste e pós-teste foi empregado por permitir a verificação da equivalência entre a atitude inicial dos dois grupos de alunos e, posteriormente, possibilitar comparações entre possíveis modificações de atitudes nos dois grupos devido à introdução da variável independente.

Um segundo instrumento, que consistia na avaliação do aproveitamento dos alunos na disciplina Estatística, foi aplicado no último dia de aula, objetivando a comparação dos dois grupos, submetidos a duas metodologias diferentes quanto ao aproveitamento na respectiva disciplina.

\section{Definição de termos}

Metodologia renovadora - Método de ensino que visa ao aprendizado através da compreensão e aplicabilidade dos conceitos e princípios estatísticos. 
Metodologia tradicional - Método de ensino que visa ao aprendizado automático dos cálculos estatísticos e à memorização dos princípios.

Método - Organização dos recursos e dos procedimentos mais adequados para atingir o fim visado da maneira mais eficiente possível.

Atitudes - Reação dos indivíduos frente à disciplina Estatística.

Aproveitamento - Nível de conhecimento adquirido através do processo ensino-aprendizagem.

\section{Seleção dos sujeitos}

Participaram do estudo os alunos que ingressaram na primeira série do Curso de Formação de Psicólogos da Faculdade Humanidades Pedro II, Rio de Janeiro, no ano de 1984. O total de 130 integrantes se distribuiu por dois turnos, com 66 matriculados no turno diurno e 64 no noturno.

A amostra foi constituída por sujeitos acima de 17 anos - rapazes e moças - que nunca tiveram algum contato prévio com a disciplina Estatística.

A escolha da instituição de ensino por parte do pesquisador se deve aos seguintes fatores:

1 - A permissão do estabelecimento para a execução deste estudo.

2 - O professor e pesquisador deste estudo é membro do corpo docente da referida instituição.

\section{Coleta de dados}

A coleta de dados prosseguiu nos seguintes moldes:

No primeiro dia de aula, 12 de março de 1984, antes de qualquer introdução ao programa, foram aplicadas as escalas de atitude. Portanto, realizou-se o pré-teste nas duas turmas, cada uma em seu respectivo horário de aula, ou seja, diurno e noturno. professor:

As escalas foram aplicadas mediante a seguinte solicitação do
"Por favor, respondam às questões sugeridas, seguindo as instruções constantes na $1^{\mathrm{a}}$ folha."

Os dois primeiros tempos de aula foram ocupados com a aplicação da escala.

No último dia de aula, 26 de junho de 1984, foi novamente aplicada a mesma escala (pós-teste).

O instrumento de avaliação do aproveitamento foi aplicado no dia 26 de junho de 1984, após o término de todo o processo de ensinoaprendizagem do conteúdo programático.

\section{Estudos psicométricos dos instrumentos}

Os dados referentes à pesquisa foram coletados mediante a aplicação de dois instrumentos de medida: uma escala de atitudes e um instrumento de avaliação do aproveitamento.

\section{Escala de atitudes}

A escala de atitudes foi especialmente construída para esta pesquisa (anexo 5). Foi aplicada em dois momentos (pré e pós-testes), objetivando a sondagem de atitudes com relação à disciplina Estatística.

Os estudos experimentais aplicados à escala e elaboração dos critérios de avaliação e a atribuição de pontos. de Likert.

A escala consta de 32 itens, construídos segundo os procedimentos

A análise de itens foi efetuada mediante a utilização do coeficiente de correção de Pearson. Os índices encontrados através da correlação itemteste foram maiores que 0,40 , com exceção de quatro $(4,17,28$ e 29). Conclui-se, então, que as correlações item-teste para cada item apoiam a hipótese de uma consistência interna adequada.

Os estudos sobre a fidedignidade realizaram-se sobre os resultados obtidos em dois grupos distintos. Calculou-se a fidedignidade através do coeficiente Alfa de Cronbach, segundo o critério de consistência interna. 
- Dados a respeito da fidedignidade da escala foram obtidos com uma amostra de 155 estudantes que ingressaram no Curso de Formação de Psicólogos, na Faculdade de Humanidades Pedro II, no ano de 1983. O coeficiente alfa obtido a partir dos resultados desta amostra foi igual a 0,92 , concluindo-se que a escala é fidedigna e apresenta um alto índice de homogeneidade entre os itens. Resultados similares, ou seja, um coeficiente alfa igual a 0,88 , foram obtidos numa segunda verificação da fidedignidade desta escala, em uma amostra constituída por 130 alunos que ingressaram na mesma faculdade no ano de 1984.

\section{Instrumento de avaliação do aproveitamento}

O instrumento de avaliação do aproveitamento (anexo 4) consta de 34 itens de múltipla escolha, referentes ao conteúdo programático.

Neste instrumento a fidedignidade foi calculada pelo coeficiente de Kuder-Richardson, segundo o critério de consistência interna, e o resultado encontrado foi igual a 0,70. Pode-se concluir, portanto, que o teste apresenta consistência interna satisfatória.

\section{Hipóteses e tratamento estatístico}

A pesquisa teve como objetivo comprovar a seguinte hipótese:

$\mathrm{O}$ processo ensino-aprendizagem da Estatística em alunos que ingressam no curso de Formação de Psicólogos, dirigido através de duas diferentes metodologias de ensino: Renovadora e Tradicional, apresenta diferenças significativas, a favor da metodologia Renovadora, com relação à atitude $\mathrm{e}$ ao aproveitamento frente à disciplina Estatística.

Com o objetivo de se comprovar esta hipótese, foram derivadas as seguintes hipóteses estatísticas.

$H_{0:}$ não há diferença entre as médias aritméticas dos dois grupos de alunos, submetidos às diferentes metodologias de ensino: Tradicional e Renovadora, com relação à atitude frente à disciplina Estatística.

$H_{l}$ : há diferença entre as médias aritméticas dos dois grupos de alunos, submetidos às diferentes metodologias de ensino: Tradicional e Renovadora, com relação à atitude frente à disciplina Estatística.
Tabela 1. Médias e desvios-padrão dos resultados obtidos nos pré e pós-teste na Escala de Atitudes nos dois grupos

\begin{tabular}{c|c|c|c}
\hline \multicolumn{2}{c|}{} & \multicolumn{2}{c}{ Grupos } \\
\hline \multirow{2}{*}{ Aplicaçõos } & & Renovador & Tradicional \\
\hline \multirow{2}{*}{$1^{a^{a}}$} & $\bar{X}$ & 79,54 & 72,22 \\
\cline { 2 - 4 } & $\mathrm{S}$ & 12,63 & 16,74 \\
\hline \multirow{2}{*}{$2^{\mathrm{a}}$} & $\overline{\mathrm{X}}$ & 76,90 & 74,16 \\
\cline { 2 - 4 } & $\mathrm{S}$ & 18,19 & 14,13 \\
\hline
\end{tabular}

Para se comprovar a significância das diferenças entre os resultados dos dois grupos com relação à atitude, utilizou-se a análise da covariância, pois, como foi dito anteriormente, não houve manipulação do grupo antes da experiência. Não se pode garantir a equivalência dos grupos quanto às variáveis relevantes. A este respeito posicionam-se Campbell e Stanley (1974):

Se o pesquisador analisa somente as diferenças do grupo com relação à variável dependente sem levar em consideração as aparentemente ligeiras diferenças entre grupos em outras medidas, ele, muitas vezes, pode obter um quadro deturpado da verdadeira diferença entre grupos (p. 86).

Para que não ocorra essa distorção, comprova-se a significância das diferenças através da análise da covariância, pois o pré-teste atua como variável concomitante.

A fim de proceder à análise da covariância, faz-se necessário obter informações sobre a homogeneidade dos grupos. Efetua-se, portanto, em primeiro lugar a prova da homogeneidade da regressão.

Aplicada esta prova aos resultados encontrados na escala de atitudes (anexo 5), obteve-se um F igual a 0,00049 , resultando não significativo $(\alpha=$ $0,05)$. Pode-se concluir que a declividade das retas de regressão é a mesma; portanto, procede o emprego da análise da covariância.

Tabela 2

\begin{tabular}{c|c|c|c|c}
\hline Fonte & SQ & GL & Q & F \\
\hline Total & 33372,447 & 128 & & \\
\hline Erro & 33200,921 & 127 & 261,42457 & \\
\hline Tratamento & 171,52576 & 1 & 171,52576 & $<1$ \\
\hline
\end{tabular}


Sumário da Análise da Covariância para os resultados obtidos nos pré e pós-teste na escala de atitudes nos dois grupos considerados.

Ao nível de significância de $0,05, \mathrm{~F}<$ I não é significativo; portanto, não se pode rejeitar $\mathrm{H}_{0}$.

Conclui-se, então, que não há diferença estatisticamente significativa entre as médias aritméticas dos dois grupos em relação à atitude frente à disciplina Estatística.

Considerando-se os resultados obtidos na segunda aplicação da escala de atitudes, utilizou-se a análise da variância com o propósito de averiguar diferenças significativas entre as médias aritméticas dos dois grupos: o grupo submetido à metodologia Renovadora e o grupo submetido à metodologia Tradicional.

Tabela 3

\begin{tabular}{ccccc}
\hline Fonte & SQ & GL & Q & F \\
\hline Total & 33475 & 129 & & \\
Erro & 33255,23 & 128 & 259,80648 & $<1$ \\
Tratamento & 220,26 & 1 & 220,26 & \\
\hline
\end{tabular}

Sumário da Análise da Variância para os resultados obtidos no pósteste na escala de atitudes nos dois grupos considerados.

Uma vez obtido um $\mathrm{F}<1$, ao nível de significância de 0,05 , pode-se aceitar a hipótese nula. Conclui-se, portanto, que o grupo submetido à metodologia Renovadora não difere significativamente com relação à atitude frente à disciplina Estatística, do grupo submetido à metodologia Tradicional.

Comprovar-se-á, em seguida, a hipótese inicial com relação ao aproveitamento dos alunos na disciplina Estatística.

\section{Tabela 4}

\begin{tabular}{ccc}
\hline & & Grupos \\
\hline & Renovador & Tradicional \\
\hline $\bar{X}$ & 18,7344 & 20 \\
$\mathrm{~S}$ & 4,9568 & 4,9144 \\
\hline
\end{tabular}

Médias e desvios-padrão obtidos no instrumento de avaliação do aproveitamento nos dois grupos considerados.
Ao se observar os resultados, verifica-se que a média aritmética dos resultados no grupo submetido à metodologia Tradicional é superior à média aritmética dos resultados obtidos pelo grupo submetido à metodologia Renovadora. Diante deste fato e observando os desviospadrão, verificou-se que o grupo submetido à metodologia Renovadora apresentou maior dispersão. Por outro lado, no grupo submetido à metodologia Tradicional, houve menor variabilidade dos resultados. Assim sendo, poder-se-ia cogitar de uma discriminação maior do grupo Renovador com relação ao nível de aproveitamento.

A comparação das variâncias nos dois grupos foi realizada através da razão entre as duas variâncias, obtendo-se um $\mathrm{F}=1,0226626$ para um nível de significância de 0,05 e 1 e 84 graus de liberdade. Desta forma, conclui-se que a diferença entre as variâncias não é significativa.

Pelo que se pode observar, os dois grupos não apresentam diferenças significativas quanto ao aproveitamento na disciplina Estatística. No entanto, o instrumento de avaliação do aproveitamento constou de Itens heterogêneos, subdivididos da seguinte forma: compreensão - 13 itens; execução de cálculos -11 itens; e comuns ${ }^{*}-10$ itens. Logo, a inexistência de diferença entre as médias aritméticas poderá estar vinculada ao acerto de itens relacionados à ênfase dada à compreensão ou memorização e automatização de acordo com a metodologia aplicada, em cada um dos grupos.

Averiguou-se, então, a média aritmética dos dois grupos com relação aos três tipos de itens propostos. Obtiveram-se os seguintes resultados:

\section{Tabela 5}

\begin{tabular}{ccccc}
\hline $\begin{array}{c}\text { MET. } \\
\text { GR. }\end{array}$ & B1 & B2 & B3 & Total \\
\hline A1 & 7,4375 & 5,4688 & 5,8281 & 18,7344 \\
A2 & 7,3182 & 6,8939 & 5,7879 & 20,000 \\
Total & 14,7557 & 12,3627 & 11,6160 & 38,7344 \\
\hline
\end{tabular}

Médias obtidas pelos grupos submetidos à metodologia Renovadora (A1) e à metodologia Tradicional (A2) nos três tipos de itens: compreensão (B1), execução de cálculos (B2) e comuns (B3).

* Fonte: Silva e Soriano de Alencar (1984). 
Finalmente, necessita-se saber se essa diferença observada nas médias aritméticas de cada grupo de itens é significativa estatisticamente. Para tal, utilizar-se-á a análise da variância num plano fatorial, onde as seguintes hipóteses serão testadas:

$\mathrm{H}_{0}$ : não há diferença entre as médias aritméticas dos dois grupos submetidos a diferentes metodologias:- Renovadora e Tradicional - com relação aos 3 níveis de aproveitamento (compreensão, execução de cálculos e comuns).

$\mathrm{H}_{1}$ : há diferença significativa entre as médias aritméticas dos dois grupos submetidos a diferentes metodologias - Renovadora e Tradicional com relação aos 3 níveis de aproveitamento (compreensão, execução de cálculos e comuns).

Considerando que, para 1 e 128 graus de liberdade, ao nível de significância de 0,05 , os valores de $\mathrm{F}$ estão entre 3,92 e 3,89, tanto os efeitos de A e B como a interação A x B não foram significativos. Aceitase, portanto, a hipótese nula: não há diferença significativa entre as médias aritméticas dos dois grupos de diferentes tipos de itens: compreensão, execução de cálculos e comuns.

Tabela 6. Sumário da Análise da Variância para 0 aproveitamento nos dois grupos considerados

\begin{tabular}{c|c|c|c|c}
\hline Fonte entre Sujeitos & SQ & GL & \multirow{2}{*}{ QM } & \multirow{2}{*}{ F } \\
\hline A & 17,344 & 1 & 17,3444 & 2,8445 \\
\hline Sujeitos dos grupos & \multirow{2}{*}{780,4948} & 128 & & \\
& & 260 & & \\
\hline Dentro dos sujeitos & 174,8216 & 2 & 87,4108 & 2,1484 \\
\hline B & 49,1608 & 2 & 24,5804 & \\
\hline AB & 10415,5977 & 256 & 40,6859 & \\
\hline E sujeitos dentro dos grupos & & &
\end{tabular}

Constatou-se que as duas metodologias empregadas no processo ensino-aprendizagem da disciplina Estatística não apresentam diferenças significativas quanto às médias aritméticas das variáveis atitude e aproveitamento dos alunos. Pensou-se, então, que possivelmente as atitudes apresentassem alguma relação com o aproveitamento.
Cogitou-se, primeiramente, que os alunos, ao apresentarem baixo aproveitamento na disciplina, tendem a mostrar-se desfavoráveis, enquanto que os que obtêm sucesso mostram-se favoráveis. Levantaram-se, então, as seguintes hipóteses: de atitude.

$\mathrm{H}_{0}$ : o aproveitamento na disciplina Estatística não provoca mudança

$\mathrm{H}_{1}$ : o aproveitamento na disciplina Estatística provoca mudança de atitude.

Procedeu-se ao cálculo do coeficiente de Correlação de Pearson.

O coeficiente de correlação obtido foi igual a 0,17 , para um nível de significância de 0,05 e 128 graus de liberdade. Aceita-se a hipótese nula. $\mathrm{O}$ aproveitamento da disciplina não provoca mudança de atitude.

Em seguida, questionou-se a relação entre a atitude inicial e o aproveitamento.

As hipóteses foram as seguintes:

$\mathrm{H}_{0}$ : a atitude inicial dos alunos não interfere no aproveitamento da disciplina Estatística.

$\mathrm{H}_{1}$ : a atitude inicial dos alunos interfere no aproveitamento da disciplina Estatística.

Pelas mesmas razões anteriores, testaram-se as hipóteses através do Coeficiente de Correlação de Pearson.

O resultado encontrado foi de 0,06 , a um nível de significância de 0,05 e 128 graus de liberdade. Aceita-se a hipótese nula. A atitude inicial não interfere no aproveitamento dos alunos. 


\section{APÊNDICE}

\section{EXERCÍCIOS*}

1. Com relação ao estudo realizado por Torres (1978): investigação da relação entre diferentes períodos do desenvolvimento cognitivo e a evolução do conceito de morte, classifique as variáveis em contínuas ou discretas.

2. Com relação ao estudo sobre autoconceito, rendimento acadêmico e escolha do lugar de sentar entre alunos de níveis socioeconômicos médio e baixo, de Silva e Soriano de Alencar (1984).

"No presente estudo foram investigadas as relações existentes entre o autoconceito do aluno, de um lado, e, de outro, o rendimento acadêmico, a escolha do lugar de sentar em sala de aula e avaliação do autoconceito do aluno pelo professor. A amostra foi constituída por 500 sujeitos da $4^{\mathrm{a}}$ série do $1^{\circ}$ grau. Informações sobre o autoconceito do aluno foram obtidas através do uso de uma escala. A avaliação do autoconceito do aluno pelo professor foi feita através de unia folha contendo instruções para que o professor registrasse sob a coluna 1 os nomes dos alunos com autoconceito positivo, sob a coluna 3 os nomes dos alunos com autoconceito negativo, e sob a coluna 2 os demais nomes. Os resultados indicaram uma relação significativa entre autoconceito, rendimento acadêmico e a avaliação do autoconceito do aluno pelo professor. Não foram observadas diferenças significativas entre alunos que frequentavam escolas localizadas em um setor da cidade habitado predominantemente por famílias de status socioeconômico médio ou em outro setor habitado por famílias de nível econômico baixo, nem entre alunos dos sexos masculino e feminino."

a - Classifique as variáveis.

b - Qual a população a que se refere o presente estudo?

c - Descreva a amostra escolhida.

\footnotetext{
* Alguns dos exercícios foram extraídos e adaptados da bibliografia utilizada na confecção deste livro.
}

3. Escores obtidos por 52 crianças na dimensão extensão no instrumento de sondagem do conceito de morte:

$\begin{array}{llllllll}14 & 10 & 16 & 9 & 14 & 18 & 19 & 21 \\ 14 & 18 & 13 & 14 & 12 & 17 & 22 & 21 \\ 22 & 13 & 13 & 14 & 15 & 14 & 22 & 19 \\ 4 & 13 & 18 & 21 & 21 & 16 & 17 & 19 \\ 8 & 13 & 2 & 7 & 21 & 16 & 3 & 26 \\ 17 & 18 & 12 & 16 & 10 & 12 & 20 & 13 \\ 16 & 21 & 27 & 22 & & & & \end{array}$

a - Esta tomada de dados denomina-se:

b - Para tomar este material mais significativo e conciso, é necessário organizá-lo num

c - Siga os passos necessários e organize uma distribuição de frequência.

d - Faça a representação gráfica.

e - Calcule a moda, a mediana e média aritmética. Situe-as no gráfico.

f - Qual foi a faixa de normalidade no grupo?

$\mathrm{g}$ - Houve homogeneidade? Por quê?

4. Observe a tabela abaixo e faça as interpretações adequadas:

\begin{tabular}{l|c|c|c|c|c|c|c|c|c|c}
\hline & \multicolumn{2}{|c|}{ Sexo } & \multicolumn{3}{c|}{$\begin{array}{c}\text { Nível } \\
\text { Socioeconômico }\end{array}$} & \multicolumn{3}{c|}{ Local de sentar } & \multicolumn{3}{c}{$\begin{array}{c}\text { Rendimento } \\
\text { acadêmico }\end{array}$} \\
\hline & M & F & Médio & Baixo & Frente & Meio & Atrás & A & M & B \\
\hline Média & 3,95 & 3,98 & 4,03 & 3,89 & 3,99 & 3,98 & 3,93 & 4,35 & 4,02 & 3,86 \\
\hline $\begin{array}{l}\text { Desvio- } \\
\text { padrão }\end{array}$ & 0,40 & 0,48 & 0,45 & 0,43 & 0,45 & 0,45 & 0,41 & 0,36 & 0,41 & 0,44 \\
\hline N & 240 & 260 & 257 & 243 & 124 & 224 & 152 & 33 & 228 & 239 \\
\hline
\end{tabular}


5. Qual o objetivo fundamental da utilização da medida de tendência central numa distribuição de frequência M?

6. Por que a média aritmética é a medida mais utilizada?

7. Que interpretação deriva do valor de tendência central?

8. Que medida de tendência central é determinada na série por sua posição ordinal?

9. Qual a mediana da série?

$$
2,4,5,5,8,9,10,10,15
$$

10. Qual a moda da série?

$$
1,2,4,5,5,5,7,9,9,12,15
$$

\section{Estudo realizado por Torres (1978):}

I - "O principal objetivo do presente estudo é investigar a relação entre diferentes períodos do desenvolvimento cognitivo e a evolução do conceito de morte. Com esta finalidade foram selecionadas quatro tarefas de avaliação do nível de desenvolvimento cognitivo em termos piagetianos, e um instrumento de sondagem do conceito de morte foi elaborado".

\section{Responda:}

a - Quais as variáveis investigadas?

b - Classifique-as em contínuas ou discretas.

II - Para este estudo foram extraídos dos 641 alunos, de um curso vespertino, situado em Ipanema, no Estado do Rio de Janeiro, 183 sujeitos de 4 a 13 anos e 11 meses de idade, de ambos os sexos, católicos que não sofreram perda de nenhum dos pais ou irmão, e cuja escolaridade estendese do jardim de infância à $7^{\mathrm{a}}$ série do $1^{\circ}$ grau.

\section{Responda:}

a - Qual a população do presente estudo?

$\mathrm{b}$ - Descreva a amostra.

III - Os escores obtidos no instrumento de sondagem em relação ao conceito de morte na dimensão significarão no período pré-operacional:

$\begin{array}{cccccccc}12 & 6 & 15 & 8 & 7 & 16 & 28 & 25 \\ 8 & 12 & 13 & 8 & 20 & 12 & 12 & 24 \\ 13 & 5 & 21 & 18 & 13 & 25 & 12 & 31 \\ 3 & 15 & 16 & 27 & 23 & 27 & 13 & 30 \\ 17 & 9 & 19 & 11 & 16 & 14 & 5 & 35 \\ 17 & 17 & 9 & 22 & 2 & 10 & 31 & 30 \\ 26 & 31 & 21 & 13 & & & & \end{array}$

a - Como se denominam esses dados?

b - Organize uma distribuição de frequência por pontos.

c - Faça a frequência acumulada.

d - Faça a frequência percentual.

12. Calcule o erro-padrão da média com a seguinte amostra composta de 30 escores amostrais.

$\begin{array}{llllll}3,0 & 4,0 & 2,0 & 5,0 & 3,0 & 1,0 \\ 3,0 & 5,0 & 1,0 & 3,0 & 2,0 & 3,0 \\ 2,0 & 1,0 & 1,0 & 3,0 & 4,0 & 4,0 \\ 1,0 & 6,0 & 2,0 & 2,0 & 6,0 & 3,0 \\ 5,0 & 3,0 & 3,0 & 2,0 & 1,0 & 4,0\end{array}$

13. Cem alunos que, no teste de rapidez de cálculo, obtiveram $X=100$ e a variância igual a 144. O que podemos dizer a respeito da fidedignidade desta média?

14. Foi aplicado um teste de aptidão acadêmica a 12.500 estudantes de uma universidade. Para fazer uma estimativa do escore médio (MD, X, Mo) foi retirada uma amostra de 225 sujeitos, obtendo-se $X=18$ e variância igual a 9. Qual é o valor do erro-padrão estimado para a distribuição amostral das médias aritméticas? 
15. Numa escala de aptidão verbal, 801 meninos de 12 anos obtiveram os seguintes resultados: $M d=21,40$ e $Q=4,90$. Até que ponto essa mediana representa a média da população da qual foi extraída a amostra?

\section{Dados:}

\section{$X=26,40$}

$0=5,20$

\section{$\mathrm{N}=100$} verdadeiro.

a - Calcular o intervalo de confiança de 0,95 para o desvio verdadeira.

b - Calcular o intervalo de confiança de 0,99 para a média

17. A média de 16 observações independentes de uma certa grandeza é 100, e o respectivo desvio-padrão, 24

a - No nível de confiança de 0,05 , quais serão os limites fiduciais da média verdadeira?

b - Considerando-se o intervalo de confiança de 0,99 , poder-se-á ter certeza de que a média verdadeira será no mínimo tão grande quanto qual valor?

18.Para um determinado grupo de 500 soldados, o resultado médio do AGCT é 95, e o desvio-padrão é 25.

a - Determinar o intervalo de confiança de 0,99 para a média verdadeira.

b-É provável que a média verdadeira seja mais do que qual valor?

19.Foram obtidas as seguintes medidas da duração da percepção para palavras não relacionadas a 5 crianças:

\begin{tabular}{|l|l|l|l|l|}
\hline 5 & 6 & 4 & 7 & 5 \\
\hline
\end{tabular}

a - Achar o intervalo de confiança de 0,99 para a média verdadeira desses resultados.
20. De uma população foram extraídas aleatoriamente seis amostras. As médias das seis amostras são: $50(N=100), 54(N=50), 46(N=100)$, $50(N=120), 58(N=80), 42(N=50) . O$ desvio-padrão da população é 12 .

a - Faça uma estimativa da média da população para cada uma das amostras.

b - Qual o resultado que apresenta o maior grau de eficiência da estimativa? Por quê?

c - Qual das amostras apresentou resultado da média mais próximo da média da população?

$\mathrm{d}$ - Observe os resultados das questões b e c, e tire suas conclusões.

Como vimos, a médias e outras medidas calculadas com base em amostras, as chamadas estatísticas, estão sujeitas a flutuações da amostragem. Por isso devemos estabelecer parâmetros, valores fixos de referências, para a população. Estes valores, como é impossível conhecêlos, são previstos a partir de determinadas condições, estabelecendo, para tanto, certos graus de precisão. O grau em que uma média de amostra representa o respectivo parâmetro constitui um índice de significância ou fidedignidade da estatística calculada. Não se pode esquecer que este erro padrão desempenha importante papel nos testes de hipóteses relacionadas com diferenças entre médias.

Embora seja de suma importância a estimativa de parâmetros, o pesquisador utiliza mais frequentemente a inferência estatística com o objetivo de testar hipóteses. Para tanto, faz-se necessária a organização de um plano de Tratamento Estatístico adequado aos dados.

21.Um teste de interesse é administrado a 6 rapazes numa classe de treinamento vocacional, e 10 numa classe de latim. Será a diferença média entre os dois grupos significante no nível 0,057? As notas apresentam-se assim:

Classe vocacional: $28,35,32,24,26,35$

Classe de latim: 20, 16, 25, 34, 20, 28, 31, 24, 27, 15 
22. Um experimentador interessado em verificar a eventual diferença de eficácia de dois métodos de ensino - método 1 e método 2-, e desejando controlar as variáveis motivação, inteligência, idade, classe social $e$ turno, resolveu criar dois blocos emparelhados com relação àqueles variáveis e alocou cada membro em um dos blocos. Encontrou os seguintes resultados:

Método de ensino 1: 8,7,6,5,9,7,8,8,9,7,4,6,5,8,3

Método de ensino 2: 8,6,6,3,4,7,7,9,5,3,4,2,7,2

Testar a diferença ao nível 0,05 .

23. Numa pesquisa, 67 alunos que participaram dos trabalhos práticos estatísticos obtiveram no exame final, média 6,85 e s =4,0. Os 73 que não participaram, obtiveram média 4,88 e $s=3$,7. Pode-se afirmar que, para o nível de significância de 1\%, o desempenho do $1^{\circ}$ grupo foi superior?

24. Num experimento, 40 ratos foram aleatoriamente divididos em dois grupos: experimental e de controle. A condição experimental consistia em proporcionar, a cada rato, um período de 12 horas para explorar $o$ labirinto. Ambos os grupos foram privados de alimento pelo mesmo período de tempo. Abaixo, encontrarão, para cada grupo, o número de ensaios necessários para cada rato percorrer o labirinto sem erro de espécie alguma.

Expressar a hipótese em termos estatísticos. Testar a hipótese admitindo um nível de significância de 0,05.

Grupo de controle: $10,7,9,6,8,6,10,13,9,7,12,12,15,6,9,11$, $9,13,4,9$

Grupo experimental: $12,7,9,6,5,9,9,9,6,4$ 8, 4, 9, 10, 11, 6, 9, 7, 10,7

25. Dois grupos equiparados em idade, nível socioeconômico, escolaridade $e$ várias características de personalidade foram submetidos a um experimento para verificar o efeito da frustração no comportamento agressivo. $O$ grupo A foi frustrado, e o grupo B serviu de controle. Em seguida, foi aplicado o teste de agressividade. Resultados:

$\begin{array}{cc}\text { GRUPO A } & \text { GRUPO B } \\ 18 & 12 \\ 17 & 10 \\ 20 & 20 \\ 17 & 18 \\ 22 & 13 \\ 15 & 11 \\ 19 & 12 \\ 4 & 6\end{array}$

26. Com os dados abaixo, siga os passos para chegar aos parâmetros da população à qual se refere esse estudo: nível de coordenação visomotora (Teste reprodução de figuras) em crianças de 5 a 6 anos e de 7 a 8 anos.

Amostra I: crianças de 5 a 6 anos

Amostra II: crianças de 7 a 8 anos

\begin{tabular}{llll|llll}
\hline \multicolumn{3}{c}{ Amostra I } & \multicolumn{4}{c}{ Amostra II } \\
\hline 16 & 17 & 16 & 18 & 23 & 22 & 21 & 20 \\
\hline 18 & 18 & 18 & 20 & 21 & 21 & 17 & 19 \\
\hline 20 & 21 & 20 & 21 & 20 & 20 & 13 & 20 \\
\hline 23 & 12 & 13 & 23 & 16 & 12 & 11 & 18 \\
\hline 17 & 20 & 18 & 23 & 15 & 07 & 07 & 17 \\
\hline
\end{tabular}

27.Sabe-se que, na escolha de uma prova estatística, algumas particularidades devem ser averiguadas, a fim de que se garanta o poder estatístico da prova.

A - Levante tais critérios nas pesquisas abaixo e diga se caberia nestes casos uma prova paramétrica ou não paramétrica.

B - Estabeleça os parâmetros da população em ambas as pesquisas

Pesquisas:

I - Os resultados abaixo referem-se às notas obtidas num teste de avaliação da capacidade de estabelecer relacionamento interpessoal no contato com o público. 
O teste consiste em comparar os padrões de respostas com as respostas dos testandos.

Os testandos respondem ao teste, ordenando da melhor à pior resposta diante de situações sociais.

Para se encontrar a medida de tendência central e a medida de dispersão representativas da população, selecionou-se uma amostra aleatória de 30 indivíduos, que obtiveram os seguintes resultados (resultados obtidos atribuindo-se valores numéricos a ordens preestabelecidas, por ex.: ABCD- grau $1^{\circ}$; ABDC-2 pontos, e assim por permutação até o grau 24)

Notas:

$24,23,22,21,20,20,19$

$18,17,16,15,15,14,13$

$11,10,10,10,11,12,10$

$21,15,12,09,08,07,06$

$05,04,03,02$

II - Uma pesquisa tem como objetivo estabelecer parâmetros para um determinado teste de aptidão mecânica. Tal teste consiste em responder questões de mecânica. $\mathrm{O}$ grau atribuído em cada questão varia de 0 a 3 , de acordo com a eficiência da resposta, que, quanto mais exata, mais vale. Num total de 30 questões, o indivíduo poderá obter, no máximo, 90 pontos.

A amostra foi extraída de uma população do RJ, considerando-se todos os níveis socioculturais e todas as áreas urbanas e rurais desse Estado, com idade variando de 17 a 50 anos.

Resultados:

$30,30,15,20,50,60,70,70$

$60,60,50,90,85,75,15,25$

$10,80,65,35,35,25,55,65$

$75,25,75,45,45,45,45,45$

$50,50,60,60,65,65,45,40$

28. Num experimento, um grupo de ratos recebeu como recompensa água pura, enquanto que outro grupo recebeu água com açúcar. No fim de determinado tempo, os dois grupos foram submetidos à mesma prova, a fim de se verificar o tempo médio gasto para alcançar a recompensa. Quais as hipóteses probanda e alternativa deste experimento?

29.Respondendo a um questionário, obtiveram-se as seguintes notas correspondentes a 9 homens e 20 mulheres:

Homens: 22, 31, 38, 47, 48, 49, 50, 52, 61

Mulheres: 22, 23, 25, 25, 31, 33, 34, 34, 35, 37, 40, 41, 42, 43, 44, $44,46,48,53,54$

Homens e mulheres diferem significativamente em suas respostas ao questionário?

30.Uma escala de Atitudes em relação à Igreja é administrada a um grupo de 78 segundanistas do curso superior. Dos 78, 57 tiveram curso de educação religiosa e 21 não o tiveram. Suponha-se que 37 dos 57 estão acima da mediana comum do grupo dos 78, e que somente 15 dos 21 estão acima dessa mediana. Os dois grupos são significativamente diferentes? 
31.Um psicólogo interessado em averiguar acerca da evasão nas universidades brasileiras levanta a hipótese de que os adolescentes ingressam na faculdade com um nivel de expectativa que vai decrescendo no decorrer do curso.

Para tanto selecionou uma amostra de 26 adolescentes, em três universidades do Rio de Janeiro, que ingressaram pela primeira vez numa faculdade. Em março fez uma expectativa com relação à faculdade. No final do primeiro período realizou a mesma medida. Obteve os seguintes resultados:

$\begin{array}{ccc}\text { Sujeito } & \text { Medida inicial } & \text { Medida fina } \\ 1 & + & + \\ 2 & + & - \\ 3 & + & - \\ 4 & + & - \\ 5 & - & + \\ 6 & + & - \\ 7 & + & - \\ 8 & - & + \\ 9 & + & - \\ 10 & + & - \\ 11 & + & - \\ 12 & + & - \\ 13 & + & - \\ 14 & + & - \\ 15 & - & - \\ 16 & + & + \\ 17 & + & - \\ 18 & + & - \\ 19 & + & + \\ 20 & - & - \\ 21 & + & - \\ 22 & + & - \\ 23 & - & + \\ 24 & - & + \\ 25 & + & - \\ 26 & + & \end{array}$

32. Um pesquisador deseja saber se o elogio influi na autoestima. Para testar sua hipótese, utilizou dois grupos: de controle e experimental.

Após três dias de elogio ao grupo experimental, fez uma medida de autoestima nos dois grupos.

A autoestima foi avaliada, considerando o número de respostas positivas com relação a si próprio. Quanto mais respostas, maior a autoestima. As notas variavam de zero a 26 .

$\begin{array}{ccc}\text { Blocos } & \text { Exp. } & \text { Cont. } \\ 1 & 12 & 25 \\ 2 & 15 & 20 \\ 3 & 18 & 26 \\ 4 & 10 & 16 \\ 5 & 10 & 17 \\ 6 & 16 & 24 \\ 7 & 18 & 17 \\ 8 & 11 & 10 \\ 9 & 12 & 13 \\ 10 & 9 & 16\end{array}$

33. Certo professor levantou a hipótese de que, sabendo-se as notas de matemática dos alunos do $2^{\circ}$ grau, poderia se prever o rendimento na disciplina Estatística. Para tanto, confrontou os resultados obtidos na disciplina Matemática com os resultados obtidos em Estatística.

$\mathrm{X}=$ notas em Matemática

$\mathrm{Y}=$ notas em Estatística

$X($ notas $)=5,5,5,5,6,6,6,6,6,7,7,7$

$\mathrm{Y}($ notas $)=2,2,3,2,2,3,3,3,2,3,3,4$

34. Um investigador determinou, para um grupo de 10 indivíduos, o seu grau de susceptibilidade à sugestão hipnótica; determinou para o outro grupo o nível mental através de um teste de inteligência. Desejou, então, calcular a correlação entre estas variáveis. Poderá calculá-las? Por quê?

35. Ao calcular o coeficiente de correlação entre dois testes de aptidão mecânica, encontrou-se o valor $r=1,45$. Que comentário você faz a este resultado? 
36.De que dados devemos dispor para decidirmos acerca da escolha do coeficiente de correlação?

37. O que expressa o coeficiente de correlação?

38. O que expressa o coeficiente de determinação?

39. A correlação de um critério (de avaliação do chefe) com uma bateria de testes é de 0,75. Responda:

a - Esta bateria seleciona?

b - Qual a percentagem da variância do critério associada à variabilidade da bateria?

40. Uma empresa de relações públicas elaborou um teste para medir a capacidade dos candidatos em resolverem situações embaraçosas, quando em atividade junto ao público. O teste consiste em ordenar do "mais fácil" para o "mais difícil" situações de embaraço. Um candidato submetido ao teste ordenou conforme a tabela abaixo:

\begin{tabular}{lccccccc}
\hline Problema & A & B & C & D & E & F & G \\
Gabarito & 5 & 3 & 2 & 1 & 4 & 6 & 7 \\
Ord. do cand. & 3 & 4 & 1 & 6 & 2 & 5 & 7 \\
\hline
\end{tabular}

a - Calcule o índice de concordância do candidato e do gabarito.

b - Calcule e interprete D.

c - A partir desse dado, você acha que esse candidato deve ser rejeitado?

41. Achar o grau de associação entre competição e busca de posição social em uma pesquisa realizada com 12 estudantes universitários.

$\mathrm{X}=3,4,2,1,8,11,10,6,7,12,5,9$

$\mathrm{Y}=2,6,5,1,10,9,8,3,4,12,7,11$
42. O coeficiente de correlação entre um teste de raciocínio verbal e notas de Português de uma turma de nível médio é de 0,80. A partir desse dado, calcule e interprete os resultados.

a - A proporção da variância que X e Y têm em comum.

b - Estime a proporção da variável Y que independe de X.

c - A eficiência de previsão dos valores de Y a partir de X.

43. Quanto maior o treinamento de pessoal para a indústria, maior o índice de produtividade. Isto significa que as duas variáveis apresentam:

44. Se o treinamento diminui efetivamente o número de acidentes no trabalho, a correlação entre essas variáveis é:

45. Em estudos realizados por pesquisadores europeus descobriram que a proporção de acidentes automobilísticos nas autoestradas é proporcionalmente maior que os ocorridos nas demais estradas. Como causas determinadas dos referidos acidentes, são apontadas as seguintes: monotonia e cansaço, que provocam falta de atenção $e$ afrouxamento dos reflexos numa percentagem de $60 \%$ dos casos.

a - Que nível de correlação existe entre o número de acidentes e a monotonia no ato de dirigir em autoestrada?

b - Como poderia ser classificada a dependência entre os fenômenos em estudo? 
Tabela A - Ordenadas da Curva Normal Padrão

TABELAS ${ }^{1}$

$$
y=\frac{1}{\sqrt{2 \pi}} \text { e }-x^{2} / 2
$$

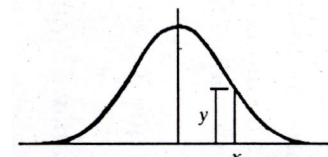

\begin{tabular}{|c|c|c|c|c|c|c|c|c|c|c|}
\hline$\frac{\mathrm{X}}{\bar{\delta}}$ & 0 & 1 & 2 & 3 & 4 & 5 & 6 & 7 & 8 & 9 \\
\hline 0,0 & 0,3989 & 0,3989 & 0,3989 & 0,3988 & 0,3986 & 0,3984 & 0,3982 & 0,3980 & 0,3977 & 0,3973 \\
\hline 0,1 & 0,3970 & 0,3965 & 0,3961 & 0,3956 & 0,3951 & 0,3945 & 0,3939 & 0,3932 & 0,3925 & 0,3918 \\
\hline 0,2 & 0,3910 & 0,3902 & 0,3894 & 0,3885 & 0,3876 & 0,3867 & 0,3857 & 0,3847 & 0,3836 & 0,3825 \\
\hline 0,3 & 0,3814 & 0,3802 & 0,3790 & 0,3778 & 0,3765 & 0,3752 & 0,3739 & 0,3725 & 0,3712 & 0,3697 \\
\hline 0,4 & 0,3683 & 0,3668 & 0,3653 & 0,3637 & 0,3621 & 0,3605 & 0,3589 & 0,3572 & 0,3555 & 0,3538 \\
\hline 0,5 & 0,3521 & 0,3503 & 0,3485 & 0,3467 & 0,3448 & 0,3429 & 0,3410 & 0,3391 & 0,3372 & 0,3352 \\
\hline 0,6 & 0,3332 & 0,3312 & 0,3292 & 0,3271 & 0,3251 & 0,3230 & 0,3209 & 0,3187 & 0,3166 & 0,3144 \\
\hline 0,7 & 0,3123 & 0,3101 & 0,3079 & 0,3056 & 0,3034 & 0,3011 & 0,2989 & 0,2966 & 0,2943 & 0,2920 \\
\hline 0,8 & 0,2897 & 0,2874 & 0,2850 & 0,2827 & 0,2803 & 0,2780 & 0,2756 & 0,2732 & 0,2709 & 0,2685 \\
\hline 0,9 & 0,2661 & 0,2637 & 0,2613 & 0,2589 & 0,2565 & 0,2541 & 0,2516 & 0,2492 & 0,2468 & 0,2444 \\
\hline 1,0 & 0,2420 & 0,2396 & 0,2371 & 0,2347 & 0,2323 & 0,2299 & 0,2275 & 0,2251 & 0,2227 & 0,2203 \\
\hline 1,1 & 0,2179 & 0,2155 & 0,2131 & 0,2107 & 0,2083 & 0,2059 & 0,2036 & 0,2012 & 0,1989 & 0,1965 \\
\hline 1,2 & 0,1942 & 0,1919 & 0,1895 & 0,1872 & 0,1849 & 0,1826 & 0,1804 & 0,1781 & 0,1758 & 0,1736 \\
\hline 1,3 & 0,1714 & 0,1691 & 0,1669 & 0,1647 & 0,1626 & 0,1604 & 0,1582 & 0,1561 & 0,1539 & 0,1518 \\
\hline 1,4 & 0,1497 & 0,1476 & 0,1456 & 0,1435 & 0,1415 & 0,1394 & 0,1374 & 0,1354 & 0,1334 & 0,1315 \\
\hline 1,5 & 0,1295 & 0,1276 & 0,1257 & 0,1238 & 0,1219 & 0,1200 & 0,1182 & 0,1163 & 0,1145 & 0,1127 \\
\hline 1,6 & 0,1109 & 0,1092 & 0,1074 & 0,1057 & 0,1040 & 0,1023 & 0,1006 & 0,0989 & 0,0973 & 0,0957 \\
\hline 1,7 & 0,0940 & 0,0925 & 0,0909 & 0,0893 & 0,0878 & 0,0863 & 0,0848 & 0,0833 & 0,0818 & 0,0804 \\
\hline 1,8 & 0,0790 & 0,0775 & 0,0761 & 0,0748 & 0,0734 & 0,0721 & 0,0707 & 0,0694 & 0,0681 & 0,0669 \\
\hline 1,9 & 0,0656 & 0,0644 & 0,0632 & 0,0620 & 0,0608 & 0,0596 & 0,0584 & 0,0573 & 0,0562 & 0,0551 \\
\hline 2,0 & 0,0540 & 0,0529 & 0,0519 & 0,0508 & 0,0498 & 0,0488 & 0,0478 & 0,0468 & 0,0459 & 0,0449 \\
\hline 2,1 & 0,0440 & 0,0431 & 0,0422 & 0,0413 & 0,0404 & 0,0396 & 0,0387 & 0,0379 & 0,0371 & 0,0363 \\
\hline 2,2 & 0,0355 & 0,0347 & 0,0339 & 0,0332 & 0,0325 & 0,0317 & 0,0310 & 0,0303 & 0,0297 & 0,0290 \\
\hline 2,3 & 0,0283 & 0,0277 & 0,0270 & 0,0264 & 0,0258 & 0,0252 & 0,0246 & 0,0241 & 0,0235 & 0,0229 \\
\hline 2,4 & 0,0224 & 0,0219 & 0,0213 & 0,0208 & 0,0203 & 0,0198 & 0,0194 & 0,0189 & 0,0184 & 0,0180 \\
\hline 2,5 & 0,0175 & 0,0171 & 0,0167 & 0,0163 & 0,0158 & 0,0154 & 0,0151 & 0,0147 & 0,0143 & 0,0139 \\
\hline 2,6 & 0,0136 & 0,0132 & 0,0129 & 0,0126 & 0,0122 & 0,0119 & 0,0116 & 0,0113 & 0,0110 & 0,0107 \\
\hline 2,7 & 0,0104 & 0,0101 & 0,0099 & 0,0096 & 0,0093 & 0,0091 & 0,0088 & 0,0086 & 0,0084 & 0,0081 \\
\hline 2,8 & 0,0070 & 0,0077 & 0,0075 & 0,0073 & 0,0071 & 0,0069 & 0,0067 & 0,0065 & 0,0063 & 0,0061 \\
\hline 2,9 & 0,0060 & 0,0058 & 0,0056 & 0,0055 & 0,0053 & 0,0051 & 0,0050 & 0,0048 & 0,0047 & 0,0046 \\
\hline 3,0 & 0,0044 & 0,0043 & 0,0042 & 0,0040 & 0,0039 & 0,0038 & 0,0037 & 0,0036 & 0,0035 & 0,0034 \\
\hline 3,1 & 0,0033 & 0,0032 & 0,0031 & 0,0030 & 0,0029 & 0,0028 & 0,0027 & 0,0026 & 0,0025 & 0,0025 \\
\hline 3,2 & 0,0024 & 0,0023 & 0,0022 & 0,0022 & 0,0021 & 0,0020 & 0,0020 & 0,0019 & 0,0018 & 0,0018 \\
\hline 3,3 & 0,0017 & 0,0017 & 0,0016 & 0,0016 & 0,0015 & 0,0015 & 0,0014 & 0,0014 & 0,0013 & 0,0013 \\
\hline 3,4 & 0,0012 & 0,0012 & 0,0012 & 0,0011 & 0,0011 & 0,0010 & 0,0010 & 0,0010 & 0,009 & 0,009 \\
\hline 3,5 & 0,0009 & 0,0008 & 0,0008 & 0,0008 & 0,0008 & 0,0007 & 0,0007 & 0,0007 & 0,0007 & 0,0006 \\
\hline 3,6 & 0,0006 & 0,0006 & 0,0006 & 0,0005 & 0,0005 & 0,0005 & 0,0005 & 0,0005 & 0,0005 & 0,0004 \\
\hline 3,7 & 0,0004 & 0,0004 & 0,0004 & 0,0004 & 0,0004 & 0,0004 & 0,0003 & 0,0003 & 0,0003 & 0,0003 \\
\hline 3,8 & 0,0003 & 0,0003 & 0,0003 & 0,0003 & 0,0003 & 0,0002 & 0,0002 & 0,0002 & 0,0002 & 0,0002 \\
\hline 3,9 & 0,0002 & 0,0002 & 0,0002 & 0,0002 & 0,0002 & 0,0002 & 0,0002 & 0,0002 & 0,0001 & 0,0001 \\
\hline
\end{tabular}

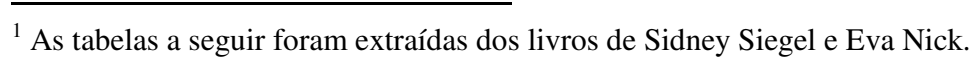


Tabela B - Áreas sob a Curva Normal (entre 0 e x)

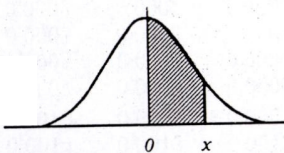

\begin{tabular}{|c|c|c|c|c|c|c|c|c|c|c|}
\hline$\frac{X}{\delta}$ & 00 & 01 & 02 & 03 & 04 & 05 & 06 & 07 & 08 & 09 \\
\hline 0,0 & 00000 & 00399 & 00798 & 01197 & 01595 & 01994 & 02392 & 02790 & 03188 & 03586 \\
\hline 0,1 & & 04380 & 4766 & & & & & & & \\
\hline 0,2 & & 08317 & $3 / 0$ & 0905 & 094 & $098^{\circ}$ & 102 & 10642 & 6 & \\
\hline 0,3 & 1 & 12172 & 552 & 1293 & 133 & 13683 & 140 & 14431 & & 15173 \\
\hline 0,4 & 554 & 15910 & 16276 & 16640 & 17003 & 17364 & 17724 & 18082 & 18439 & 18793 \\
\hline 0,5 & 9146 & 19497 & 19847 & 20194 & 20450 & 20884 & 21226 & 21566 & 21904 & 22240 \\
\hline 0,6 & 22575 & 22907 & 23237 & 23565 & 23891 & 24215 & 24537 & 24857 & 25175 & 25490 \\
\hline 0,7 & 5804 & 26115 & 26424 & 26730 & 27035 & 27337 & 27637 & 27935 & 28230 & 28524 \\
\hline 0,8 & 8814 & 29103 & 29389 & 29673 & 29955 & 30234 & 30511 & 30785 & 31057 & 31327 \\
\hline 0,9 & 594 & 31859 & 32121 & 32381 & 32639 & 32894 & 33147 & 33398 & 33646 & 33891 \\
\hline 1,0 & 134 & 34375 & 4614 & 34850 & 35083 & 3531 & 35543 & 35769 & 3599 & 36214 \\
\hline 1,1 & 3 & 3665 & 864 & $370^{\circ}$ & 372 & 374 & 376 & 37900 & & 38298 \\
\hline 1,2 & 3 & 38686 & 8877 & 3906 & 392 & 39435 & 39616 & 39796 & 40073 & 40147 \\
\hline 1,3 & 320 & 40490 & 40658 & 40824 & 40988 & 41149 & 41308 & 41466 & 41621 & 41774 \\
\hline 1,4 & 1924 & 42073 & 42220 & 42364 & 42507 & 42647 & 42786 & 42922 & 43056 & 43189 \\
\hline 1,5 & 43319 & 43448 & 43574 & 43699 & 43822 & 43943 & 44062 & 44179 & 44295 & 44408 \\
\hline 1,6 & 520 & 44630 & 44738 & 44845 & 44950 & 45053 & 45154 & 45254 & 45352 & 45449 \\
\hline 1,7 & 543 & 45637 & 5728 & 45818 & 45907 & 45994 & 460 & 46164 & 46246 & 46327 \\
\hline 1,8 & 407 & 46485 & 562 & 466 & 467 & 4678 & & & & 47062 \\
\hline 1,9 & 12 & 47193 & 257 & 473 & & 474 & & & & 47670 \\
\hline 2,0 & 725 & 8 & 831 & 478 & 47 & 82 & & 480 & & 48169 \\
\hline 2,1 & 4 & 4825 & 300 & 483 & 483 & 48422 & 484 & 48500 & 485 & 48574 \\
\hline 2,2 & 610 & 48645 & 8679 & 48713 & 48745 & 48778 & 48809 & 48840 & 48870 & 48899 \\
\hline 2,3 & 928 & 48956 & 48983 & 49010 & 49036 & 49061 & 49086 & 49111 & 49134 & 49158 \\
\hline 2,4 & 49180 & 49202 & 49224 & 49245 & 49266 & 49286 & 49305 & 49324 & 49343 & 49361 \\
\hline 2,5 & 49379 & 49396 & 49413 & 49430 & 49446 & 49461 & 49477 & 49492 & 49506 & 49520 \\
\hline 2,6 & 49534 & 49547 & 49560 & 49573 & 49585 & 49598 & 49609 & 49621 & 49632 & 49643 \\
\hline 2,7 & 49653 & 49664 & 9674 & 49683 & 49693 & 49702 & 49711 & 49720 & 49728 & 49736 \\
\hline 2,8 & 744 & 49752 & 9760 & 4976 & 49774 & & & & 49801 & 49807 \\
\hline 2,9 & & & & & & & & 298 & & 49861 \\
\hline 3,0 & & & & & & & & & & 49900 \\
\hline 3,1 & & & & 499 & & & & & & 49929 \\
\hline 3,2 & 931 & 499 . & 49936 & 4993 & & 499 & 499 & 499 & 499 & 49950 \\
\hline 3,3 & 49952 & 49953 & 49955 & 49957 & 49958 & 49960 & 49961 & 49962 & 49964 & 49965 \\
\hline 3,4 & 49966 & 49968 & 49969 & 49970 & 49971 & 49972 & 49973 & 49974 & 49975 & 49976 \\
\hline 3,5 & 49977 & 49978 & 49978 & 49979 & 49980 & 49981 & 49981 & 49982 & 49983 & 49983 \\
\hline 3,6 & 49984 & 49985 & 49985 & 49986 & 49986 & 49987 & 49987 & 49988 & 49988 & 49989 \\
\hline 3,7 & 49989 & 49990 & 49990 & 49990 & 49991 & 49991 & 49992 & 49992 & 49992 & 49992 \\
\hline 3,8 & 49993 & 49993 & 49993 & 49994 & 49994 & 49994 & 49994 & 49995 & 49995 & 49995 \\
\hline 3,9 & 49995 & 49995 & 49996 & 49996 & 49996 & 49996 & 49996 & 49996 & 49997 & 49997 \\
\hline
\end{tabular}

104
Tabela C - Valores Percentílicos ( $t p$ )

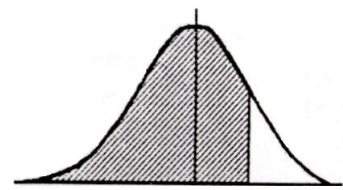

Para a distribuição $t$ de Student com $v$ graus de liberdade.

Área sombreada $=p$

\begin{tabular}{|c|c|c|c|c|c|c|c|c|c|c|}
\hline$v$ & $t 0,995$ & $t 0,99$ & $t 0,975$ & $t 0,95$ & $t 0,90$ & $t \mathbf{0 , 8 0}$ & $t 0,75$ & $t \mathbf{0 , 7 0}$ & $t \mathbf{0 , 6 0}$ & $t \mathbf{0 , 5 5}$ \\
\hline 1 & 63,66 & 31,82 & 12,71 & 6,31 & 3,08 & 1,376 & 1,000 & 0,727 & 0,325 & 0,158 \\
\hline 2 & 9,92 & 6,96 & 4,80 & 2,92 & 1,89 & 1,061 & 0,816 & 0,617 & 0,289 & 0,142 \\
\hline 3 & 5,84 & 4,54 & 3,18 & 2,35 & 1,64 & 0,978 & 0,765 & 0,584 & 0,277 & 0,137 \\
\hline 4 & 4,60 & 3,75 & 2,78 & 2,13 & 1,53 & 0,941 & 0,741 & 0,569 & 0,271 & 0,134 \\
\hline 5 & 4,03 & 3,36 & 2,57 & 2,02 & 1,48 & 0,920 & 0,727 & 0,559 & 0,267 & 0,132 \\
\hline 6 & 3,71 & 3,14 & 2,45 & 1,94 & 1,44 & 0,906 & 0,718 & 0,553 & 0,265 & 0,131 \\
\hline 7 & 3,50 & 3,00 & 2,36 & 1,90 & 1,42 & 0,896 & 0,711 & 0,549 & 0,263 & 0,130 \\
\hline 8 & 3,36 & 2,90 & 2,31 & 1,86 & 1,40 & 0,889 & 0,706 & 0,546 & 0,262 & 0,130 \\
\hline 9 & 3,25 & 2,82 & 2,26 & 1,83 & 1,38 & 0,883 & 0,703 & 0,543 & 0,261 & 0,129 \\
\hline 10 & 3,17 & 2,76 & 2,23 & 1,81 & 1,37 & 0,879 & 0,700 & 0,542 & 0,260 & 0,129 \\
\hline 11 & 3,11 & 2,72 & 2,20 & 1,80 & 1,36 & 0,876 & 0,697 & 0,540 & 0,260 & 0,129 \\
\hline 12 & 3,06 & 2,68 & 2,18 & 1,78 & 1,36 & 0,873 & 0,695 & 0,539 & 0,259 & 0,128 \\
\hline 13 & 3,01 & 2,65 & 2,16 & 1,77 & 1,35 & 0,870 & 0,694 & 0,538 & 0,259 & 0,128 \\
\hline 14 & 2,98 & 2,62 & 2,14 & 1,76 & 1,34 & 0,868 & 0,692 & 0,537 & 0,258 & 0,128 \\
\hline 15 & 2,95 & 2,60 & 2,13 & 1,75 & 1,34 & 0,866 & 0,691 & 0,536 & 0,258 & 0,128 \\
\hline 16 & 2,92 & 2,58 & 2,12 & 1,75 & 1,34 & 0,865 & 0,690 & 0,535 & 0,258 & 0,128 \\
\hline 17 & 2,90 & 2,57 & 2,11 & 1,74 & 1,33 & 0,863 & 0,689 & 0,534 & 0,257 & 0,128 \\
\hline 18 & 2,88 & 2,55 & 2,10 & 1,73 & 1,33 & 0,862 & 0,688 & 0,534 & 0,257 & 0,127 \\
\hline 19 & 2,86 & 2,54 & 2,09 & 1,73 & 1,33 & 0,861 & 0,688 & 0,533 & 0,257 & 0,127 \\
\hline 20 & 2,84 & 2,53 & 2,09 & 1,72 & 1,32 & 0,860 & 0,687 & 0,533 & 0,257 & 0,127 \\
\hline 21 & 2,83 & 2,52 & 2,08 & 1,72 & 1,32 & 0,859 & 0,686 & 0,532 & 0,257 & 0,127 \\
\hline 22 & 2,82 & 2,51 & 2,07 & 1,72 & 1,32 & 0,858 & 0,686 & 0,532 & 0,256 & 0,127 \\
\hline 23 & 2,81 & 2,50 & 2,07 & 1,71 & 1,32 & 0,858 & 0,685 & 0,532 & 0,256 & 0,127 \\
\hline 24 & 2,80 & 2,49 & 2,06 & 1,71 & 1,32 & 0,857 & 0,685 & 0,531 & 0,256 & 0,127 \\
\hline 25 & 2,79 & 2,48 & 2,06 & 1,71 & 1,32 & 0,856 & 0,684 & 0,531 & 0,256 & 0,127 \\
\hline 26 & 2,78 & 2,48 & 2,06 & 1,71 & 1,32 & 0,856 & 0,684 & 0,531 & 0,256 & 0,127 \\
\hline 27 & 2,77 & 2,47 & 2,05 & 1,70 & 1,31 & 0,855 & 0,684 & 0,531 & 0,256 & 0,127 \\
\hline 28 & 2,76 & 2,47 & 2,05 & 1,70 & 1,31 & 0,855 & 0,683 & 0,530 & 0,256 & 0,127 \\
\hline 29 & 2,76 & 2,46 & 2,04 & 1,70 & 1,31 & 0,854 & 0,683 & 0,530 & 0,256 & 0,127 \\
\hline 30 & 2,75 & 2,46 & 2,04 & 1,70 & 1,31 & 0,854 & 0,683 & 0,530 & 0,256 & 0,127 \\
\hline 40 & 2,70 & 2,42 & 2,02 & 1,68 & 1,30 & 0,851 & 0,681 & 0,529 & 0,255 & 0,126 \\
\hline 60 & 2,66 & 2,39 & 2,00 & 1,67 & 1,30 & 0,848 & 0,679 & 0,527 & 0,254 & 0,126 \\
\hline 120 & 2,62 & 2,36 & 1,98 & 1,66 & 1,29 & 0,845 & 0,677 & 0,526 & 0,254 & 0,126 \\
\hline$\infty$ & 2,58 & 2,33 & 1,96 & 1,645 & 1,28 & 0,842 & 0,674 & 0,524 & 0,253 & 0,126 \\
\hline
\end{tabular}


Tabela D - Distribuição do $x^{2} p$

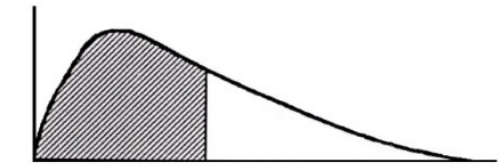

Com $v$ graus de liberdade. Área sombreada $=p$

\begin{tabular}{|c|c|c|c|c|c|c|c|c|c|c|c|c|c|}
\hline$v$ & $\mathrm{x}^{2} \mathbf{0 , 9 9 5}$ & $x^{2} 0,99$ & $\mathrm{x}^{2} \mathbf{0 , 9 7 5}$ & $\begin{array}{l}x^{2} 0,95 \\
\end{array}$ & $x^{2} 0,90$ & $x^{2} 0,75$ & $\mathrm{x}^{2} \mathbf{0 , 5 0}$ & $x^{2} 0,25$ & $\mathbf{x}^{2} \mathbf{0 , 1 0}$ & $x^{2} 0,05$ & $\mathrm{x}^{2} \mathbf{0 , 0 2 5}$ & $\mathbf{x}^{2} \mathbf{0 , 0 1}$ & $\mathrm{x}^{2} \mathbf{0 , 0 0 5}$ \\
\hline 1 & 7,88 & 6,63 & 5,02 & 3,84 & 2,71 & 1,32 & 0,455 & 0,102 & 0,0158 & 0,0039 & 0,0010 & 0,0002 & 0,0000 \\
\hline 2 & 10,6 & 9,21 & 7,38 & 5,99 & 4,61 & 2,77 & 1,39 & 0,575 & 0,211 & 0,103 & 0,0506 & 0,0201 & 0,0001 \\
\hline 3 & 12,8 & 11,3 & 9,35 & 7,81 & 6,25 & 4,11 & 2,37 & 1,21 & 0,584 & 0,352 & 0,216 & 0,115 & 0,072 \\
\hline 4 & 14,9 & 13,3 & 11,1 & 9,49 & 7,78 & 5,39 & 2,36 & 1,92 & 1,06 & 0,711 & 0,484 & 0,297 & 0,207 \\
\hline 5 & 16,5 & 15,1 & 12,8 & 11,1 & 9,24 & 6,63 & 4,35 & 2,67 & 1,61 & 1,15 & 0,831 & 0,554 & 0,412 \\
\hline 6 & 18,5 & 16,8 & 14,4 & 12,6 & 10,6 & 7,84 & 5,35 & 3,45 & 2,20 & 1,64 & 1,24 & 0,872 & 0,676 \\
\hline 7 & 20,3 & 18,5 & 16,0 & 14,1 & 12,0 & 9,04 & 6,35 & 4,25 & 2,83 & 2,17 & 1,69 & 1,24 & 0,989 \\
\hline 8 & 22,0 & 20,1 & 17,5 & 15,5 & 13,4 & 10,2 & 7,34 & 5,07 & 3,49 & 2,73 & 2,18 & 1,65 & 1,34 \\
\hline 9 & 23,6 & 21,7 & 19,0 & 16,9 & 14,7 & 11,4 & 8,34 & 5,90 & 4,17 & 3,33 & 2,70 & 2,09 & 1,73 \\
\hline 10 & 25,2 & 23,2 & 20,5 & 18,3 & 16,0 & 12,5 & 9,34 & 6,74 & 4,87 & 3,94 & 3,25 & 2,56 & 2,16 \\
\hline 11 & 26,8 & 24,7 & 21,9 & 19,7 & 17,3 & 13,7 & 10,3 & 7,58 & 5,58 & 4,57 & 3,82 & 3,05 & 2,60 \\
\hline 12 & 28,3 & 26,2 & 23,3 & 21,0 & 18,5 & 14,8 & 11,3 & 8,44 & 6,30 & 5,23 & 4,40 & 3,57 & 3,07 \\
\hline 13 & 29,8 & 27,7 & 24,7 & 22,4 & 19,8 & 16,0 & 12,3 & 9,30 & 7,04 & 5,89 & 5,01 & 4,11 & 3,57 \\
\hline 14 & 31,3 & 29,1 & 26,1 & 23,7 & 21,1 & 17,1 & 13,3 & 10,2 & 7,79 & 6,57 & 5,63 & 4,66 & 4,07 \\
\hline 15 & 32,8 & 30,6 & 27,5 & 25,0 & 22,3 & 18,2 & 14,3 & 11,0 & 8,55 & 7,26 & 6,26 & 5,23 & 4,60 \\
\hline 16 & 34,3 & 32,0 & 28,8 & 26,3 & 23,5 & 19,4 & 15,3 & 11,9 & 9,31 & 7,96 & 6,91 & 5,81 & 5,14 \\
\hline 17 & 35,7 & 33,4 & 30,2 & 27,6 & 24,8 & 20,5 & 16,3 & 12,8 & 10,1 & 8,67 & 7,56 & 6,41 & 5,70 \\
\hline 18 & 37,2 & 34,8 & 31,5 & 28,9 & 26,0 & 21,6 & 17,3 & 13,7 & 10,9 & 9,39 & 8,23 & 7,01 & 6,26 \\
\hline 19 & 38,6 & 36,2 & 32,9 & 30,1 & 27,2 & 22,7 & 18,3 & 14,6 & 11,7 & 10,1 & 8,91 & 7,63 & 6,84 \\
\hline 20 & 40,0 & 37,6 & 34,2 & 31,4 & 28,4 & 23,8 & 19,3 & 15,5 & 12,4 & 10,9 & 9,59 & 8,26 & 7,43 \\
\hline 21 & 41,4 & 38,9 & 35,5 & 32,7 & 29,6 & 24,9 & 20,3 & 16,3 & 13,2 & 11,6 & 10,3 & 8,90 & 8,03 \\
\hline 22 & 42,8 & 40,3 & 36,8 & 33,9 & 30,8 & 26,0 & 21,3 & 17,2 & 14,0 & 12,3 & 11,0 & 9,54 & 8,64 \\
\hline 23 & 44,2 & 41,6 & 38,1 & 35,2 & 32,0 & 27,1 & 22,3 & 18,1 & 14,8 & 13,1 & 11,7 & 10,2 & 9,26 \\
\hline 24 & 45,6 & 43,0 & 39,4 & 36,4 & 33,2 & 28,2 & 23,3 & 19,0 & 15,7 & 13,8 & 12,4 & 10,9 & 9,89 \\
\hline 25 & 46,9 & 44,3 & 40,6 & 37,7 & 34,4 & 29,3 & 24,3 & 19,9 & 16,5 & 14,6 & 13,1 & 11,5 & 10,5 \\
\hline 26 & 48,3 & 45,6 & 41,9 & 38,9 & 35,6 & 30,4 & 25,3 & 20,8 & 17,3 & 15,6 & 13,8 & 12,2 & 11,2 \\
\hline 27 & 49,6 & 47,0 & 43,2 & 40,1 & 36,7 & 31,5 & 26,3 & 21,7 & 18,1 & 16,2 & 14,6 & 12,9 & 11,8 \\
\hline 28 & 51,0 & 48,3 & 44,5 & 41,3 & 37,9 & 32,6 & 27,3 & 22,7 & 18,9 & 16,9 & 15,3 & 13,6 & 12,5 \\
\hline 29 & 52,3 & 49,6 & 45,7 & 42,6 & 39,1 & 33,7 & 28,3 & 23,6 & 19,8 & 17,7 & 16,0 & 14,3 & 13,1 \\
\hline 30 & 53,7 & 50,9 & 47,0 & 43,8 & 40,3 & 34,8 & 29,3 & 24,5 & 20,6 & 18,5 & 16,8 & 15,0 & 13,8 \\
\hline 40 & 66,8 & 63,7 & 59,3 & 55,8 & 51,8 & 45,6 & 39,3 & 33,7 & 29,1 & 26,5 & 24,4 & 22,2 & 20,7 \\
\hline 50 & 79,5 & 76,2 & 71,4 & 67,5 & 63,2 & 56,3 & 49,3 & 42,9 & 37,7 & 34,8 & 32,4 & 29,7 & 28,0 \\
\hline 60 & 92,0 & 88,4 & 83,3 & 79,1 & 74,4 & 67,0 & 59,3 & 52,3 & 46,5 & 43,2 & 40,5 & 37,5 & 35,5 \\
\hline 70 & 104,2 & 100,4 & 95,0 & 90,5 & 85,5 & 77,6 & 69,3 & 61,7 & 55,3 & 51,7 & 48,8 & 45,4 & 43,3 \\
\hline 80 & 116,3 & 112,3 & 106,6 & 101,9 & 96,6 & 88,1 & 79,3 & 71,1 & 64,3 & 60,4 & 57,2 & 53,5 & 51,2 \\
\hline 90 & 128,3 & 124,1 & 118,1 & 113,1 & 107,6 & 98,6 & 89,3 & 80,6 & 73,3 & 69,1 & 65,6 & 61,8 & 59,2 \\
\hline 100 & 140,2 & 135,8 & 129,6 & 124,3 & 118,5 & 109,1 & 99,3 & 90,1 & 82,4 & 77,9 & 74,2 & 70,1 & 67,3 \\
\hline
\end{tabular}

Tabela E - Valores de $\mathbf{P}_{95}$ para a Distribuição F

\begin{tabular}{|c|c|c|c|c|c|c|c|c|c|c|c|c|c|c|c|}
\hline \multicolumn{16}{|c|}{$\begin{array}{l}v_{1}:=\text { graus de liberdade do numerador } \\
v_{2}:=\text { graus de liberdade do denominador } \\
\text { Área sombreada }=0,95\end{array}$} \\
\hline & 1 & 2 & 3 & 4 & 5 & 6 & 8 & 12 & 16 & 20 & 30 & 40 & $\mathbf{5 0}$ & 100 & $\infty$ \\
\hline 1 & 161,4 & 199.5 & 215,7 & 224,6 & 230,2 & 234,0 & 238,9 & 243,9 & 246,3 & 248,0 & 250,1 & 251,1 & 252,2 & 253,0 & 254,3 \\
\hline 2 & 18,51 & 19,00 & 19,16 & 19,25 & 19,30 & 19,33 & 19,37 & 19,41 & 19,43 & 19,45 & 19,46 & 19,46 & 19,47 & 19,49 & 19,50 \\
\hline 3 & 10,13 & 9,55 & 9,28 & 9,12 & 9,01 & \begin{tabular}{|l}
8,94 \\
\end{tabular} & 8,85 & 8,74 & 8,69 & 8,66 & 8,62 & 8,60 & 8,58 & \begin{tabular}{|l|l|}
8,56 \\
\end{tabular} & 8,53 \\
\hline 4 & 7,71 & 6,94 & 6,59 & 6,39 & 6,26 & 6,16 & 6,04 & 5,91 & 5,84 & 5,80 & 5,75 & 5,71 & 5,70 & 5,66 & 5,63 \\
\hline 5 & 6,61 & 5,79 & 5,41 & 5,19 & 5,05 & 4,95 & 4,82 & 4,68 & 4,60 & 4,56 & 4,50 & 4,46 & 4,44 & 4,40 & 4,36 \\
\hline 6 & 5,99 & 5,14 & 4,76 & 4,53 & 4,39 & 4,28 & 4,15 & 4,00 & 3,92 & 3,87 & 3,81 & 3,77 & 3,75 & 3,71 & 3,67 \\
\hline 7 & 5,59 & 4,74 & 4,35 & 4,12 & 3,97 & 3,87 & 3,73 & 3,57 & 3,49 & 3,44 & 3,38 & 3,34 & 3,32 & 3,28 & 3,23 \\
\hline 8 & 5,32 & 4,46 & 4,07 & 3,84 & 3,69 & 3,58 & 3,44 & 3,28 & 3,20 & 3,15 & 3,08 & 3,05 & 3,03 & 2,98 & 2,93 \\
\hline 9 & 5,12 & 4,26 & 3,86 & 3,63 & 3,48 & 3,37 & 3,23 & 3,07 & 2,98 & 2,93 & 2,86 & 2,82 & 2,80 & 2,76 & 2,71 \\
\hline 10 & 4,96 & 4,10 & 3,71 & 3,48 & 3,33 & 3,22 & 3,07 & 2,91 & 2,82 & 2,77 & 2,70 & 2,67 & 2,64 & 2,59 & 2,54 \\
\hline 11 & 4,84 & 3,98 & 3,59 & 3,36 & 3,20 & 3,09 & 2,95 & 2,79 & 2,70 & 2,65 & 2,57 & 2,53 & 2,50 & 2,45 & 2,40 \\
\hline 12 & 4,75 & 3,89 & 3,49 & 3,26 & 3,11 & 3,00 & 2,85 & 2,69 & 2,60 & 2,54 & 2,46 & 2,42 & 2,40 & 2,35 & 2,30 \\
\hline 13 & 4,67 & 3,81 & 3,41 & 3,18 & 3,03 & 2,92 & 2,77 & 2,60 & 2,51 & 2,46 & 2,38 & 2,34 & 2,32 & 2,26 & 2,21 \\
\hline 14 & 4,60 & 3,74 & 3,34 & 3,11 & 2,96 & 2,85 & 2,70 & 2,53 & 2,44 & 2,39 & 2,31 & 2,27 & 2,24 & 2,19 & 2,13 \\
\hline 15 & 4,54 & 3,68 & 3,29 & 3,06 & 2,90 & 2,79 & 2,64 & 2,48 & 2,39 & 2,33 & 2,25 & 2,21 & 2,18 & 2,12 & 2,07 \\
\hline 16 & 4,49 & 3,63 & 3,24 & 3,01 & 2,85 & 2,74 & 2,59 & 2,42 & 2,33 & 2,28 & 2,20 & 2,16 & 2,13 & 2,07 & 2,01 \\
\hline 17 & 4,45 & 3,59 & 3,20 & 2,96 & 2,81 & 2,70 & 2,55 & 2,38 & 2,29 & 2,23 & 2,15 & 2,11 & 2,08 & 2,02 & 1,96 \\
\hline 18 & 4,41 & 3,55 & 3,16 & 2,93 & 2,77 & 2,66 & 2,51 & 2,34 & 2,25 & 2,19 & 2,11 & 2,07 & 2,04 & 1,98 & 1,92 \\
\hline 19 & 4,38 & 3,52 & 3,13 & 2,90 & 2,74 & 2,63 & 2,48 & 2,31 & 2,21 & 2,15 & 2,07 & 2,02 & 2,00 & 1,94 & 1,88 \\
\hline 20 & 4,35 & 3,49 & 3,10 & 2,87 & 2,71 & 2,60 & 2,45 & 2,28 & 2,18 & 2,12 & 2,04 & 1,99 & 1,96 & 1,90 & 1,84 \\
\hline 22 & 4,30 & 3,44 & 3,05 & 2,82 & 2,66 & 2,55 & 2,40 & 2,22 & 2,13 & 2,07 & 1,98 & 1,93 & 1,91 & 1,84 & 1,78 \\
\hline 24 & 4,26 & 3,40 & 3,01 & 2,78 & 2,62 & 2,51 & 2,36 & 2,18 & 2,09 & 2,03 & 1,94 & 1,89 & 1,86 & 1,80 & 1,73 \\
\hline 26 & 4,23 & 3,37 & 2,98 & 2,74 & 2,59 & 2,47 & 2,32 & 2,15 & 2,05 & 1,99 & 1,90 & 1,85 & 1,82 & 1,76 & 1,69 \\
\hline 28 & 4,20 & 3,34 & 2,95 & 2,71 & 2,56 & 2,45 & 2,29 & 2,12 & 2,02 & 1,96 & 1,87 & 1,81 & 1,78 & 1,72 & 1,65 \\
\hline 30 & 4,17 & 3,32 & 2,92 & 2,69 & 2,53 & 2,42 & 2,27 & 2,09 & 1,99 & 1,93 & 1,84 & 1,79 & 1,76 & 1,69 & 1,62 \\
\hline 30 & 4,08 & 3,23 & 2,84 & 2,61 & 2,45 & 2,34 & 2,18 & 2,00 & 1,90 & 1,84 & 1,74 & 1,69 & 1,66 & 1,59 & 1,51 \\
\hline 50 & 4,03 & 3,18 & 2,79 & 2,56 & 2,40 & 2,29 & 2,13 & 1,95 & 1,85 & 1,78 & 1,69 & 1,63 & 1,60 & 1,52 & 1,44 \\
\hline 60 & 4,00 & 3,15 & 2,76 & 2,53 & 2,37 & 2,25 & 2,10 & 1,92 & 1,81 & 1,75 & 1,65 & 1,59 & 1,56 & 1,48 & 1,39 \\
\hline 70 & 3,98 & 3,13 & 2,74 & 2,50 & 2,35 & 2,23 & 2,07 & 1,89 & 1,79 & 1,72 & 1,62 & 1,56 & 1,53 & 1,45 & 1,35 \\
\hline 80 & 3,96 & 3,11 & 2,72 & 2,48 & 2,33 & 2,21 & 2,05 & 1,88 & 1,77 & 1,70 & 1,60 & 1,54 & 1,51 & 1,42 & 1,32 \\
\hline 100 & 3,94 & 3,09 & 2,70 & 2,46 & 2,30 & 2,19 & 2,03 & 1,85 & 1,75 & 1,68 & 1,57 & 1,51 & 1,48 & 1,39 & 1,28 \\
\hline 150 & 3,91 & 3,06 & 2,67 & 2,43 & 2,27 & 2,16 & 2,00 & 1,82 & 1,71 & 1,64 & 1,54 & 1,47 & 1,44 & 1,34 & 1,22 \\
\hline 200 & 3,89 & 3,04 & 2,65 & 2,41 & 2,26 & 2,14 & 1,98 & 1,80 & 1,69 & 1,62 & 1,52 & 1,45 & 1,42 & 1,32 & 1,19 \\
\hline 400 & 3,86 & 3,02 & 2,62 & 2,39 & 2,23 & 2,12 & 1,96 & 1,78 & 1,67 & 1,60 & 1,49 & 1,42 & 1,38 & 1,28 & 1,13 \\
\hline & 3,84 & 2,99 & 2,60 & 2,37 & 2,21 & 2,09 & 1,94 & 1,75 & 1,64 & 1,57 & 1,46 & 1,40 & 1,32 & 1,24 & 1,00 \\
\hline
\end{tabular}


Tabela F - Valores críticos de $\boldsymbol{T}$ na prova de Wilcoxon

\begin{tabular}{c|c|c|c}
\hline \multirow{2}{*}{$\mathbf{N}$} & \multicolumn{3}{|c}{ Nível de significância para prova unilateral } \\
\cline { 2 - 4 } & $\mathbf{0 , 0 2 5}$ & $\mathbf{0 , 0 1}$ & $\mathbf{0 , 0 0 5}$ \\
\cline { 2 - 4 } & \multicolumn{2}{|c|}{ Nível de significância para prova bilateral } \\
\cline { 2 - 4 } & $\mathbf{0 , 0 5}$ & $\mathbf{0 , 0 2}$ & $\mathbf{0 , 0 1}$ \\
\hline 6 & 0 & --- & --- \\
\hline 7 & 2 & 0 & --- \\
\hline 8 & 4 & 2 & 2 \\
\hline 9 & 6 & 3 & 3 \\
\hline 10 & 8 & 5 & 5 \\
\hline \multicolumn{4}{|c}{} \\
\hline 11 & 11 & 7 & 10 \\
\hline 12 & 14 & 10 & 13 \\
\hline 13 & 17 & 13 & 16 \\
\hline 14 & 21 & 16 & \multicolumn{2}{c}{} \\
\hline 15 & 25 & 20 & \multicolumn{2}{c}{} \\
\hline
\end{tabular}

\begin{tabular}{l|l|l|l}
\hline 16 & 30 & 24 & 20 \\
\hline 17 & 35 & 28 & 23 \\
\hline 18 & 40 & 33 & 28 \\
\hline 19 & 46 & 38 & 32 \\
\hline 20 & 52 & 43 & 38 \\
\hline
\end{tabular}

\begin{tabular}{l|l|l|l}
\hline 21 & 59 & 49 & 43 \\
\hline 22 & 66 & 56 & 49 \\
\hline 23 & 73 & 62 & 55 \\
\hline 24 & 81 & 69 & 61 \\
\hline 25 & 89 & 77 & 68 \\
\hline
\end{tabular}

* Adaptado de Table I of Wilcoxon, F. 1949. Some rapid approximate statistical procedures.

New York: American Cyanamid Company p. 13, com permissão dos autores e editor.

\section{BIBLIOGRAFIA}

CERDÁ, Enrique. Psicometria general. Barcelona, Editorial Herder, 1972.

CUNHA, Ezequiel. Estatística descritiva, na psicologia e na educação. Petrópolis, Vozes, 1975, 2a ed.

DE CAMPOS, Paulo Henrique Borges \& Azevedo, Amilcar Gomes. Estatística básica. Rio de Janeiro, Ao Livro Técnico, 1970.

GARRET, Henry E. A estatística na psicologia e na educação. Rio de Janeiro, Fundo de Cultura, 1961.

LEVIN, Jack. Estatística, aplicada a ciências humanas. São Paulo, Harbra, 1977.

MAYO, T. Samuel \& Kurtz K. Albert. Statistical rnethods in education and psychology. New York, Ed. Springer-Verlag, 1979.

McCOLLOUGH, Celeste \& Van Atta, Loche. Statistical concepts. New York, Editora McGraw-Hill, 1963.

NICK, Eva \& Kellner, Sheilah. Fundamentos de estatística para as ciências do comportamento. Rio de Janeiro, Renes, 1971.

SIEGEL, Sidney. Estatística não-paramétrica. Brasil, Editora McGrawHill, 1979. 